\title{
Exchange Inlet Design Optimization by Genetic Algorithm
}

by

\author{
Gregory R. Chorkawy
}

\author{
A Thesis submitted to \\ the Faculty of Graduate and Postdoctoral Affairs \\ in partial fulfilment of the requirements \\ for the degree of \\ Master of Applied Science \\ in \\ Aerospace Engineering
}

Carleton University

Mechanical and Aerospace Engineering

Ottawa, Ontario

(C) 2011

Gregory R. Chorkawy 


$\begin{array}{ll}\begin{array}{l}\text { Library and Archives } \\ \text { Canada }\end{array} & \begin{array}{l}\text { Bibliothèque et } \\ \text { Archives Canada }\end{array} \\ \begin{array}{l}\text { Published Heritage } \\ \text { Branch }\end{array} & \begin{array}{l}\text { Direction du } \\ \text { Patrimoine de l'édition }\end{array} \\ \begin{array}{l}\text { 395 Wellington Street } \\ \text { Ottawa ON K1A ON4 } \\ \text { Canada }\end{array} & \begin{array}{l}\text { 395, rue Wellington } \\ \text { Ottawa ON K1A ON4 } \\ \text { Canada }\end{array}\end{array}$

Your file Votre référence

ISBN: 978-0-494-81675-2

Ourfile Notre référence

ISBN: 978-0-494-81675-2

NOTICE:

The author has granted a nonexclusive license allowing Library and Archives Canada to reproduce, publish, archive, preserve, conserve, communicate to the public by telecommunication or on the Internet, loan, distribute and sell theses worldwide, for commercial or noncommercial purposes, in microform, paper, electronic and/or any other formats.

The author retains copyright ownership and moral rights in this thesis. Neither the thesis nor substantial extracts from it may be printed or otherwise reproduced without the author's permission.
AVIS:

L'auteur a accordé une licence non exclusive permettant à la Bibliothèque et Archives Canada de reproduire, publier, archiver, sauvegarder, conserver, transmettre au public par télécommunication ou par l'Internet, prêter, distribuer et vendre des thèses partout dans le monde, à des fins commerciales ou autres, sur support microforme, papier, électronique et/ou autres formats.

L'auteur conserve la propriété du droit d'auteur et des droits moraux qui protège cette thèse. $\mathrm{Ni}$ la thèse ni des extraits substantiels de celle-ci ne doivent être imprimés ou autrement reproduits sans son autorisation.
In compliance with the Canadian Privacy Act some supporting forms may have been removed from this thesis.

While these forms may be included in the document page count, their removal does not represent any loss of content from the thesis.
Conformément à la loi canadienne sur la protection de la vie privée, quelques formulaires secondaires ont été enlevés de cette thèse.

Bien que ces formulaires aient inclus dans la pagination, il n'y aura aucun contenu manquant.

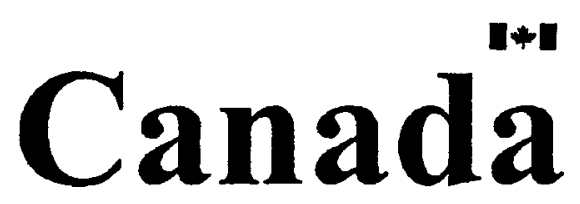


The undersigned recommend to

the Faculty of Graduate and Postdoctoral Affairs

acceptance of the Thesis

\title{
Exchange Inlet Design Optimization by Genetic Algorithm
}

\author{
Submitted by Gregory R. Chorkawy \\ in partial fulfilment of the requirements for the degree of \\ Master of Applied Science
}

\begin{tabular}{c}
\hline J. Etele \\
\hline M. Yaras, Department Chair
\end{tabular}

M. Yaras, Department Chair

Carleton University

2011 


\section{Abstract}

An active area of research is the development of advanced space transportation technologies to allow more cost effective access to space. In order to reduce launch cost, more efficient propulsion systems are being considered. An approach that incorporates existing rocket technologies that can increase propulsive efficiency is a Rocket-Based Combined-Cycle (RBCC) engine. A launch vehicle with this engine will operate in four modes from lift-off to orbit: rocket-ejector mode, ramjet, scramjet, and pure-rocket mode.

A novel RBCC design is being developed at Carleton University. This design aims to increase the efficiency of a conventional RBCC engine by improving the performance of the rocket-ejector mode. The novel geometry of this design increases mixing of the primary rocket stream and the secondary atmospheric air stream, thereby increasing the potential thrust augmentation of the rocket-ejector mode.

This thesis develops a Genetic Algorithm (GA) that optimizes the configuration of the novel rocket-ejector based on pre-specified performance criteria. The GA uses an adaptive technique that shows better performance when compared with standard techniques. 


\section{Acknowledgments}

I would like to thank Professor Etele for the opportunities given to me over the past few years. Working with him and his research group has always been enjoyable. Thank you for allowing me to travel to Nice, France to present a paper at ICAS 2010. The experience was invaluable.

Thank you to all past and present teammates of the Snowflakes. Some of my fondest memories have come as a result of our time on and off the ice.

I would also like to thank Professor Matida and Stephane Daviault for sharing their lab space with me. Thank you to Laurence Smith for the many thought provoking discussions.

Finally, I would like to thank my family for all their support. 


\section{Table of Contents}

$\begin{array}{lll}\text { Abstract } & \text { iii }\end{array}$

$\begin{array}{ll}\text { Acknowledgments } & \text { iv }\end{array}$

Table of Contents $\quad$ v

List of Tables $\quad$ viii

$\begin{array}{ll}\text { List of Figures } & \text { ix }\end{array}$

Nomenclature $\quad$ xii

1 Introduction $\quad 1$

1.1 Motivation for Research ................... 1

1.2 A Novel Rocket-Ejector Design . . . . . . . . . . . . . 7

1.3 Problem Statement ...................... 8

1.4 History of Genetic Algorithms . . . . . . . . . . . . . . . . 9

1.5 Models of Evolution Mechanisms ... . . . . . . . . . 10

1.5.1 Genetic Representation . . . . . . . . . . . . . 11

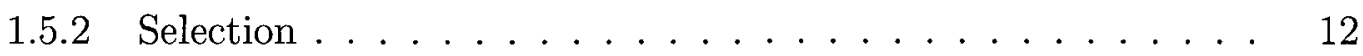

1.5.3 Reproduction ..................... 16

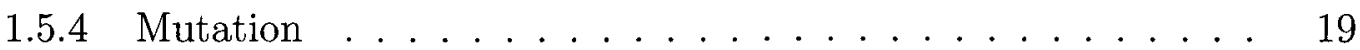

1.6 Variations of the Standard Genetic Algorithm . . . . . . . . . . . 20 
1.7 Applications of Genetic Algorithms . . . . . . . . . . . . . 20

2 Methodology 23

2.1 Development of the Genetic Algorithm . . . . . . . . . . . . . 23

2.2 Rocket Flowpath . . . . . . . . . . . . . . . 27

2.2.1 Rocket Flowpath Design Variables . . . . . . . . . . 28

2.2.2 Rocket Flowpath Evaluation . . . . . . . . . . . . . 31

2.3 Air Flowpath . . . . . . . . . . . . . . . . . . . . . 33

2.3.1 Air Flowpath Design Variables . . . . . . . . . . . . . 34

$2.3 .2 \quad$ Air Flowpath Evaluation . . . . . . . . . . . . . . 37

2.4 Dealing with Invalid Solutions . . . . . . . . . . . . . . . 39

3 Genetic Algorithm Convergence Results $\quad 40$

3.1 Expected Convergence History . . . . . . . . . . . . . . . . . . . . 41

3.2 Effect of Population Size . . . . . . . . . . . . . . . . . . 44

3.3 Effect of Probability of Mutation . . . . . . . . . . . 47

3.4 Effect of Selection Pressure . . . . . . . . . . . . . . 50

3.5 Effect of Elitism . . . . . . . . . . . . . . . . 53

3.6 Effect of Adaptive Genetic Operators . . . . . . . . . . . . . 54

4 Rocket Flowpath Optimization Results $\quad 57$

4.1 Atlas E/F LR-105-5 . . . . . . . . . . . . . . . 57

4.1 .1 Performamce Criteria Weights . . . . . . . . . . . . . 59

4.2 H-IIA LE-7A . . . . . . . . . . . . . . . . . . . . 62

4.2.1 LE-7A: Rocket Flowpath Convergence History . . . . . . . 63

4.3 Solution Space Hyperplanes _ . . . . . . . . . . . . . . . 66

5 Air Flowpath Optimization Results $\quad 72$

5.1 Air Flowpath Optimization _ . . . . . . . . . . . . . 74 
5.2 Exchange Inlet Optimization . . . . . . . . . . . . . . . 77

6 Conclusions and Recommendations $\quad 81$

$\begin{array}{lc}\text { List of References } & 84\end{array}$ 


\section{List of Tables}

1.1 Example of selection pressure influence on selection probability. . . . 13

1.2 Rank and selection probability for Ranked Selection method. . . . . 15

2.1 Rocket Flowpath Design Variables. . . . . . . . . . . . . . . 29

2.2 Air Flowpath Design Variables. . . . . . . . . . . . . . . 34

2.3 Simulated Ariane 4 Flight Profile [56] . . . . . . . . . . . . . . 38

3.1 Genetic Operators of GA. . . . . . . . . . . . . 56

4.1 Approximate Atlas E/F LR-105-5 Specifications. . . . . . . . . . . . . 58

4.2 Rocket flowpath fitness function weights. . . . . . . . . . . . . 59

4.3 Performance criteria results. . . . . . . . . . . . . . 61

4.4 Approximate LE-7A Specifications. . . . . . . . . . . . . . 62 


\section{List of Figures}

1.1 NASA GTX reference vehicle (A.K.A. Trailblazer) [4]. . . . . . . 3

1.2 Schematic diagram of a typical RBCC engine. . . . . . . . . . . 3

1.3 Mission thrust augmentation ratio. . . . . . . . . . . . . 4

1.4 An example of one Exchange Inlet configuration. . . . . . . . . . 7

1.5 Example of selection pressure influence on selection probability. . . . 14

1.6 SUS versus Roulette Wheel method. . . . . . . . . . . . . . . . . 14

1.7 Example of common crossover methods. . . . . . . . . . 18

2.1 Flow diagram of GA . . . . . . . . . . . . . . . . 24

2.2 Orthographic views of the rocket flowpath. The dashed lines on (a) represent half a clover. . . . . . . . . . . . . 28

2.3 Three performance criteria of rocket flowpath design. . . . . . . . . 31

2.4 Side view of half of the air flowpath. The dotted line shows the rocket flowpath within the air flowpath. . . . . . . . . . 33

2.5 Two examples of the effect of varying $z_{2} \ldots \ldots \ldots \ldots$

2.6 Two examples of the effect of varying $\tilde{c}_{f a i r_{\max }} \ldots \ldots \ldots \ldots$

2.7 Two examples of the effect of varying $\tilde{r}_{C B_{1}} \ldots \ldots \ldots \ldots$

3.1 Three sample runs of GA with same initial population $X^{0} \ldots \ldots 43$

3.2 Three sample runs of GA with random initial population $X^{0} \ldots \ldots 43$

3.3 Effect of varying population size. Constant genetic operators: $P_{m}=$ $0.1, s=1$ and $P_{c}=0.6 \ldots \ldots \ldots \ldots \ldots \ldots \ldots \ldots \ldots \ldots \ldots \ldots \ldots$ 
3.4 Histogram plots for several values of $m$ showing the expected rate of convergence. . . . . . . . . . . . . . . . . 46

3.5 Effect of varying probability of mutation. Constant genetic operators: $m=50, s=1$ and $P_{c}=0.6 \ldots \ldots \ldots \ldots \ldots \ldots$

3.6 Histogram plots for several values of $P_{m}$ showing the expected rate of convergence. . . . . . . . . . . . . . . . .

3.7 Effect of varying selection pressure. Constant genetic operators: $m=$ $50, P_{m}=0.1$ and $P_{c}=0.6 \ldots \ldots \ldots \ldots \ldots \ldots \ldots \ldots \ldots \ldots \ldots \ldots \ldots$

3.8 Histogram plots for several values of $s$ showing the expected rate of

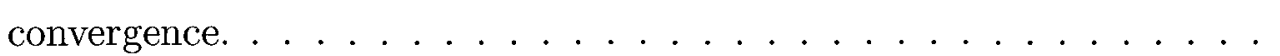

3.9 Three runs of GA without Elitism. Constant genetic operators: $m=$ $50, P_{m}=0.1, s=1$ and $P_{c}=0.6 \ldots \ldots \ldots \ldots$

3.10 Histogram of $\Gamma$ for several population sizes. Comparing constant genetic operator parameters (solid bars and solid lines) versus adaptive genetic operator parameters (hollow bars and dotted lines). . . . . . .

4.1 Pre-specified Mach number distribution corresponding to Atlas E/F LR-105-5 nozzle. . . . . . . . . . . . . . . . 58

4.2 Four cases of different fitness function weights showing the most fit rocket flowpath for each case. . . . . . . . . . . . . . . 61

4.3 Pre-specified Mach number distribution corresponding to H-IIA LE-7A. 63

4.4 LE-7A fitness convergence history. . . . . . . . . . . . . . . . 64

4.5 LE-7A performance criteria convergence history. . . . . . . . . . . 64

4.6 Most fit individual at $k=0,5,40(\Gamma=0,250,2000) \ldots \ldots 65$

4.7 An example of the creation of the $\tilde{z}_{g}-\tilde{r}_{g}$ projection-plane. . . . . 68 
$4.8 \tilde{z}_{g}-\tilde{r}_{g}$ projection-plane illustrating evaluation of new solutions, progression of the most fit solution, and formation of hyperplanes. The most fit individual of the population is represented by a double circle. Individuals with fitness greater than zero are represented by filled circles. Invalid individuals are represented by empty circles. . . . . 70

$4.9 \tilde{\psi}_{e}-\tilde{\psi}_{g}$ projection-plane illustrating evaluation of new solutions, progression of the most fit solution, and formation of hyperplanes. The most fit individual of the population is represented by a double circle. Individuals with fitness greater than zero are represented by filled circles. Invalid individuals are represented by empty circles. . . . . . 71

5.1 1-D rocket-ejector used for rocket-ejector analysis. . . . . . . . . 73

5.2 Convergence history for the optimization of the air flowpath design. . $\quad 75$

5.3 Optimized Exchange Inlet design considering five air flowpath design

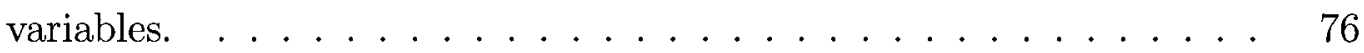

5.4 Convergence history for the optimization of the Exchange Inlet design. 78

5.5 Optimized Exchange Inlet design considering all 10 design variables. . 80 


\section{Nomenclature}

\section{List of Subscripts:}

\begin{tabular}{|c|l|}
\hline Symbol & Description \\
\hline 1 & Plane 1 of Exchange Inlet Corresponding to Throat of the Rocket Flowpath \\
2 & Plane 2 of Exchange Inlet \\
3 & Plane 3 of Exchange Inlet Corresponding to Exhaust of the Rocket Flowpath \\
air & Atmospheric Air Stream \\
$e$ & Cowl of Exchange Inlet \\
$g$ & Rocket Flowpath Exhaust Plane \\
$i$ & Rocket Flowpath Gate \\
$j$ & Gene of an Individual \\
$k$ & Generation Number \\
$L E$ & Leading Edge of the Cowl of Exchange Inlet \\
rocket & Rocket Stream \\
\hline
\end{tabular}




\section{Rocket Flowpath Symbols:}

\begin{tabular}{|c|l|c|}
\hline Symbol & Description & Units \\
\hline$\chi$ & Clover Half-Angle & deg. \\
$\varepsilon$ & Number of Clovers & - \\
$\phi$ & Flow-Turning Angle at the Gate & deg. \\
$\psi_{e}$ & Rocket Flowpath Exhaust Profile Arc Angle & deg. \\
$\psi_{g}$ & Rocket Flowpath Gate Arc Angle & deg. \\
$A_{\text {intake }}$ & Air Intake Area of Rocket Flowpath & $m^{2}$ \\
$A_{m a x}$ & Cross Sectional Area of Rocket Flowpath at Exhaust Plane & $m^{2}$ \\
$I_{s p}$ & Specific Impulse & $s$ \\
$L_{e}$ & Arc Length of Rocket Flowpath Exhaust Profile & $m$ \\
$L_{m a x}$ & Circumference of Rocket Flowpath at Exhaust Plane & $m$ \\
$O / F$ & Oxygen-Fuel Ratio & - \\
$r_{e}$ & Radius of Rocket Flowpath at Exhaust Plane & $m$ \\
$r_{f}$ & Fillet Radius of Rocket Flowpath at the Gate & $m$ \\
$r_{g}$ & Depth of Rocket Flowpath Gate & $m$ \\
$r_{t h}$ & Radius of Rocket Flowpath at Nozzle Throat & $m$ \\
$z_{e}$ & Depth of Rocket Flowpath Exhaust Plane & $m$ \\
$z_{g}$ & Depth of Rocket Flowpath Gate & $m$ \\
\hline
\end{tabular}




\section{Exchange Inlet Symbols:}

\begin{tabular}{|c|l|c|}
\hline Symbol & Description & Units \\
\hline$\alpha$ & Entrainment Ratio & - \\
$\Phi$ & Thrust Augmentation Ratio & - \\
$\sigma$ & Rocket-Total Flow Area Ratio & - \\
$A$ & Air Flowpath Area of Exchange Inlet & $m^{2}$ \\
$A_{R}$ & Area of Rocket Flowpath Exhaust Profile & $m^{2}$ \\
$A R$ & Plane 2 - Plane 3 Air Flowpath Area Ratio of Exchange Inlet & $m^{2}$ \\
$c_{f a i r_{m a x}}$ & Maximum Fairing Chord Length & $m$ \\
$C R$ & Cowl Lip Contraction Ratio & - \\
$h_{a l t}$ & Altitude & $m$ \\
$M$ & Mach Number & - \\
$\dot{m}$ & Mass Flow Rate & $\mathrm{kg} / \mathrm{s}$ \\
$p$ & Pressure & $\mathrm{kPa}$ \\
$r_{C B}$ & Radius of Center Body & $m$ \\
$r_{N Z}$ & Radius of Rocket Flowpath Within Exchange Inlet & $m$ \\
$t$ & Cowl Thickness & $m$ \\
\hline
\end{tabular}




\section{Genetic Algorithm Symbols:}

\begin{tabular}{|c|l|}
\hline Symbol & Description \\
\hline$\Gamma$ & Convergence Metric \\
$B_{J_{\max }}$ & Arithmetical Crossover Factor \\
$B_{J_{m} n}$ & Lower Bound of Design Variable $j$ \\
$D_{k}$ & Genetic Diversity of Population $k$ \\
$D_{k}^{*}$ & Lower Limit of Acceptable Genetic Diversity \\
$F$ & Vector of Population's Fitness \\
$f_{2}^{k}-$ & Fitness of Least Fit Individual of Mating Pool \\
$f_{1}^{k}$ & Fitness of Most Fit Individual of Mating Pool \\
\hline$F^{k}$ & Average Fitness of Mating Pool \\
$f_{\imath}$ & Fitness of Individual $i$ \\
$k_{C}$ & Convergence Criteria \\
$k_{T}$ & Trap Criteria \\
$m$ & Population Size \\
$N$ & Number of Crossover Points for N-Point Crossover \\
$n$ & Number of Genes that Define an Individual \\
$P_{\imath}$ & Probability of Selection of Individual $i$ \\
$P_{c}$ & Probability of Crossover \\
$P_{m}$ & Probability of Mutation \\
$R_{J}$ & Resolution of Design Variable $j$ \\
$r_{\imath}$ & Rank of Individual $i$ \\
$S$ & Size of Search Space \\
$s$ & Selection Pressure \\
$s_{T}$ & Tournament Size \\
$X_{k}$ & Truncation Selection Parameter \\
$x_{\imath, j}^{k}$ & Population of Generation $k$ \\
\hline
\end{tabular}


List of Acronyms: The following acronyms are used throughout the thesis:

\begin{tabular}{|c|l|}
\hline Acronym & Description \\
\hline AGA & Adaptive Genetic Algorithm \\
CCP & Combined-Cycle Propulsion \\
DAB & Diffusion and AfterBurning \\
EA & Evolutionary Algorithm \\
GA & Genetic Algorithm \\
HRST & Highly Reusable Space Transportation \\
IRS & Independent Ramjet Stream \\
RBCC & Rocket-Based Combined-Cycle \\
RLV & Reusable Launch Vehicle \\
SMC & Simultaneous Mixing and Combustion \\
SPI & Shielded Primary Injection \\
SUS & Stochastic Universal Sampling \\
TBCC & Turbine-Based Combined-Cycle \\
\hline
\end{tabular}




\section{Chapter 1}

\section{Introduction}

\subsection{Motivation for Research}

"Throughout history, the great nations have always been the ones at the forefront of the frontiers of their time" [1]. The Roman Empire (27 BC - 416 AD) expanded to cover most of Southern Europe and parts of Northern Africa and the Middle East [2]. The British Empire was dominant throughout the $17^{\text {th }}$ and $18^{\text {th }}$ century due to its exploration and mastery of the seas. The $20^{\text {th }}$ century saw America rise to power due largely to its mastery of the air. It seems that the next nation will rise to power through mastery of outer space.

There are many foreseeable benefits for humanity to explore outer space. Several benefits are being realized at the present day. Telecommunication satellites enable global communication, navigation, and entertainment systems. Earth observation 
satellites have environmental monitoring and meteorological capabilities. Scientific satellites provide insight to the nature of our universe. There are also many theoretical benefits that may come to fruition as a result of the exploitation and exploration of outer space. Space-based solar power proposes to generate enough electricity for the world with the help of a network of solar panels orbiting around the sun. Colonization of celestial bodies might solve the world's over population problem. Mining the asteroid belt could supply all necessary materials for future generations.

In order to facilitate the exploration of outer space, it has been widely stated that the development of reliable and cost effective access to outer space is crucial. This goal has served as the driving force for many recent research projects. One such project is the Highly Reusable Space Transportation (HRST) Study conducted by NASA [3]. Mankins highlighted Combined-Cycle Propulsion (CCP) as a potential solution. He defined CCP as "incorporating two or more primary propulsion cycles/modes into a single thrust-generating machine". A candidate example of CCP is the Rocket-Based Combined-Cycle (RBCC) propulsion system.

The RBCC propulsion system proposed by NASA is shown in Fig 1.1 [4]. Trailblazer is a Reusable Launch Vehicle (RLV) with three RBCC engines built into the airframe. Fig. 1.2 shows a schematic diagram of a typical RBCC engine with an annular rocket exhaust profile. This RLV will operate in four modes from lift-off to orbit: rocket-ejector mode, ramjet, scramjet, and pure-rocket mode. RBCC engines have been thoroughly studied over the past 50 years. The focus of this thesis is the first mode of operation, the rocket-ejector mode. The purpose of the rocket-ejector is to entrain atmospheric air into the mixer of the RBCC engine. Therefore, this thesis considers the geometry of the RBCC engine upstream of the mixer.

The rocket-ejector mode serves two purposes in the operation of the RBCC engine. The first purpose is to entrain atmospheric air for afterburning. The goal is that this operation will generate more thrust than the rocket itself (i.e. positive thrust 


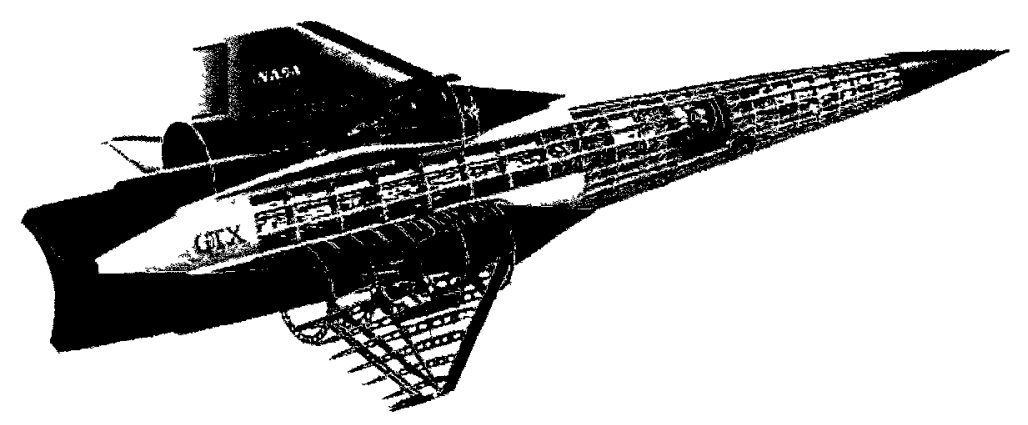

Figure 1.1: NASA GTX reference vehicle (A.K.A. Trailblazer) [4].

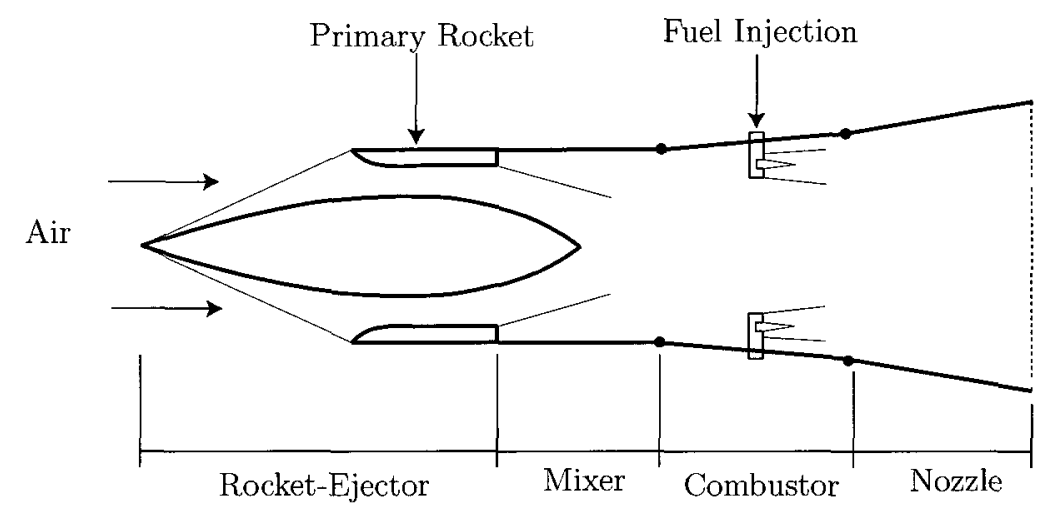

Figure 1.2: Schematic diagram of a typical RBCC engine.

augmentation). The second purpose is to accelerate the launch vehicle to the velocity required for the ramjet mode to become operational. Fig 1.3 illustrates this point. The dashed line showing a thrust augmentation ratio of one represents the thrust developed by the rocket-only mode. Fig 1.3(a) shows an ideal case with positive thrust augmentation for all flight conditions. Fig 1.3(b) shows a case where the rocket-ejector mode produces negative thrust augmentation at low Mach numbers. Although this situation is not ideal, the RBCC engine does outperform the rocketonly engine because the mission averaged thrust augmentation is greater than one. Negative thrust augmentation may result due to poor air intake design. For example the rocket-ejector may produce more drag than additional thrust or the primary rocket stream may not mix well with the atmospheric air stream, leading to poor combustion and afterburning. 


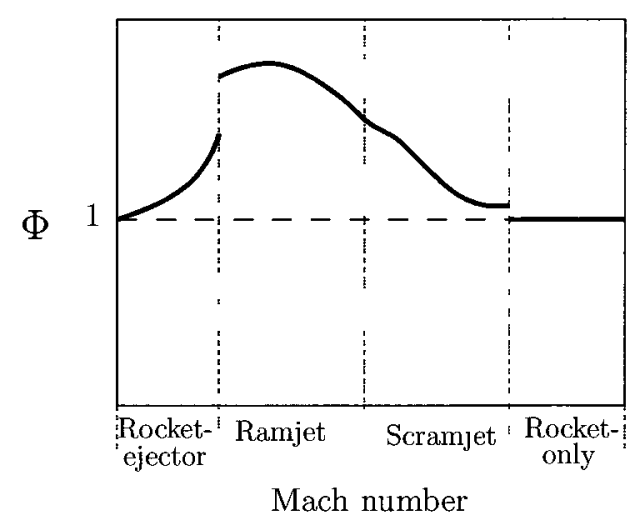

(a) Ideal Case

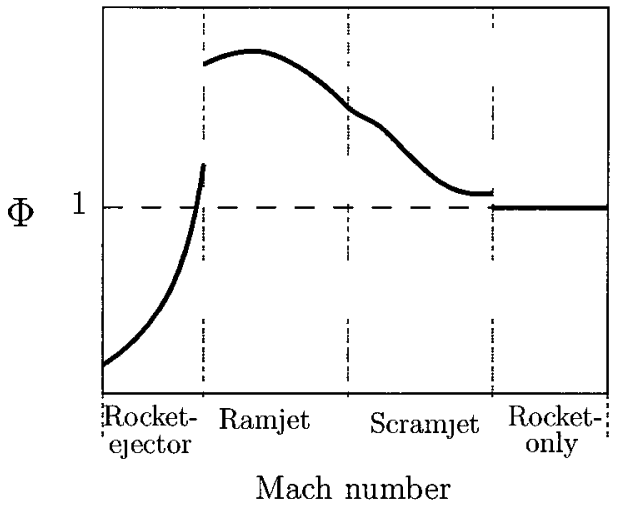

(b) Non-Ideal Case

Figure 1.3: Mission thrust augmentation ratio.

The performance of the rocket-ejector mode depends on the quality of mixing and combustion of the atmospheric air stream and the primary rocket stream. Therefore, mixing configuration is a crucial matter. There are two general strategies for combustion: Diffusion and Afterburning (DAB) and Simultaneous Mixing and Combustion (SMC). In the DAB cycle, the inert rocket stream and atmospheric air stream are mixed and diffused, then fueled and burned subsonically in an afterburner. In the SMC cycle, the fuel-rich rocket stream is continuously mixed and reacted with the air stream. DAB yields better performance than SMC at sea-level static conditions, however the performance converges with increasing altitude and flight speed [5]. The SMC cycle is less complex than the DAB cycle and requires a shorter mixing duct, leading to lower structural weight.

Other mixing schemes have been considered. The Independent Ramjet Stream (IRS) cycle has been considered by NASA [6]. In this cycle, the air stream is fueled upstream and the rocket plume is used to ignite the fuel-air mixture. It has been found by Yungster and Trefny that at subsonic speeds the IRS cycle shows lower performance when compared with other rocket-ejector schemes [7].

The Shielded Primary Injection (SPI) scheme, developed by Russel et al. [8], is a combination of the SMC and DAB cycles. Fuel is injected upstream in the inert 
rocket stream and is shielded from the oxidizing air stream. Russell et al. have shown that SPI combines the advantages of DAB and SMC. A comparison of computational analyses and experimental data shows that delayed combustion results in increased mixing, which allows for shorter mixing ducts.

Brocco and Daines [9] studied how the primary rocket exit pressure affects the rocket-ejector performance. They found that as rocket exit pressure decreased, thrust and specific impulse decreased, while air entrainment increased. Mixing of the primary rocket stream and secondary air stream appeared to increase with decreased rocket exit pressure. The potential for afterburning could offset the loss of thrust and specific impulse.

Daines and Russell [5] conducted a multidimensional computational analysis of reacting flowfields in RBCC engines operating in the rocket-ejector mode at sea-level static conditions. Comparison of SMC and DAB configurations showed that SMC produced negative thrust augmentation except for very fuel-rich conditions $(\mathrm{O} / \mathrm{F}=$ 2.7). DAB produced positive thrust augmentation for cases where fuel was injected after significant mixing.

Cramer et al. [10] experimentally examined the effects of twin thruster configuration on the mixing and pumping processes of the rocket-ejector mode at flight conditions from Mach 0 (sea-level static) to Mach 1.9. The results indicate that the twin thruster configuration entrains more air $(\approx 15 \%)$, mixes in a shorter distance $(\approx 50 \%)$, and produces a higher static pressure rise in the duct $(\approx 26 \%)$ than the single thrust configuration at the same operating point.

At Purdue University, Jos et al. [11] tested the effects of varying fuel injection rates for afterburning and air flow rates for a RBCC engine using the SMC scheme. Thrust augmentation was found to increase with airflow before ignition became unsteady. The same was true for increasing afterburning fuel injection.

At The Pennsylvania Sate University, Lehman et al. [12] conducted experiments 
of a RBCC engine operating for both DAB and SMC schemes. Results show that for the DAB configuration, the thrust developed is higher for stoichiometric rocket cases than that of the corresponding fuel-rich rocket cases.

At the Glenn Research Center's Engine Components Research Laboratory, Kamhawi et al. [13] evaluated the rocket-ejector and ramjet mode of a semiaxisymmetric RBCC engine operating under the SMC scheme at sea-level static and Mach 2.5. Results showed that little mixing and combustion occurred between the fuel-rich rocket exhaust and the air stream. They suggest that a significantly longer duct or some form of mixing enhancement would be required for the SMC scheme to be operable with a single-thruster arrangement.

Dijkstra et al. [14] conducted an experimental study to investigate the performance of the rocket-ejector mode at Mach numbers between 0 and 2.2. Their results show that the rocket-ejector mode can achieve a thrust augmentation ratio of $1.1-1.2$ at sea-level static conditions. The entrained air mass flow rate primarily depends on ejector geometry and secondarily on the primary rocket flow rate.

The shape of the rocket exhaust profile affects mixing between the primary rocket stream and secondary air stream, which then affects the efficiency of the rocket-ejector mode. The Marquardt Corporation [15] developed a correlation for mixing length as a function of several parameters, including the total number of thrusters in the duct; the relationship states that the mixing length is inversely proportional to the number of thrusters in the duct. It has also been found that mixing performance improved with an annular rocket exhaust profile $[16,17]$. It was found that the increased shear layer area between the annular rocket stream and the central air stream produced better mixing for shorter duct lengths. 


\subsection{A Novel Rocket-Ejector Design}

To take advantage of the performance improvements due to an annular rocket exhaust profile, such as: increased entrainment of atmospheric air, improved mixing of primary rocket stream and secondary air stream, and shorter mixing duct length, a novel rocket-ejector concept has been developed at Carleton University. The novel rocket-ejector is composed of two geometries: a rocket flowpath and an air flowpath. The combination of these two geometries forms a single rocket-ejector inlet called the Exchange Inlet. The rocket flowpath produces an annular or segmented-annular rocket exhaust profile from a single circular throat. The air flowpath surrounds the rocket flowpath and defines the contour of the entrained atmospheric air. The purpose of these two geometries is to generate an annular primary rocket stream that encircles the secondary atmospheric air stream in order to produce high shear layer area between the two streams in the mixing duct. Fig. 1.4 shows an example of one possible configuration of the Exchange Inlet.

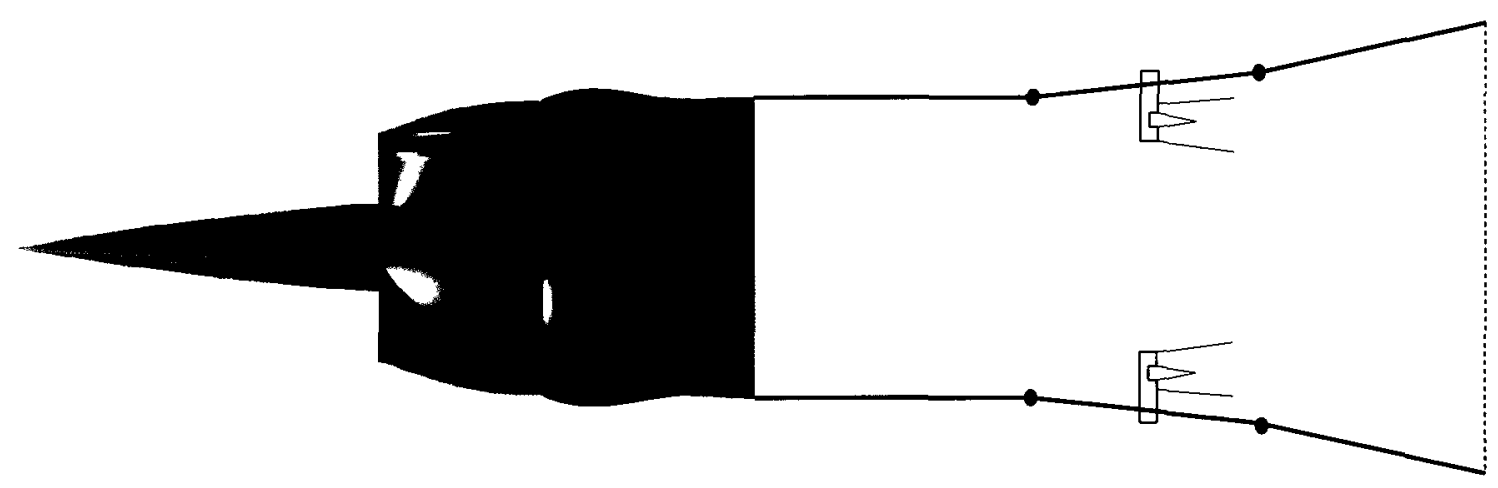

Figure 1.4: An example of one Exchange Inlet configuration.

It is expected that the Exchange Inlet design will show performance increases over conventional rocket-ejector designs due to the expected increase of mixing efficiency and potential for high entrainment of atmospheric air. Several computation studies conducted by Etele et al. [18] have shown that an annular rocket exhaust profile 
results in increased mixing of the primary rocket stream and secondary air stream. Furthermore, the experimental results of Escher et al. [19] have shown that a high rocket exhaust shear layer area configuration results in minimum required mixing duct length, which is an indication of the efficiency of the rocket-ejector.

\subsection{Problem Statement}

The design of the Exchange Inlet is controlled by many geometric variables. Each variable has corresponding bounds and constraints. The matter is further complicated by the fact that the variables are interdependent. By manipulating these variables the user is capable of generating a wide variety of Exchange Inlet configurations, each with varying performance. Thus, the problem is: Given user defined performance criteria which Exchange Inlet configuration is best? More specifically, which combination of geometric variables results in an optimal Exchange Inlet design.

This is a nonlinear combinatorial optimization problem. The solution space is expected to have many local optima and potentially several global optima. Depending on the definition of the fitness function, it is conceivable that two or more solutions may produce the same optimal fitness. For example, suppose a problem is posed to find the optimal path between two points. If the fitness function is based on the distance traveled, then the optimal solution is a straight line between the two points. However if speed is a variable in this problem, then an infinite number of optimal solutions exist, since one can travel in a straight line between the two points at any desired speed. Therefore, it is more appropriate to define a fitness function that is based on distance traveled and duration of travel.

In engineering design optimization problems finding a global optimal solution is not necessarily required; a more realistic goal is to find a near-optimal solution. Continuing the previous example, if we apply a constraint on the maximum speed 
of travel, it becomes obvious that the global optimal solution is to travel along a straight line at the maximum speed. However, for a realistic engineering problem, a near-optimal solution that is a fraction of a second slower than the global optimal solution is also suitable solution. Therefore, the purpose of this thesis is to develop a Genetic Algorithm (GA) that is capable of finding near-optimal solutions for the design of the Exchange Inlet.

\subsection{History of Genetic Algorithms}

A genetic algorithm (GA) is a commonly used optimization technique. This technique represents a subset of evolutionary algorithms (EA). In general, EAs attempt to develop numerical models which represent processes that are observed in nature; the goal being to create a model that can evolve toward the optimal solution of a given problem. John Holland was the first to apply the idea of evolution to optimization problems in 1975 [20].

In 1859, Charles Darwin described the tendency of a species or population to evolve toward a state that enables them to best survive in their environment. It is the ability to reproduce and pass on genetic information that determines if individuals of a population are strong survivors. Darwin found that through the process of "natural selection" individuals who are well adapted to their environment are more likely to pass on their genetic information than individuals who are not. The measure of how well adapted an individual is to the environment is called fitness. Over the course of many generations a population tends to resemble the characteristics of the most fit individuals, since these individuals pass on their genetic information more often. GAs mimic Darwin's natural selection in the following sense. Potential solutions of the problem are represented as individuals. A set of solutions is represented as a population of individuals. The optimality of a solution is represented as the fitness 
of an individual.

The combination of Gregor Mendel's discovery (1865) that hereditary characteristics, called genes, are passed from parent to child, and Thomas Morgan's discovery (1890) that genes are the basis of chromosomes led to the understanding that the genetic information of an individual can be described by its chromosomes and the genetic information of a child comes from the crossover of chromosomes of the parents. GAs mimic this natural process by representing the chromosomes of an individual as a solution vector. Genes within chromosomes are represented as variables within the solution vector. Alleles of a gene are represented as numerical values of a variable. During reproduction the crossover of chromosomes is represented as crossover of solution vectors. At this point, GAs differ from nature. In nature, individuals are described by several chromosomes that contain many genes. However, in general a GA describes solutions by only one vector that contains several variables.

The final mechanism of evolution that GAs attempt to model is mutation of genes. The only way that GAs can model mutation is by a simplified stochastic method. This is another point where GAs differ from nature. It has been proposed that in nature mutations are responsible for not only creating new alleles but also for creating new genes and even new chromosomes. The result is that mutations can cause a species to evolve into a complete different species. The stochastic mutation methods of GAs are only capable of creating new numerical values for a variable. Thus, mutation cannot create new variables by which to define the problem at hand.

\subsection{Models of Evolution Mechanisms}

The majority of literature on GAs is aimed at improving existing models or developing new, more effective models to make GAs more efficient. There are four basic evolution mechanisms required for a standard GA: genetic representation, selection, 
reproduction, and mutation.

\subsubsection{Genetic Representation}

The first evolution mechanism is the genetic representation of solutions. Holland and the original pioneers of GAs used binary encoding to represent solutions [20,21]. For example, consider an individual who is described by one chromosome with three genes $(n)$, where each gene has five alleles $(r)$. This example has $r^{n}=5^{3}=125$ possible individuals. The binary genetic representation would require 9 bits and the chromosomal representation would be $\{a a a b b b c c c\}$, where $a, b, c$ are binary numbers and $a a a, b b b, c c c$ are the first, second, and third genes, respectively. Unfortunately, the binary encoding model is susceptible to decoding errors. If each gene only has 5 alleles, the allowable alleles for gene aaa would be: $\{000\},\{001\},\{010\},\{011\}$, and $\{100\}$. However, it is possible by crossover or mutation that the bit string for gene aaa, for example, could be altered such that it becomes $\{111\}$. When decoded this would represent a $7^{\text {th }}$ allele, which does not exist.

The variant to this model is real-parameter genetic representation which is favoured by several researchers [22-24]. Using the example above, the real-parameter genetic representation of the individual would be $\{A B C\}$, where $A, B, C \in D=$ $\{1,2,3,4,5\}$. Again, there are $r^{n}=5^{3}=125$ possible solutions. However, this model is not susceptible to decoding errors since only five alleles exist.

Due to the simplicity of the real-parameter representation and the fact that this method is not susceptible to decoding errors, the GA developed in this thesis uses real-parameter genetic representation of solutions. 


\subsubsection{Selection}

GAs use a selection mechanism to select individuals from the population to insert into a mating pool. This mechanism attempts to simulate Darwinian natural selection by selecting the more fit individuals of the population. There are a wide variety of selection models used by researchers and there is no general consensus as to which model is better than the others.

The selection models can be divided into two categories: stochastic and deterministic selection methods. Commonly used stochastic selection methods are Tournament Selection [25], Roulette Wheel [26], Stochastic Universal Sampling (SUS) [27], Truncation Selection [28], and Ranked Selection [29]. A commonly used deterministic selection method is Elitism [30,31].

Tournament Selection is accomplished by holding a tournament among $s_{T}$ random competitors, with $s_{T}$ being the tournament size. The winner of the tournament is the individual with the highest fitness, and the winner is then inserted into the mating pool. The selection pressure is controlled by $s_{T}$ (larger $s_{T}$ indicates greater selection pressure), since larger $s_{T}$ favours the selection of the more fit individuals. Suppose that $s_{T}=m$, in this case the tournament size is equal to the size of the population, only the most fit individual can be selected for insertion into the mating pool. This would nullify the exploitative power of the selection mechanism. Goldberg et al. [32] have shown that GAs are successful under a wide range of selection pressures. However if the selection pressure is too low, the convergence rate will be slow. If the selection pressure is too high, there is an increased chance of the GA becoming trapped in a local optimal solution.

Roulette Wheel selection is accomplished by assigning an area of a roulette wheel to each individual of the population. The area that an individual holds is proportional 
to its fitness and is calculated by Eq 1.1 .

$$
P_{\imath}=\frac{f_{\imath}^{s}}{\sum_{u=1}^{m} f_{u}^{s}}
$$

The roulette wheel is spun and the selected individual is inserted into the mating pool. Similar to the Tournament selection method, high selection pressure will favour the more fit individuals, since they will be assigned a larger area of the roulette wheel. To illustrate this point, suppose we have a population of $m=4$ individuals with corresponding fitness values shown in Table 1.1. A selection pressure of $s=0.1$ results in a roulette wheel with all individuals having a nearly equal probability of selection, as shown in Fig 1.5(a). A selection pressure of $s=4$ results in the roulette wheel shown in Fig 1.5(b) where individual 1 has a significantly higher probability of being selected than the other individuals. The selection pressure of the Roulette Wheel method is susceptible to the same convergence problems as the selection pressure of the Tournament Selection method; low selection pressure results in slow convergence rate, high selection pressure results in increased chance of GA becoming trapped in a local optimal solution.

Table 1.1: Example of selection pressure influence on selection probability.

\begin{tabular}{|c|c|c|c|}
\hline Individual & $f_{\imath}$ & $P_{\imath}(s=0.1)$ & $P_{\imath}(s=4)$ \\
\hline \hline 1 & 0.6 & 0.26 & 0.57 \\
2 & 0.5 & 0.25 & 0.28 \\
3 & 0.4 & 0.25 & 0.11 \\
4 & 0.3 & 0.24 & 0.04 \\
\hline sum & 1.8 & 1 & 1 \\
\hline \hline
\end{tabular}

SUS selection is similar to Roulette Wheel selection because each individual of the population is assigned an area of the roulette wheel based on its fitness. However, for 


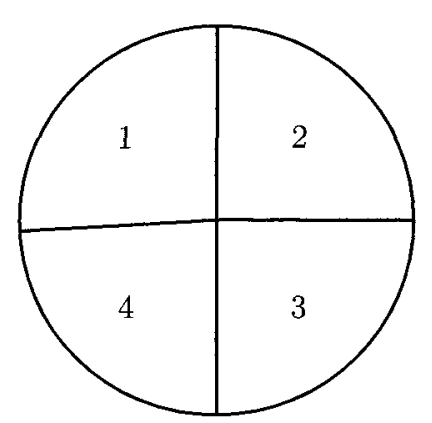

(a) $\mathrm{s}=0.1$

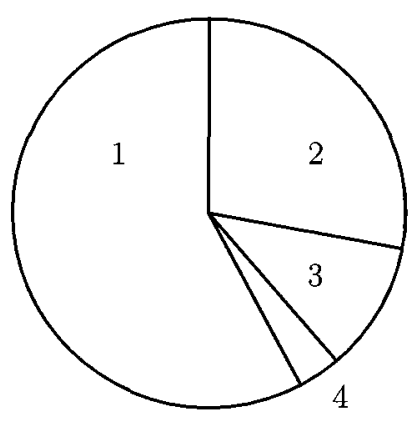

(b) $\mathrm{s}=4$

Figure 1.5: Example of selection pressure influence on selection probability.

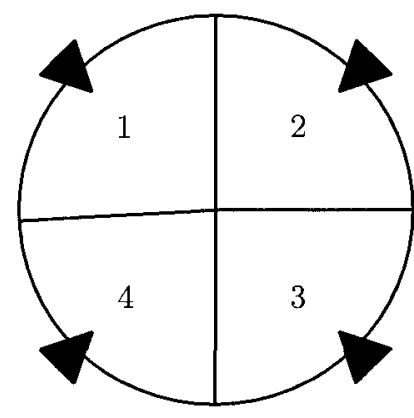

(a) SUS

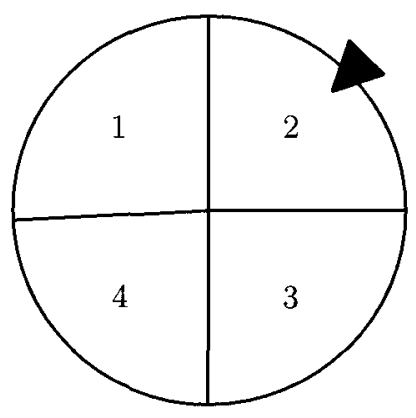

(b) Roulette Wheel

Figure 1.6: SUS versus Roulette Wheel method.

SUS the wheel has $m$ evenly spaced selectors and the wheel is only spun once; the mating pool is selected by one spin rather than $m$ spins. Fig 1.6(a) and 1.6(b) show the difference between the SUS and Roulette Wheel methods. Using the previous example from Table 1.1 with $s=0.1$, the SUS method will select all four individuals for the mating pool with a probability of 0.99 , whereas the Roulette Wheel method (which requires four spins of the wheel) will select all four individuals with a probability of $P_{1} \cdot P_{2} \cdot P_{3} \cdot P_{4}=0.09375$. Thus the SUS selection method maintains better diversity but results in slow convergence rates.

For Truncation Selection only the top $T$ individuals of the population are eligible for selection. Each individual above the threshold $T$ is given the same probability of selection for the mating pool. This selection model is not comparable to Darwinian 
Table 1.2: Rank and selection probability for Ranked Selection method.

\begin{tabular}{|c|c|c|c|c|}
\hline Individual & $f_{\imath}$ & $r_{\imath}$ & $P_{\imath}$ (Linear) & $P_{\imath}$ (Exponential) \\
\hline \hline 1 & 0.6 & 4 & 0.4 & 0.64 \\
2 & 0.5 & 3 & 0.3 & 0.24 \\
3 & 0.4 & 2 & 0.2 & 0.09 \\
4 & 0.3 & 1 & 0.1 & 0.03 \\
\hline sum & 1.8 & 10 & 1 & 1 \\
\hline \hline
\end{tabular}

natural selection since the selection of individuals is not proportional to their fitness.

For Ranked Selection the individuals are ranked according to their fitness values; the rank $r_{1}=m$ is assigned to the most fit individual and the rank $r_{m}=1$ to the least fit individual. The probability of selection is linearly assigned (see Eq 1.2) or exponentially assigned (see Eq 1.3) according to their rank. Table 1.2 shows the rank and selection probability using the Rank Selection method for the same example as Table 1.1. The disadvantage of the Ranked Selection method is the probability of selection for the mating pool is not proportional to an individual's fitness but rather its rank. Two individuals with the same fitness won't have the same rank, therefore they won't have the same probability of being selected for the mating pool. Similar to Truncation Selection, Ranked Selection is not comparable to Darwinian natural selection since individuals are selected based on rank rather than fitness.

$$
\begin{aligned}
& P_{\imath}=\frac{2}{m(m+1)} r_{\imath} \\
& P_{\imath}=\frac{e^{m}-1}{e-1} e^{m-\imath}
\end{aligned}
$$

A commonly used deterministic selection method is the Elitism method. The Elitism method ensures that the most fit individual of a generation (the elite) is 
passed on to the following generation. This ensures that the GA does not diverge toward less optimal solutions. There are two disadvantages of the Elitist method: The mechanisms that explore the search space do not operate on the elite, which could hinder the progression of the algorithm. The algorithm may become trapped if the elite represents a local optima. This effect becomes more significant as the number of elite individuals approaches the population size. Assuming a population size of $m=2$, if Elitism is implemented, then $50 \%$ of the population is immediately passed onto the next generation without allowing the reproduction or mutation mechanisms to help search for the optimal solution. Therefore, the number of Elite individuals should represent a small fraction of the population size.

It is the author's opinion that an ideal selection mechanism should have a balance of explorative and exploitative capabilities, and should closely mimic Darwinian natural selection of fitness proportional selection. The ability to manipulate the exploitative powers of the GA by increasing or decreasing the selection pressure is also highly desirable. For this reason, the Roulette Wheel method along with the Elitism method is used throughout the GA developed in this thesis.

Exploration is the ability of the GA to search new regions of the search space, while exploitation is the ability of the GA to focus on a given local area of the search space. Eiben and Schippers [59] discuss the effect of exploration versus exploitation, however there is no generally accepted conclusion as to which is most important.

\subsubsection{Reproduction}

At the beginning of every generation a new set of individuals is reproduced from parents in the mating pool of the previous generation. Reproduction is accomplished via recombination or crossover of the genetic information. The purpose of the reproduction mechanism is to exploit the solution space that is represented by the current population. Several models for reproduction are used by researchers, such as: 
N-point crossover [33], Cut-and-Splice [34], Arithmetical crossover [35] and Uniform crossover $[36,37]$.

The following example illustrates these four reproduction methods. Fig 1.7(a)1.7(d) show N-point Crossover, Cut-and-Splice, Arithmetical Crossover, and Uniform Crossover, respectively. Suppose we have individuals that are described by six genes, with the circle individual being more fit than the square individual.

Fig 1.7(a) shows N-point Crossover where the random crossover is located between genes 2 and 3. For individuals with long chromosomes, this method can lead to drastic differences between the parents and the children, which makes the reproduction mechanism explorative rather than exploitative. Therefore the rate of convergence will be slow, but good genetic diversity is maintained.

Fig 1.7(b) shows Cut-and-Splice where the random cut point can be different for each parent, in the example here it is between genes 3 and 4 for the more fit individual and between genes 1 and 2 for the less fit individual. Since the cut point is different, when the genes are spliced back together the children's chromosomal length has changed. This presents a problem similar to the decoding issues of the binary representation of solutions, a $7^{\text {th }}$ and $8^{\text {th }}$ gene are produced and have no physical meaning. Therefore this method does not work well for real-parameter genetic representation.

Fig 1.7(c) shows Arithmetical Crossover with a crossover factor $\lambda=0.5$, meaning that the children have $50 \%$ of the genetic characteristics of each parent. This reproduction method is accomplished by Eq 1.4 and is not applicable to binary representation. Arithmetical Crossover is an explorative reproduction method since it creates new alleles by taking an average of existing alleles.

$$
x_{1,3}^{k+1}=\lambda x_{1, \jmath}^{k}+(1-\lambda) x_{2,3}^{k}
$$

Fig 1.7(d) shows Uniform Crossover where a probability of crossover, $P_{c}$, is applied 
at each gene. Researchers generally set $P_{c} \approx 60 \%$ [38]. The Uniform Crossover method leads to minor differences between the parents and children, strengthening the exploitative power of the reproduction mechanism. This method can be easily applied to both binary and real-parameter genetic representation, and does not lead to decoding errors.

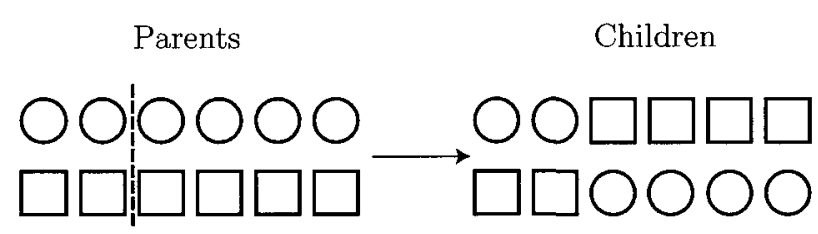

(a) N-point crossover $(\mathrm{N}=1)$

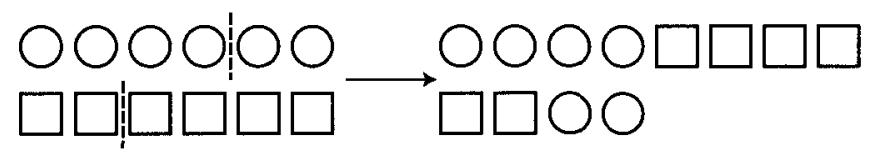

(b) Cut-and-Splice

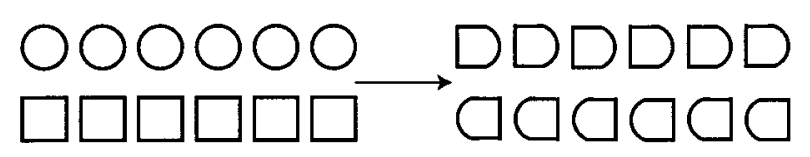

(c) Arithmetical crossover $(\lambda=0.5)$

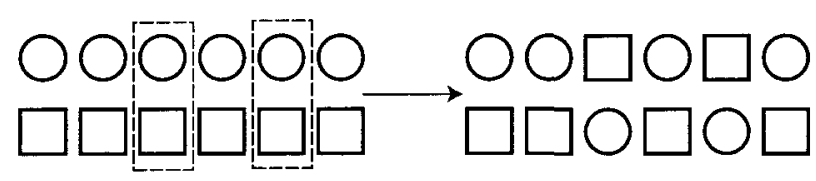

(d) Uniform crossover

Figure 1.7: Example of common crossover methods.

An ideal reproduction mechanism should have stronger exploitative abilities than explorative, since the purpose of the reproduction mechanism is to exploit the genes that make each parent fit and produce a child that is more fit. Therefore, the Uniform Crossover method is used throughout the GA developed in this thesis. 


\subsubsection{Mutation}

The mutation mechanism is an explorative tool used to search new areas of the solution space. This is accomplished by randomly altering the alleles of genes. The mutation mechanism gives GAs the ability to avoid trap situations and to maintain sufficient variance in the population. It has been suggested that the probability of mutation should be low $\left(P_{m} \approx 1 \%\right)[20,21,39]$, since a high probability of mutation reduces the GA to a random search function. Several mutation mechanisms have been proposed: Random Mutation [35], Arithmetic Mutation [40], Real Number Creep [41], Continuous Modal Mutation [42]. Random Mutation and Arithmetic Mutation simply generate a new random allele for a given gene, whereas Real Number Creep and Continuous Model Mutation use the current allele of a gene to influence the new random allele. Real Number Creep randomly alters the allele of a given gene by increasing or decreasing the value of the allele by one step size of that gene's resolution. As a result Real Number Creep behaves similar to a hill climbing method, however the step is not guaranteed to be "up" the hill. Herrera gives a comprehensive description of many mutation mechanisms [27].

The purpose of the mutation mechanism is to explore the search space. However if the mutation mechanism is too dominant the GA may become overly explorative, therefore it is desirable to use a mutation mechanism where the strength of the explorative ability can be controlled. The Random Mutation method is used throughout the GA developed in this thesis. By increasing the probability of mutation, $P_{m}$, the GA can become more explorative. By decreasing $P_{m}$ the GA can be rendered less explorative, allowing the exploitative mechanisms to become more influential. 


\subsection{Variations of the Standard Genetic Algorithm}

The standard GA described by Holland and Goldberg [20,21] used a "generational" model where a new population is created at each successive generation. A variation is the "steady-state" model [43], which maintains a relatively constant population by switching only a few weak individuals with newly produced fit individuals. Vavek et al. [44] found that the steady-state model, which they referred to as an "incremental model", outperforms the generational model in terms of convergence rate (number of evaluations before the optimum is found). The generational model is better at exploring the search space since at each generation the entire population (minus the elite individual) is free to roam the search space.

Several researchers use Adaptive Genetic Algorithms (AGAs) $[45,46]$, which vary the probability of crossover and mutation depending on the fitness values of the population in order to improve the performance of GAs. Hybrid GAs can improve performance by combining a simple GA with a gradient based routine [47]. The GA is used to find good starting points to seed the gradient based routine. Hybrid GAs are better at finding exact optimal solutions rather than near-optimal solutions at the expense of an increased probability of converging to a local optimal solution.

\subsection{Applications of Genetic Algorithms}

Given the wide variety of methods available, GAs have been widely used for engineering optimization problems. For example, Lampinen used a GA to determine the optimal shape of a cam shape [40]. His GA used real-parameter genetic representation and a population size of 40 individuals, where each individual was expressed by 40 genes. Each gene represented a point along a B-spline curve which defined the boundary shape of the cam profile. Arithmetic Crossover with $P_{c}=0.25$ and 
Arithmetic Mutation with $P_{m}=0.015$ was implemented. Lampinen compared the effect of random initial populations versus non-random initial populations on the convergence history; he concluded that non-random initialization improved convergence rate and produced better optimization results. One run of his optimization routine was shown to converge after 18000 individuals were evaluated or 450 generations. Lampinen compared his optimized cam design with a conventional cam design by trial-and-error and found that his solution was significantly improved.

West used a GA to investigate synthesis of a four bar mechanism for path generation and design of a mechanical prosthetic knee joint [48]. He used binary genetic representation. West's GA implemented Elitism and Population Decimation. Population Decimation is a Truncation method whereby an extremely large random initial population is generated and evaluated, then only the top $m$ individuals are eligible for selection and reproduction. West studied the effect of varying the genetic operator parameters. He considered population sizes between $m=40-220$ and found that his GA converged within 50000 function evaluations or 830 generations with a probability of 0.99 for a population size of $m=60$. West used Uniform Crossover with $P_{c}$ between $0-1$ and found that his GA had the highest probability of success with $P_{c}=0.6$. He also considered probability of mutation between $P_{m}=0-0.02$ and found that the effect of $P_{m}$ between this range did not significantly affect the performance of his GA.

In the aerospace field there have been numerous researchers that have employed GAs for a variety of problems. Oyama used a GA to optimize the shape of a transonic wing [49]. Oyama's GA used a population size of $m=10$. Selection was accomplished by the Stochastic Universal Search method and Elitism with the top two individuals considered as Elite. Uniform Crossover with $P_{c}=0.4$ and Random Mutation with $P_{m}=0.1$ was implemented. Oyama optimized a simplified case where only airfoil thickness and twist angle distributions were used as design variables. A more complex 
case was optimized where the airfoil shape was controlled by five design variables. The goal of the optimization routine was to design a wing geometry that maximizes Lift-to-Drag ratio while maintaining enough wing thickness to withstand the bending moment due to lift distribution. Oyama's GA used 3D Navier-Stokes equations to evaluate individuals. Convergence was attained after 25 generations and 2 days of computational time.

GAs have also been used for launch vehicle and missile design optimization [50-52]. Anderson used a GA to optimize the design of a missile's solid rocket motor, aerodynamic shape, and autopilot [31]. He used binary genetic representation. Anderson considered Roulette Wheel and Tournament Selection, he also used Elitism. Reproduction was accomplished via 1-Point Crossover with $P_{c}=0.7$, the crossover point is random. Random Mutation with $P_{m}=0.001$ and Creep Mutation was implemented. For the design of the solid rocket motor, Anderson found that several near-optimal solutions exist that are $1.5 \%$ of the desired thrust level. A global optimal solution may exist, however additional computational time was not warranted for his preliminary design studies. Convergence was achieved within 100 generations and required less than 8 hours of computation time. For the aerodynamic shape optimization of the missile, Anderson used a population size of 250 individuals defined by 15 design variables. Again, convergence to a near-optimal solution was attained within 100 generations.

Clough used a hybrid GA and gradient based routine to optimize the design of a Turbine-Based Combined-Cycle engine [53]. Clough used a population size of 50 individuals and set 800 generations as a convergence criteria. Clough states that the algorithm successfully designed an optimal TBCC engine.

Jahingir and Huque used neural networks to optimize the design of a RBCC inlet/ejector system [54]. The author has not found work involving the design optimization of a RBCC engine by GA. 


\section{Chapter 2}

\section{Methodology}

The method followed to determine the most fit Exchange Inlet design is described in this chapter. Section 2.1 describes the development of the GA used throughout this work. Section 2.2 describes the application of the GA to optimize the rocket flowpath. Optimization of the rocket flowpath is relatively fast, therefore the convergence studies in Chapter 3 are based on the rocket flowpath design optimization. Section 2.3 describes the application of the GA to optimize the air flowpath.

\subsection{Development of the Genetic Algorithm}

There are a wide variety of GA packages available for use. However, there is no guarantee that a given GA package will solve a specific problem. Rather than searching for a GA package to solve the problem at hand, a GA suited to the particular task has been developed. Fig. 2.1 shows the flow diagram of the GA. 


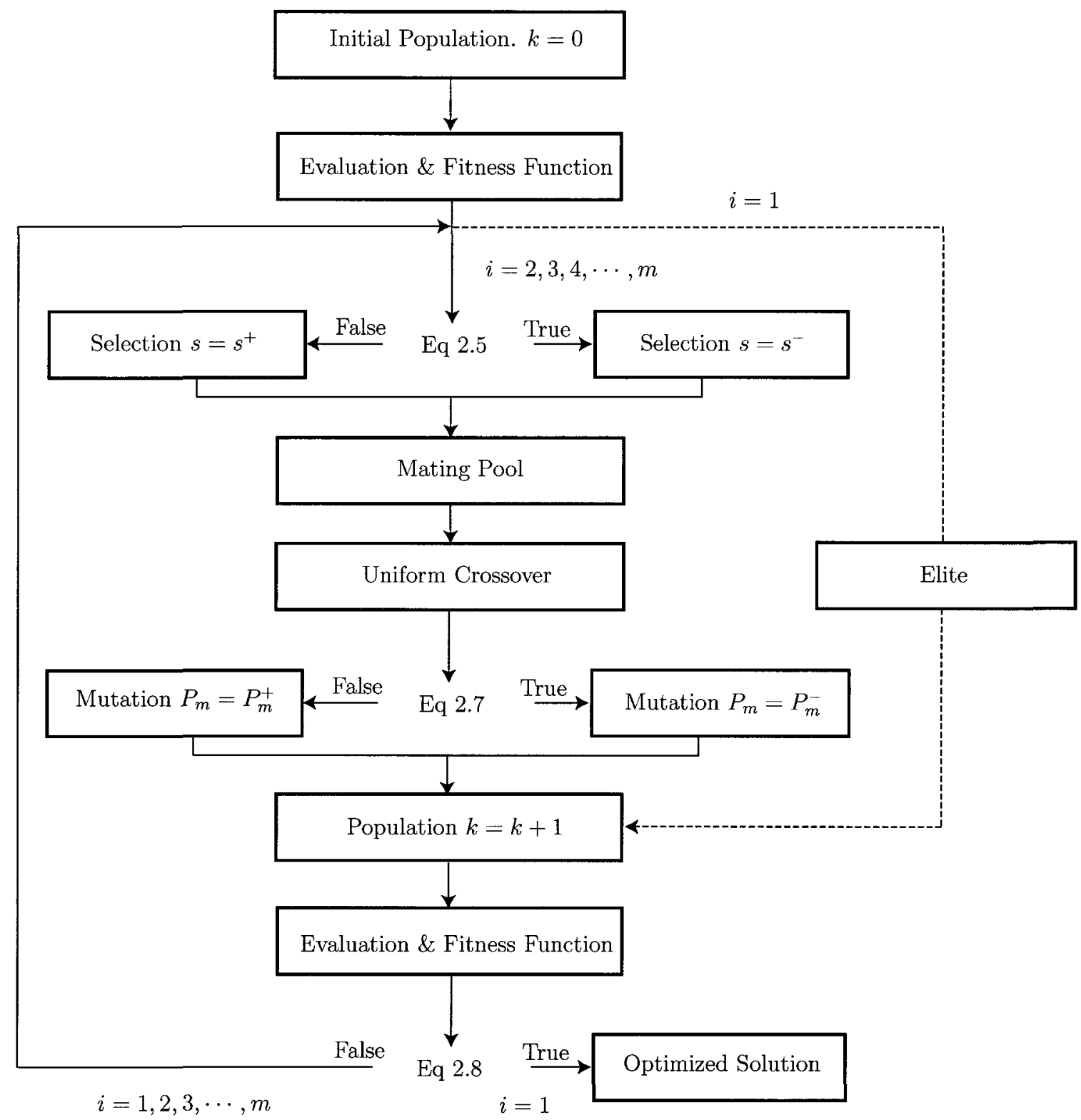

Figure 2.1: Flow diagram of GA.

The algorithm starts with an initial population, $X_{0}$, of $m$ randomly generated individuals. Since real-parameter genetic representation is used, this is accomplished by randomly generating the alleles of each gene. This is an advantage when compared to conventional optimization techniques where a suitable initial guess is required to begin the optimization process. In general, a population of individuals is represented 
by

$$
X^{k}=\left[\begin{array}{llllll} 
& & & & & \\
x_{1}^{k} & x_{2}^{k} & \cdots & x_{\imath}^{k} & \cdots & x_{m}^{k}
\end{array}\right]
$$

where $k$ is the generation number, $i$ is an individual, and $m$ is the population size. An individual is then expressed by

$$
x_{\imath}^{k}=\left[\begin{array}{llllll}
x_{\imath, 1}^{k} & x_{\imath, 2}^{k} & \cdots & x_{\imath, 3}^{k} & \cdots & x_{\imath, n}^{k}
\end{array}\right]
$$

where $j$ is an arbitrary gene and $n$ is the number of genes that define an individual.

All individuals are passed through the evaluation function and ranked by the fitness function (the evaluation function and fitness function will be discussed in the following sections). The fitness of the population is expressed by

$$
F^{k}=\left[\begin{array}{llllll} 
& & & & & \\
f_{1}^{k} & f_{2}^{k} & \cdots & f_{\imath}^{k} & \cdots & f_{m}^{k}
\end{array}\right]
$$

The most fit individual, $f_{1}^{k}$, is immediately pushed to the following generation by the Elitist method. Next, $2(m-1)$ individuals are selected by the Roulette Wheel method to enter the mating pool. The probability of an individual being selected for the mating pool is given by $\mathrm{Eq} 2.4$.

$$
P\left(x_{\imath}^{k}\right)=\frac{f\left(x_{\imath}^{k}\right)^{s}}{\sum_{u=1}^{m} f\left(x_{u}^{k}\right)^{s}}
$$

In order to help improve the performance of the GA, if the algorithm has been trapped for $k_{T}$ consecutive generations then a loose selection pressure of $s=s^{-}$is used to exploit a large portion of the current search space. Otherwise a selection pressure of $s=s^{+}$is used to exploit a smaller portion of the current search space (see Section 1.5.2 for more details). The current search space (without considering 
mutation) is defined by all possible combinations of the alleles of the fertile individuals of the current generation. A fertile individual is an individual with a fitness greater than zero. Conversely, an infertile individual is an individual with a fitness equal to zero. An infertile individual represents an invalid solution, this will be discussed in Section 2.4. A trap situation is defined by Eq 2.5. This is simply an indication that the most fit individual has not changed for $k_{T}$ consecutive generations. For the purposes of this work $k_{T}=20$ (which is a user defined parameter).

$$
f\left(x_{1}^{k}\right)=f\left(x_{1}^{k-1}\right)=f\left(x_{1}^{k-2}\right)=\cdots=f\left(x_{1}^{k-k_{T}}\right)
$$

The parents in the mating pool produce $m-1$ children via the Uniform Crossover method. $P_{c}$ is the probability that a child receives a given gene from the more fit parent. An example of a possible result of reproduction is shown below.

$$
\begin{aligned}
\text { Parent } u: x_{u}^{k} & =\left[\begin{array}{llllll}
x_{u, 1}^{k} & x_{u, 2}^{k} & \cdots & x_{u, j}^{k} & \cdots & x_{u, n}^{k}
\end{array}\right] \\
\text { Parent v : } x_{v}^{k} & =\left[\begin{array}{llllll}
x_{v, 1}^{k} & x_{v, 2}^{k} & \cdots & x_{v, j}^{k} & \cdots & x_{v, n}^{k}
\end{array}\right] \\
\text { Child } w: x_{w}^{k+1} & =\left[\begin{array}{llllll}
x_{u, 1}^{k} & x_{v, 2}^{k} & \cdots & x_{v, j}^{k} & \cdots & x_{u, n}^{k}
\end{array}\right] \\
& =\left[\begin{array}{llllll}
x_{w, 1}^{k+1} & x_{w, 2}^{k+1} & \cdots & x_{w, j}^{k+1} & \cdots & x_{w, n}^{k+1}
\end{array}\right]
\end{aligned}
$$

The diversity of the population is calculated by Eq 2.6 and is a measure of the variance of the population's fitness. If the population is not diverse (see Eq 2.7) then a high mutation probability of $P_{m}=P_{m}^{+}$is applied in order to increase the diversity of the population, otherwise a lower mutation probability of $P_{m}=P_{m}^{-}$is used to avoid genetic drift. $D_{k}^{*}$ is a user defined parameter. For the purpose of this work $D_{k}^{*}=0.01$.

$$
D_{k}=\operatorname{Var}\left(F_{k}\right)=E\left[F_{k}^{2}\right]-\left(E\left[F_{k}\right]\right)^{2}
$$




$$
D_{k}<D_{k}^{*}
$$

After the crossover and mutation steps, the next generation is now fixed. This new population, $X^{k+1}$, is now passed through the evaluation function and ranked by the fitness function. The algorithm continues to loop until Eq 2.8 is satisfied,

$$
k \geq \frac{k_{C}}{m}
$$

where $k_{C}$ is the maximum number of times the evaluation function is called. For the purposes of this work $k_{C}=20000$.

\subsection{Rocket Flowpath}

The purpose of the rocket flowpath is to channel the supersonic rocket exhaust from a single circular throat to an annular or segmented-annular exhaust profile. This is accomplished by replacing the diverging portion of a conventional rocket nozzle with the rocket flowpath geometry shown in Fig 2.2 [55]. The rocket flowpath must also allow for the possibility of entraining atmospheric air into the center of the annulus. Therefore, the geometry shown in Fig. 2.2 is described as having distinct clovers. Each clover represents the flowpath of the rocket exhaust and the openings between each clover allow the possibility for secondary air to be drawn into the engine.

The shape of each clover is calculated to yield a pre-specified Mach number distribution while passing through a gate. By adjusting the location and shape of the gate, a wide variety of rocket flowpath configurations can be produced. Using a symmetry plane along the center of the clover, the geometry of the gate only covers half a clover. Fig 2.2(a) and 2.2(b) show the nine geometric variables that along with the pre-specified Mach number distribution define the shape of the rocket flowpath. 


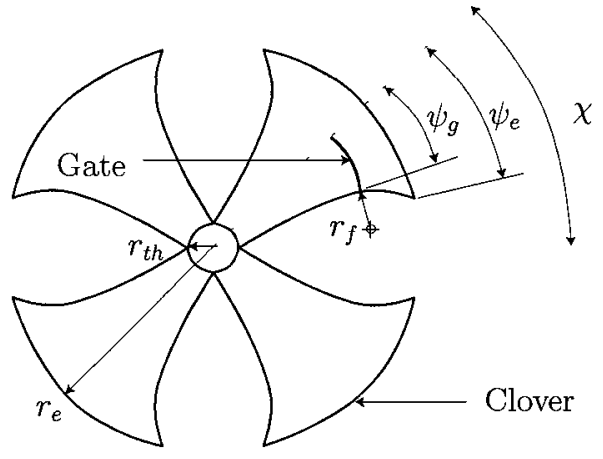

(a) Top View

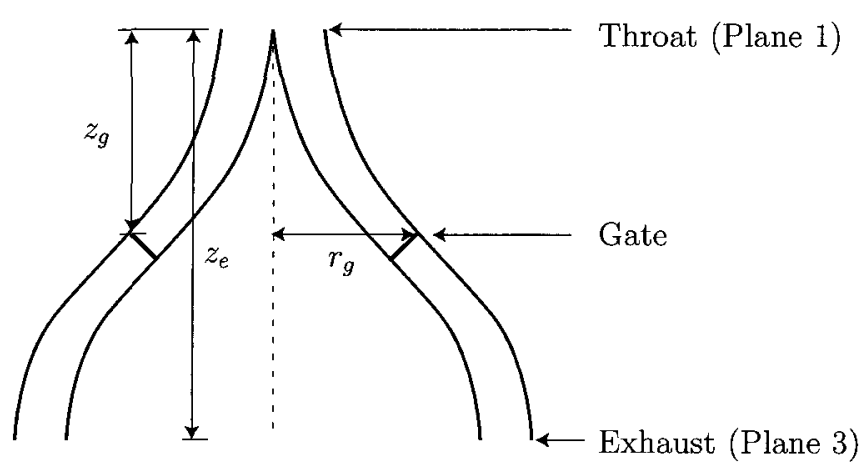

(b) Side View

Figure 2.2: Orthographic views of the rocket flowpath. The dashed lines on (a) represent half a clover.

\subsubsection{Rocket Flowpath Design Variables}

In order for the evolution mechanisms of the GA to be able to manipulate potential rocket flowpath configurations a genetic representation of individuals is required. This section describes the selection of the design variables that make up the genetic representation.

In order to define the Exchange Inlet shape, several of the design variables must be set by the user. Table 2.1 shows the design variables used in this work. These five design variables (of the nine in total) are selected because they strongly influence the rocket flowpath design. The remaining variables are fixed throughout the optimization process. All the design variables are non-dimensionalized to make the GA more robust as this makes the bounds of each design variable more predictable. For each individual the GA selects the value for the five non-dimensionalized design variables shown in Table 2.1.

The number of clovers, $\varepsilon$, determines the number of channels through which the rocket flowpath is ducted. This can be any integer greater than 2. However, for the 
Table 2.1: Rocket Flowpath Design Variables.

\begin{tabular}{|c|c|l|c|c|}
\hline Design Variable & Equation & Description & Bounds $(B)$ & Resolution $(R)$ \\
\hline \hline$\varepsilon$ & 2.9 & Number of clovers & $3 \rightarrow 6$ & 1 \\
$\tilde{\psi}_{e}$ & 2.10 & Exit arc angle ratio & $0.3 \rightarrow 1$ & 0.02 \\
$\tilde{\psi}_{g}$ & 2.11 & Gate arc angle ratio & $0.3 \rightarrow 0.9$ & 0.02 \\
$\tilde{z}_{g}$ & 2.12 & Gate depth ratio & $0.2 \rightarrow 0.9$ & 0.05 \\
$\tilde{r}_{g}$ & 2.13 & Gate radius ratio & $0.2 \rightarrow 0.9$ & 0.05 \\
\hline \hline
\end{tabular}

purposes of this work $\varepsilon \in\{3,4,5,6\}$. The clover half-angle, $\chi$, is a function of $\varepsilon$.

$$
\chi=180 / \varepsilon
$$

The exit arc angle ratio, $\tilde{\psi}_{e}$, determines the percentage of the circumference that the rocket flowpath covers at the exit. The exit arc angle, $\psi_{\boldsymbol{e}}$, is calculated from,

$$
\psi_{e}=\tilde{\psi}_{e} \chi
$$

Similarly, the gate arc angle ratio, $\tilde{\psi}_{g}$, determines the percentage of the circumference that the rocket flowpath covers at the gate. The gate arc angle, $\psi_{g}$, is determined by,

$$
\psi_{g}=\tilde{\psi}_{g} \chi
$$

The gate depth ratio, $\tilde{z}_{g}$, determines the axial location of the gate between the throat $(z=0)$ and the exit $\left(z=z_{e}\right)$,

$$
z_{g}=\tilde{z}_{g} z_{e}
$$

The gate radius ratio, $\tilde{r}_{g}$, determines the radial location of the gate between the 
centerline $(r=0)$ and the exit radius $\left(r=r_{e}\right)$,

$$
r_{g}=\tilde{r}_{g} r_{e}
$$

In order to define the shape of the rocket flowpath using Eq 2.12 and 2.13, two user defined inputs are required. They are the overall length $\left(z_{e}\right)$ and the exhaust radius $\left(r_{e}\right)$ which represent the outer dimensions of the exhaust path. These are considered constraints that the user would input based on the available space for the rocket flowpath design.

Real-parameter genetic representation is used, therefore each design variable corresponds to a gene of an individual ( $\mathrm{Eq} 2.14)$. For the rocket flowpath design optimization five genes are used to describe each individual. Therefore, the search space has five dimensions with a total of $S \approx 1 \times 10^{6}$ possible individuals, as calculated by Eq 2.15 with $n=5$.

$$
\begin{aligned}
& x_{\imath}^{k}=\left[\begin{array}{lllll}
\varepsilon & \tilde{\psi}_{e} & \tilde{\psi}_{g} & \tilde{z}_{g} & \tilde{r}_{g}
\end{array}\right] \\
& S=\prod_{\jmath=1}^{n}\left(\frac{\left(B_{\jmath_{\max }}-B_{\jmath_{\min }}\right)}{R_{\jmath}}+1\right)
\end{aligned}
$$

The bounds, $B$, of each design variable define the boundaries of the search space. Increasing the bounds will increase the size of the search space and increase the complexity of the problem. The bounds are set such that the GA does not consider values of the design variables that cannot produce valid solutions. For example, the maximum boundary of $\tilde{\psi}_{e}$ is set at $B_{2_{\max }}=1$ since $\psi_{e}$ cannot be greater than $\chi$. If it were, the rocket flowpath would overlap itself at the exhaust plane.

The resolution, $R$, of a design variable defines the precision or step size at which that variable is considered. A fine resolution results in many possible solutions, which increases the size of the search space and the complexity of the problem. A coarse resolution reduces the number of possible solutions, but as a result the optimized 
solution may not be as good as that found by a fine resolution. A trade-off must be made between the size of the search space and the quality of the optimized solution. A fine resolution is guaranteed to find an equal if not better solution than a coarse resolution, the cost is the amount of computational time required. In some cases the resolution cannot be adjusted. For example, the number of clovers must be an integer, therefore the resolution of $\varepsilon$ is $R_{1}=1$.

\subsubsection{Rocket Flowpath Evaluation}

At the beginning of each generation the individuals of the population are passed one at a time through the evaluation function in order to determine the individual's performance characteristics. For this work three performance criterion are highlighted as characteristics of a desirable rocket flowpath design. Fig 2.3 shows a top view of a four clover configuration and illustrates the three performance criterion.

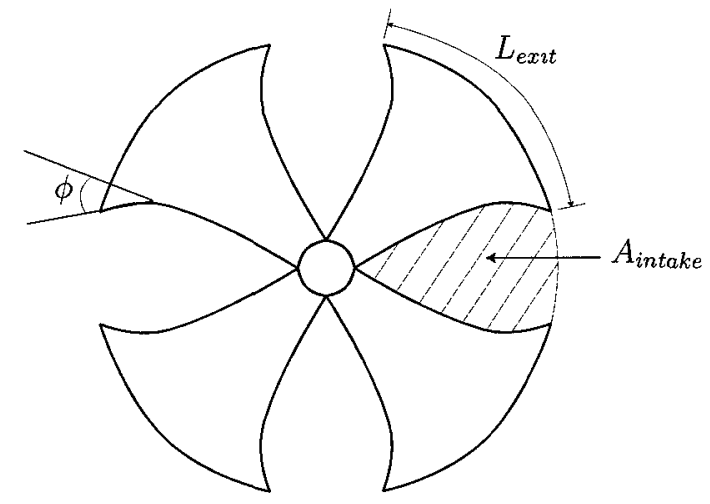

Figure 2.3: Three performance criteria of rocket flowpath design.

- Large air intake area, $A_{\text {intake }}$, for entraining atmospheric air. This is considered important since the air intake area will have a direct influence on the amount of atmospheric air which the Exchange Inlet is able to entrain.

- Large exhaust arc length, $L_{e x i t}$, to increase the shear layer area between the primary rocket stream and secondary air stream. This is considered important 
since it has been shown by previous researchers that the quality of mixing of the two streams is related to the shear layer area between the two streams.

- Low flow-turning angle at the gate, $\phi$, so that the rocket exhaust does not experience excessive expansion in the circumferential direction.

The fitness function (Eq 2.16) assigns a fitness value to each individual based on the desirable performance characteristics shown above. The fitness function is a linear combination of the normalized criterion with weighting factors. The weighting factors allow the user to easily manipulate the fitness function. By varying the weights more significance can be applied to one of the three performance criteria. The effects of varying the weighting factors is discussed in Chapter 4 . The weighting factors must satisfy Eq 2.17 and Eq 2.18 .

$$
\begin{gathered}
f_{\imath}^{k}=K_{a} \frac{A_{\text {intake }}}{A_{\text {max }}}+K_{b}\left[1-\left|\frac{\phi}{180^{\circ}}\right|\right]+K_{c} \frac{L_{\text {exit }}}{L_{\text {max }}} \\
K_{a} \geq 0 \quad K_{b} \geq 0 \quad K_{c} \geq 0 \\
K_{a}+K_{b}+K_{c}=1
\end{gathered}
$$

The terms of the fitness function are normalized such that each term cannot be greater than one. The first term is normalized by $A_{\max }=\pi r_{e}^{2}$, which represents the entire frontal area of the rocket flowpath. The air intake area, $A_{\text {vntake }}$, will always be less than $A_{\max }$. Therefore, when the first term is considered in Eq 2.16 (i.e. $K_{a} \neq 0$ ) the fitness will also be less than one $\left(f_{\imath}^{k}<1\right)$. The second term is normalized by $180^{\circ}$. The ideal case of $\phi=0$ results in the second term equating to $K_{b}$. If $K_{b}=1$ then it follows that $f_{\imath}^{k}=1$. Similarly, a fully annular rocket exhaust profile gives $L_{\text {exit }}=L_{\max }=2 \pi r_{e}$, and if $K_{c}=1$ then $f_{\imath}^{k}=1$. The manner in which the fitness function is formulated results in the fact that the fitness of any possible solution is bounded between 0 and 1 . As a result, the fitness of the most fit individual will 
approach 1. It is not possible to achieve a fitness of exactly 1 because the terms of the fitness function are normalized by exaggerated values. For example, $A_{\max }$ is significantly greater than the most optimistic value of $A_{\text {intake }}$.

\subsection{Air Flowpath}

The purpose of the air flowpath is to provide a smooth contour to entrain atmospheric air into the mixing duct, while minimizing total pressure and mass flow losses. The air flowpath also provides the structural body in which the rocket flowpath is housed. The air flowpath is composed of three bodies: a center body, cowl, and fairings. The center body is the fore body of the engine and houses the combustion chamber. The cowl is the forward section of the nacelle. The fairings are symmetric airfoils that provide a streamline body to enclose the rocket flowpath, they also provide a structural member between the center body and cowl. A thorough description of the design is given by Waung [56]. Fig. 2.4 shows the 15 geometric variables that, along with the rocket flowpath geometry, control the shape of the air flowpath.

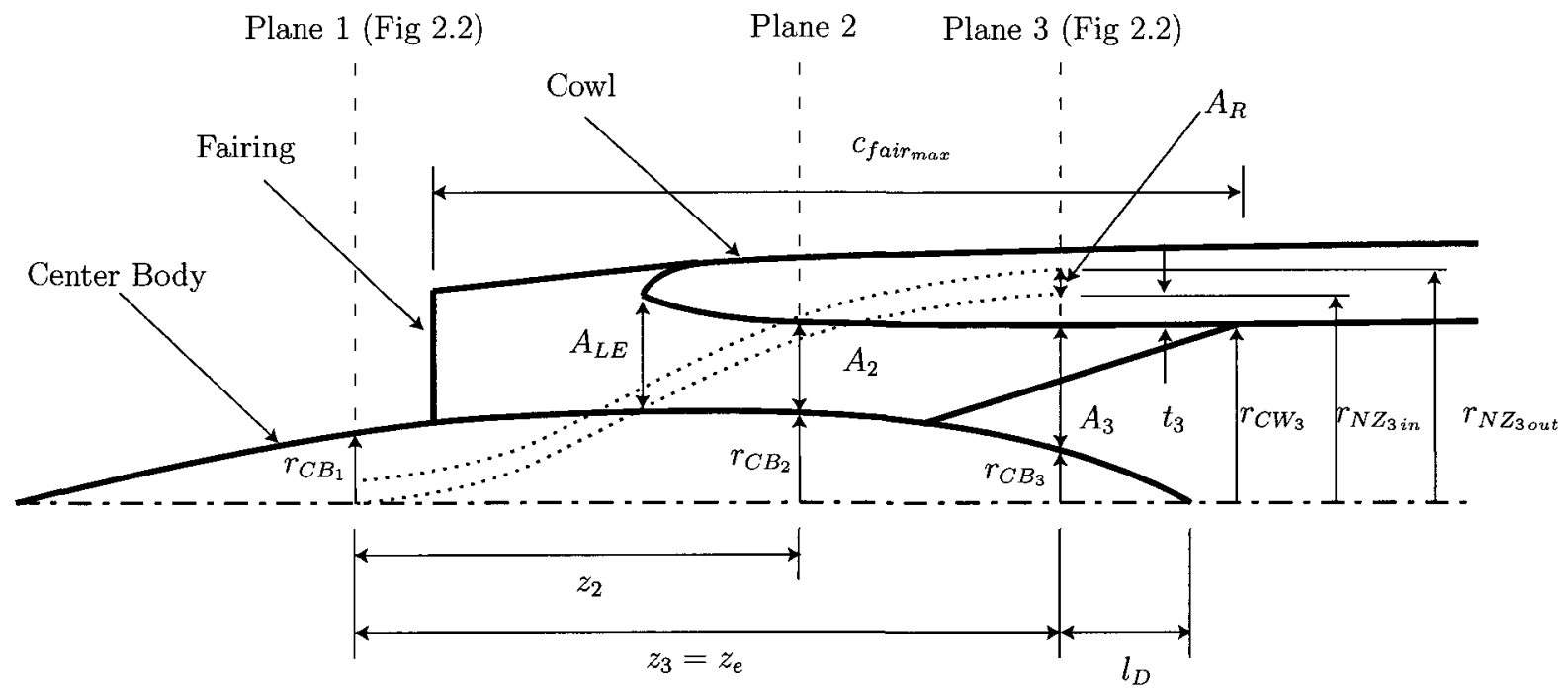

Figure 2.4: Side view of half of the air flowpath. The dotted line shows the rocket flowpath within the air flowpath. 


\subsubsection{Air Flowpath Design Variables}

Five design variables are chosen to define the air flowpath within the GA (shown in Table 2.2). These variables control the geometry of the three air intake bodies.

Table 2.2: Air Flowpath Design Variables.

\begin{tabular}{|c|c|l|c|c|}
\hline Design Variable & Equation & Description & Bounds & Resolution \\
\hline \hline$\tilde{z}_{2}$ & 2.19 & Duct length ratio & $0.3 \rightarrow 0.5$ & 0.02 \\
$\tilde{c}_{f a i_{\max }}$ & 2.20 & Max fairing chord ratio & $0.9 \rightarrow 1.3$ & 0.02 \\
$\tilde{t}_{3}$ & 2.21 & Cowl thickness ratio & $0.06 \rightarrow 0.2$ & 0.02 \\
$\tilde{r}_{C B_{1}}$ & 2.22 & Center body radius ratio & $2 \rightarrow 8$ & 0.5 \\
$C R$ & 2.23 & Cowl lip contraction ratio & $1.06 \rightarrow 1.4$ & 0.02 \\
\hline \hline
\end{tabular}

The duct length ratio, $\tilde{z}_{2}$, determines the position of the minimum airflow area $\left(A_{2}\right), z_{2}$, relative to the length of the rocket flowpath, $z_{3}=z_{e}$,

$$
z_{2}=z_{3}\left(1-\tilde{z}_{2}\right)
$$

The air intake duct can be any length up to the length of the rocket flowpath. Fig 2.5(a) shows an example of a duct length ratio of $\tilde{z}_{2}=0.9$. The result is plane 2 is nearly coincident with plane 3 of Fig 2.4 . The cowl is moved radially outward and longitudinally downstream. In order to maintain a consistent air flowpath area profile throughout the air intake duct the shape of the center body shape becomes more broad. Conversely, a duct length ratio of $\tilde{z}_{2}=0.1$ would result in plane 2 being nearly coincident with plane 1 (see Fig 2.5(b)). As a result the cowl becomes thicker and is moved inward and forward. The cowl and the center body intersect, resulting in complete air flowpath blockage. Obviously this is not a valid solution and thus for the purposes of this work the air intake duct length is bounded between $30 \%-50 \%$ of the length of the rocket flowpath. 


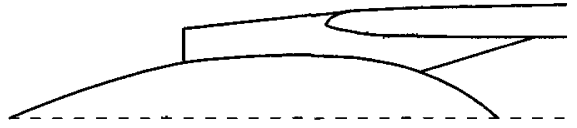

(a) $\tilde{z}_{2}=0.9$

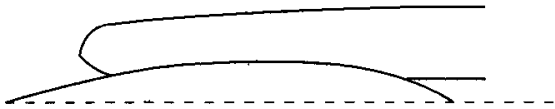

(b) $\tilde{z}_{2}=0.1$

Figure 2.5: Two examples of the effect of varying $\tilde{z}_{2}$.

The maximum fairing chord ratio, $\tilde{c}_{\text {farr } \max }$, determines the chord length of the fairing, $c_{f a r r_{\max }}$, at the outer most radial position relative to the length of the rocket flowpath, $z_{3}=z_{e}$,

$$
c_{f a i r_{\max }}=\tilde{c}_{\text {farr } \max } z_{3}
$$

The chord length of the fairing can be any non-zero length. However, if $c_{\text {farr } \max }$ is too long (i.e. $\tilde{c}_{f a r r_{\max }}=2$ ) then the leading edge of the fairing will pass the leading edge of the center body (see Fig 2.6(a)). This is an undesirable situation since the leading edge of the fairing is not as streamlined as the center body and will lead to higher drag. A short chord length (i.e. $\tilde{c}_{f a r r_{\max }}=0.5$ ) is detrimental if the maximum thickness of the fairing is large relative to the chord length, since this will produce a fairing profile that causes separation and high drag (see Fig 2.6(b)).

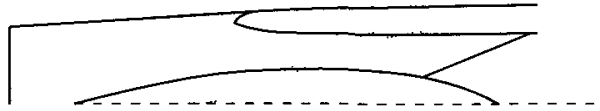

(a) $\tilde{c}_{f a r r_{m a x}}=2$

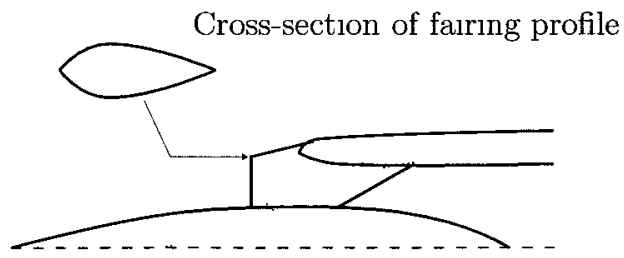

(b) $\tilde{c}_{f a \imath r_{\max }}=0.5$

Figure 2.6: Two examples of the effect of varying $\tilde{c}_{f a \imath r_{\max }}$.

The cowl thickness ratio, $\tilde{t}_{3}$, determines the thickness of the cowl, $t_{3}$, at plane 3 
relative to the inner radius of the rocket flowpath exit, $r_{N Z_{32 n}}$,

$$
t_{3}=\tilde{t}_{3} r_{N Z_{3 n}}
$$

As the cowl thickness approaches $r_{N Z_{3} \text { in }}$ (i.e. $\tilde{t}_{3} \rightarrow 1$ ), the cowl blocks more and more of the air flowpath, eventually leading to complete air flowpath blockage. Ideally, $t_{3}$ is minimal with enough thickness to provide structural integrity. The cowl thickness is not fixed since the ability to manipulate $t_{3}$ gives control over the air flowpath area profile.

The center body radius ratio, $\tilde{r}_{C B_{1}}$, determines the radius of the center body at plane $1, r_{C B_{1}}$, relative to the rocket flowpath throat radius, $r_{t h}$,

$$
r_{C B_{1}}=\tilde{r}_{C B_{1}} r_{t h}
$$

The center body radius at plane 1 can be any real value greater than one. However, as $\tilde{r}_{C B_{1}} \rightarrow 1$ the gap between the rocket flowpath throat and the center body approaches zero. Since the air flowpath area ratio must remain consistent, $r_{C B_{1}}$ also influences the curvature of the center body downstream of plane 1 (see Fig 2.7(a)). Therefore, the minimum bound is set at $\tilde{r}_{C B_{1}}=2$. If $r_{C B_{1}}$ is too large (i.e. $\tilde{r}_{C B_{1}}=10$ ), the resulting curvature of the center body may lead to flow separation and low entrainment of atmospheric air (see Fig 2.7(b)).

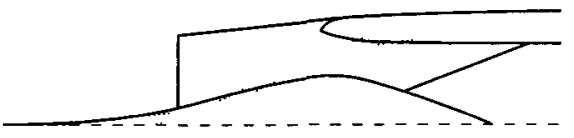

(a) $\tilde{r}_{C B_{1}}=1$

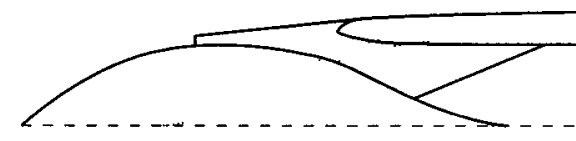

(b) $\tilde{r}_{C B_{1}}=10$

Figure 2.7: Two examples of the effect of varying $\tilde{r}_{C B_{1}}$. 
The cowl lip contraction ratio, $C R$, determines the cowl leading edge area, $A_{L E}$, relative to $A_{2}$,

$$
A_{L E}=C R A_{2}
$$

The cowl lip contraction ratio also has a strong influence on the incoming atmospheric flow field. At low free stream Mach conditions, a low CR causes the incoming flow to turn an abrupt corner, leading to high peak velocities and flow separation off of the cowl lip. As the free stream Mach number approaches supersonic conditions a large $\mathrm{CR}$ will lead to increased drag. The cowl lip contraction ratio must be greater than one, since $C R<1$ would represent an air flowpath throat upstream of plane 2 which is not a valid solution.

The real-parameter genetic representation of individuals for the air flowpath design is expressed by five genes (Eq 2.24). The search space has five dimensions with a total of $S \approx 430 \times 10^{3}$ possible individuals, as calculated by Eq 2.15 with $n=5$.

$$
x_{i}^{k}=\left[\begin{array}{lllll}
\tilde{z}_{2} & \tilde{c}_{f a i r_{\max }} & \tilde{t}_{3} & \tilde{r}_{C B_{1}} & C R
\end{array}\right]
$$

\subsubsection{Air Flowpath Evaluation}

The evaluation function for the air flowpath design is the air intake design code developed by Waung [56]. The code generates the three-dimensional geometry of the air flowpath design and provides estimates for total pressure loss, entrained air mass flow rate, and separation point. The air flowpath is designed for a given flight condition. For this work, the flight condition corresponds to the beginning of a launch at static sea-level conditions $\left(M_{\infty}=0.01, h_{\text {alt }}=40 \mathrm{~m}, p_{3}=97.7 \mathrm{kPa}\right)$. Table 2.3 lists the flight conditions of five points along the trajectory of the Ariane 4 flight profile. This flight profile was selected as an example of a typical launch vehicle profile and was derived from Turner [57]. 
Table 2.3: Simulated Ariane 4 Flight Profile [56].

\begin{tabular}{|c|ccccc|}
\hline Flight Profile Point & 1 & 2 & 3 & 4 & 5 \\
\hline \hline$M_{\infty}$ & 0.01 & 0.19 & 0.41 & 0.64 & 0.89 \\
$h_{\text {alt }}(\mathrm{m})$ & 40 & 929 & 2196 & 3800 & 5741 \\
$p_{3}(\mathrm{kPa})$ & 97.7 & 89.2 & 83.1 & 79.1 & 77.6 \\
\hline \hline
\end{tabular}

The performance criteria of the rocket flowpath considered the air intake area, $A_{\text {intake }}$, as an indication of the potential for entrainment of atmospheric air. Since the panel method of the air flowpath design provides a more accurate indication of the entrained atmospheric air, the performance criteria of the air flowpath design is described by the following criterion:

- High entrainment ratio, $\alpha$. Where $\alpha$ is defined by Eq 2.25.

- Large exit arc length, $L_{\text {ext }}$, to increase the shear layer area between the primary rocket stream and secondary air stream.

- Low flow-turning angle at the gate, $\phi$, so that the rocket exhaust does not experience excessive expansion in the circumferential direction.

$$
\alpha=\frac{\dot{m}_{\text {arr }}}{\dot{m}_{\text {rocket }}}
$$

The fitness function for the air flowpath design (Eq 2.26) is a linear combination of the normalized criterion with corresponding weighting factors. Similar to the rocket flowpath fitness function, by varying the weights of $\mathrm{Eq} 2.26$ more significance can be applied to one of the three performance criteria.

$$
f_{\imath}^{k}=K_{a} \frac{\alpha}{\alpha_{\max }}+K_{b}\left[1-\left|\frac{\phi}{180^{\circ}}\right|\right]+K_{c} \frac{L_{e x \imath t}}{L_{\max }}
$$

The weighting factors must satisfy $\mathrm{Eq} 2.17$ and 2.18. The first term of Eq 2.26 
is normalized by $\alpha_{\max }=7.52$ which represents the ideal value of $\alpha$ with no viscous losses and complete mixing of the rocket stream and entrained air stream. The 1-D rocket-ejector analysis method developed by Etele et al. [58] was used to determine $\alpha_{\text {max }}$ based on flight profile point 1 in Table 2.3. For conditions 2, 3, 4, and 5 the values of $\alpha_{\max }=6.96,6.96,6.93,6.79$, respectively. These values are calculated based on the assumption that the area of the rocket exhaust relative to the overall air flowpath area is $10 \%$.

\subsection{Dealing with Invalid Solutions}

Despite efforts made to implement bounds that prevent the creation of invalid solutions, it is inevitable that an invalid solution will arise. An invalid solution is defined as an individual that cannot be translated into a realistic physical solution. An invalid solution is considered to be an infertile individual by applying a fitness value of

zero, $f_{\imath}^{k}=0$. As a result infertile individuals cannot be selected for the mating and therefore cannot reproduce. 


\section{Chapter 3}

\section{Genetic Algorithm Convergence Results}

A study of the convergence trends of the GA is conducted to observe the behaviour of the GA. The rocket flowpath design is used to conduct the following analyses since it can be calculated in a shorter period of time than the air flowpath design. This is due to the fact that the evaluation of the rocket flowpath design requires approximately 1 second to evaluate each individual, whereas the evaluation of the air flowpath design requires approximately 2 minutes. One iteration of the GA without evaluating the individuals requires approximately $20 \mathrm{~ms}$. Therefore, it is the evaluation function that is the most significant in terms of computational time.

MATLAB $\cap 7.0 .1$ is used to run the GA and the evaluation functions. The system used throughout the analyses is an AMD Athlon ${ }^{\mathrm{TM}} 64$ X2 Dual Core Processor (2.21 GHz, 1.75 GB of RAM).

The effects of various population sizes, probability of mutation, and selection pressure is discussed. The effect of elitism is also studied. A comparison of constant genetic operator parameters versus adaptive genetic operator parameters is presented. 


\subsection{Expected Convergence History}

The stochastic nature of GAs make prediction of the convergence trends difficult. A given run of the GA might converge within a few generations or might require many generations and several hours of computational time. The GA might successfully find the most fit solution or might become trapped and prematurely converge to a sub-optimal solution.

Successful, quick convergence may be due to any of the following reasons: The random initial population contains one or more very fit individuals (near-optimal solutions). One or more favourable crossovers or mutations produce a very fit individual. The population size is so large that a significant portion of the possible individuals are evaluated at each generation.

An extremely large population size might reach convergence after a few generations, but this is not a good measure of the rate of convergence (how much time is required to attain the most fit solution). A better metric to compare rate of convergence is the number of times the evaluation function is called, since this is the most computationally intensive component of the GA. Eq 3.1 shows the metric used to compare rate of convergence. The metric is the population size $(m)$ multiplied by the generation number $(k)$.

$$
\Gamma=m k
$$

Consider an extremely large population size of $m=100000$. If the GA converges to the most fit solution after only two generations $(k=2)$, then the convergence metric would be $\Gamma=200000$. Since the size of the search space for the rocket flowpath design optimization is $S \approx 1 \times 10^{6}$, this means that $20 \%(\Gamma / S \cdot 100 \%)$ of the entire search space would have been evaluated in order to find the most fit solution. However, a population size of $m=50$ might converge after 100 generations $(k=100)$ resulting in a convergence metric of $\Gamma=5000$ which represents only $0.5 \%$ of the search space 
being evaluated. Furthermore, the percentage of the explored search space will always be less than $\Gamma / S \cdot 100 \%$ because at each generation not every individual is unique.

In order to compare the effects of varying the genetic operator parameters, the algorithm is seeded with the same initial population for each run. This ensures that a "lucky" initial population will not make one run appear better than an "unlucky" run. For all of the following simulations the GA is run until $\Gamma=20000$. However, the history is only plotted up to the point of convergence, since all data points after convergence are not relevant to the following analyzes. As a result, convergence is defined as the point at which the GA reaches the maximum fitness value.

Fig 3.1 shows three runs of the GA starting from the same initial population. The fitness of the most fit individual $\left(f_{1}^{k}\right)$ is plotted versus $\Gamma$. The solid line converges first $(\Gamma=800)$, followed by the dotted line $(\Gamma=1400)$, and the dashed line converges last $(\Gamma=1850)$ even though it showed the best progress earlier in the convergence history. Despite the consistent initial population, each run has a unique convergence rate and follows a different path toward convergence. This is due to a combination of all the stochastic processes of the GA.

Fig 3.1 depicts the characteristic shape of the GA's convergence history: the asymptotic trend illustrates the fact that the algorithm easily finds improved solutions early in the convergence history, then progress slows as it becomes more difficult to find an improved solution later in the convergence history. Occasionally, a large step improvement is observed as a result of a fortunate crossover or mutation.

Fig 3.2 illustrates three sample runs (of approximately 100 trials) of the GA starting from random initial populations. The solid line $(\Gamma=1400)$ represents a lucky initial population with a higher initial fitness than the other two examples and is the first to converge to the most fit solution. The dotted line represents an unlucky initial population with the lowest initial fitness. Despite the unlucky initial population, the dotted line $(\Gamma=1750)$ converges before the dashed line $(\Gamma=2250)$. 


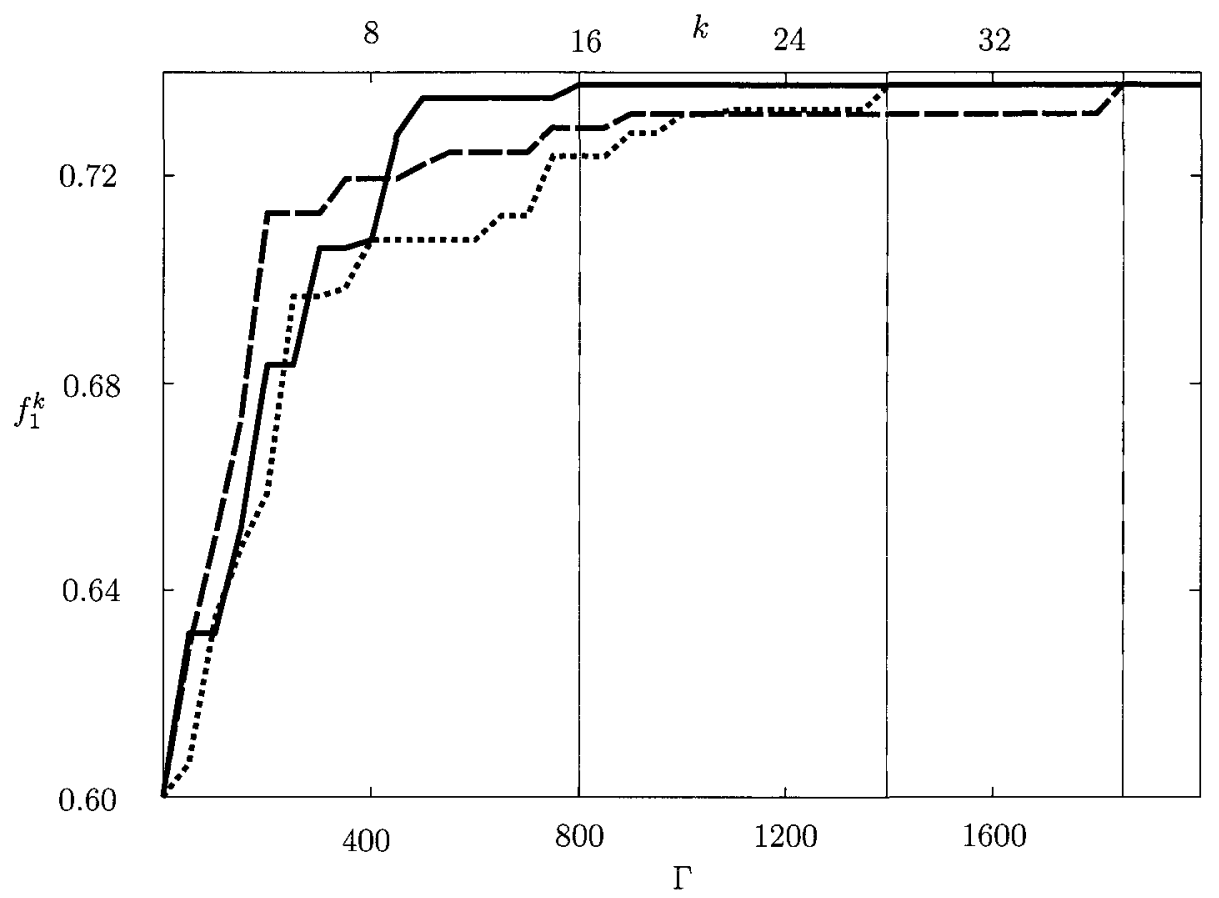

Figure 3.1: Three sample runs of GA with same initial population $X^{0}$.

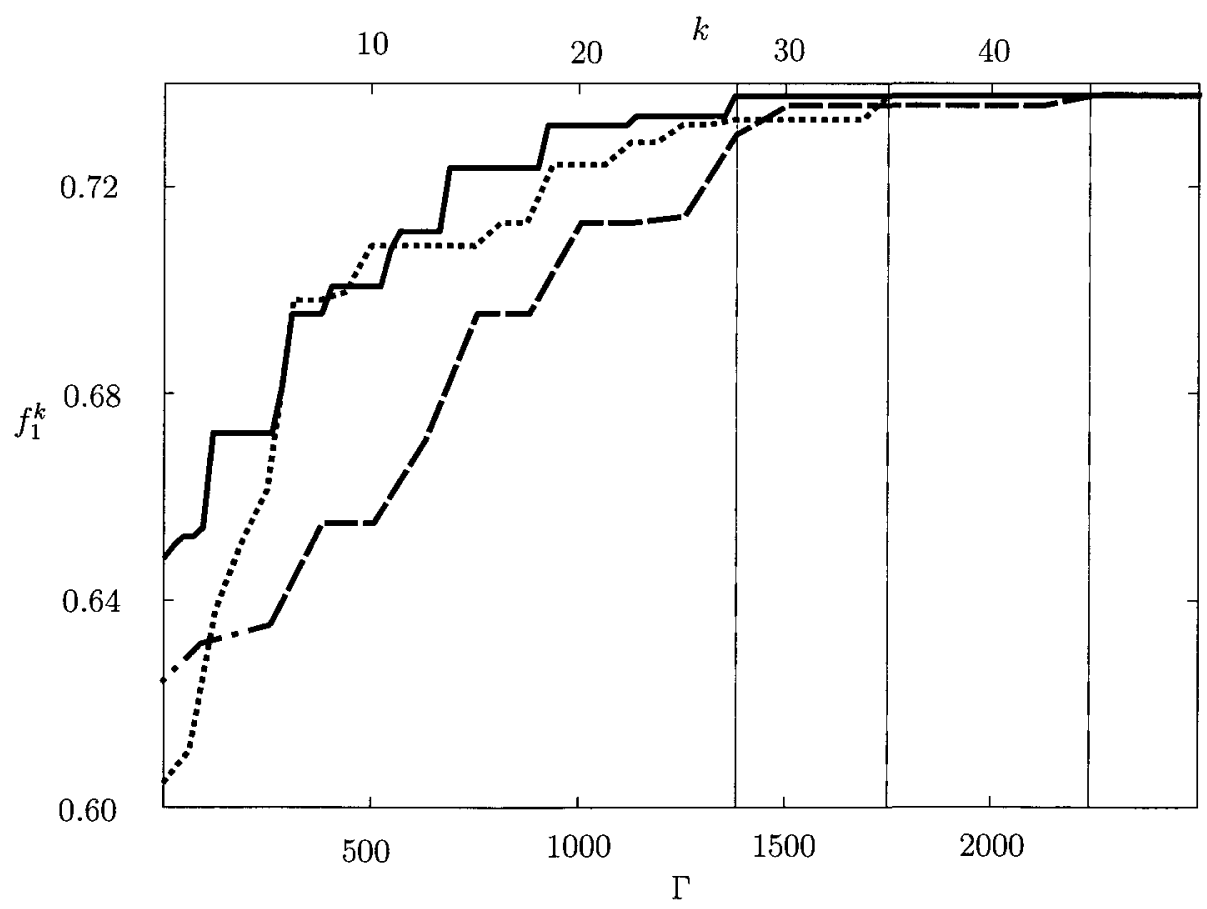

Figure 3.2: Three sample runs of GA with random initial population $X^{0}$. 


\subsection{Effect of Population Size}

The effect of population size is studied by analyzing the convergence trends of three population sizes: $m=10,50,100$. Fig 3.3(a), 3.3(b), and 3.3(c) illustrate three typical runs of the GA corresponding to $m=10,50$, and 100, respectively. Each plot shows the convergence history of the most fit individual of the population $\left(f_{1}^{k}\right)$, the average fitness of the population $\left(\overline{F^{k}}\right)$, and the least fit individual of the mating pool $\left(f_{i-}^{k}\right)$. The remaining genetic operator parameters are fixed throughout the analyzes $\left(P_{m}=0.1, s=1\right.$, and $\left.P_{c}=0.6\right)$. Fig 3.4(a), 3.4(b), and 3.4(c) show histogram plots of the convergence rate for 100 simulations of the GA corresponding to $m=10,50,100$, respectively.

Fig 3.4(a) shows that for $m=10$ the most frequent convergence rate corresponds to the $\Gamma=250-500$ bin $(k=25-50)$, with a percent occurrence of $28 \%$. It is expected that for this setting of the genetic operator parameters $\left(m=10, P_{m}=0.1\right.$, $s=1$, and $P_{c}=0.6$ ), the GA will converge to the most fit solution within $\Gamma=0-500$ $(k=0-50) 34.7 \%$ of the time. The next most frequent convergence rate corresponds to the $\Gamma=500-750 \mathrm{bin}$, with a frequency of $21.3 \%$. The GA is expected to converge to the most fit solution within $\Gamma=0-750(k=0-75) 56 \%$ of the time. The bars in the $20000+$ bin indicates the GA had not converged to the global most fit solution after $\Gamma=20000$ evaluations and was terminated. For a population size of $m=10$ the GA is expected to require more than $\Gamma=20000$ evaluations ( $k=2000$ generations) $18.7 \%$ of the time.

Fig 3.3(a) shows a typical convergence history for $m=10$ with convergence being reached at $\Gamma=580(k=58)$. Considering Fig 3.3(a) it is observed that at $\Gamma=330$

and $580, f_{1}^{k} \approx \overline{F^{k}} \approx f_{i-}^{k}$ indicating that the majority of the population is composed of identical individuals. This is an undesirable situation since the algorithm is needlessly evaluating the same individual and genetic diversity is lost. Fig 3.3(b) and 3.3(c) do 
not show this situation since the population size is large enough to maintain genetic diversity.

Fig 3.4(b) shows that for $m=50$ the most frequent convergence rate corresponds to the $\Gamma=500-750$ bin $(k=10-15)$, with a percent occurrence of $32 \%$. It is expected that for this setting of the genetic operator parameters $\left(m=50, P_{m}=0.1\right.$, $s=1$, and $\left.P_{c}=0.6\right)$, the GA will converge to the most fit solution within $\Gamma=0-750$ $(k=0-15) 56 \%$ of the time. For $m=50$ the GA is expected to require more than $\Gamma=20000$ evaluations ( $k=400$ generations) only $4 \%$ of the time.

Fig 3.4(c) shows that for $m=100$ the most frequent convergence rate corresponds to the $\Gamma=500-750$ bin $(k=5-7.5)$, with a percent occurrence of $28 \%$. It is expected that for this setting of the genetic operator parameters $\left(m=100, P_{m}=0.1, s=1\right.$, and $\left.P_{c}=0.6\right)$, the GA will converge to the most fit solution within $\Gamma=0-750$ $(k=0-7.5) 49.3 \%$ of the time. For $m=100$ the GA is expected to require more than $\Gamma=20000$ evaluations ( $k=200$ generations) $9.3 \%$ of the time.

Comparing the results of Fig 3.3 and 3.4 it is observed that a mid population size of $m=50$ shows a consistently good rate of convergence with a low probability of failed convergence and termination. A low population size of $m=10$ shows a similar rate of convergence, however the probability of failed convergence and termination is significantly greater ( $18.7 \%$ compared to $4 \%$ ). This is due to the fact that the GA becomes inefficient when genetic diversity is lost. A high population size of $m=100$ shows a slower rate of convergence and a greater probability of failed convergence when compared with $m=50$. This is a result of the GA spending too much time evaluating individuals rather than allowing the explorative and exploitative genetic operators to perform their task. The explorative and exploitative operators are only effective as new generations are developed. 


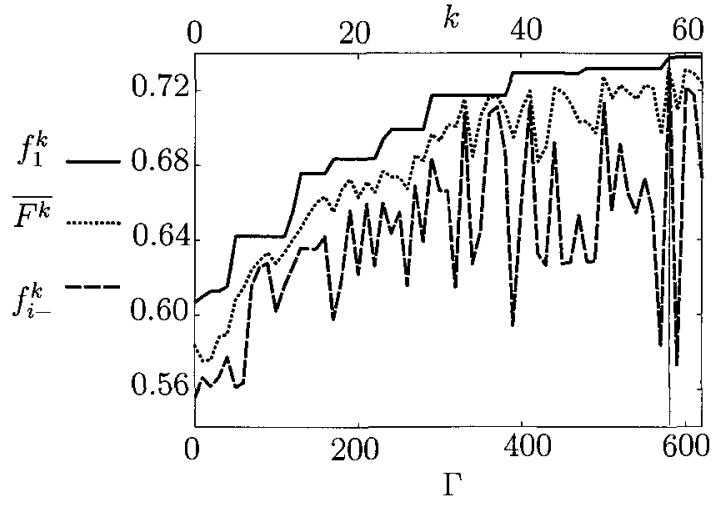

(a) $m=10$

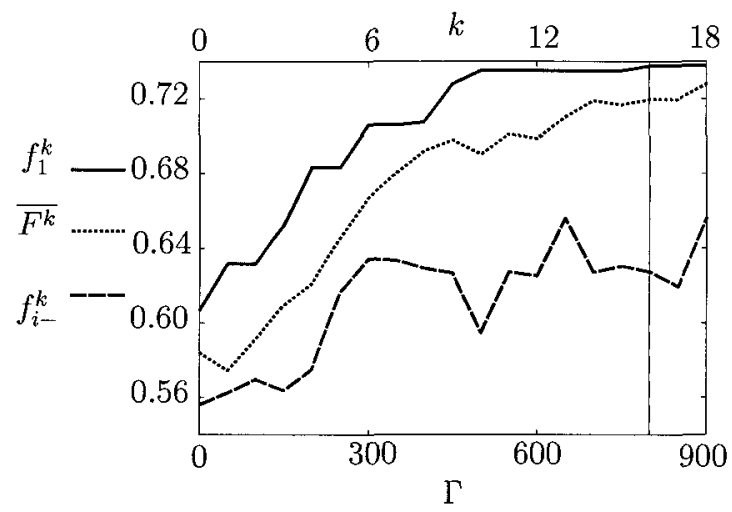

(b) $m=50$

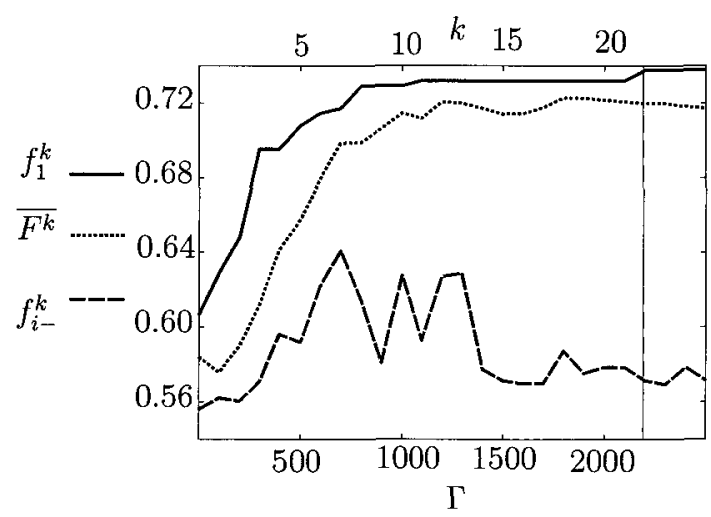

(c) $m=100$

Figure 3.3: Effect of varying population size. Constant genetic operators: $P_{m}=0.1, s=1$ and $P_{c}=0.6$.

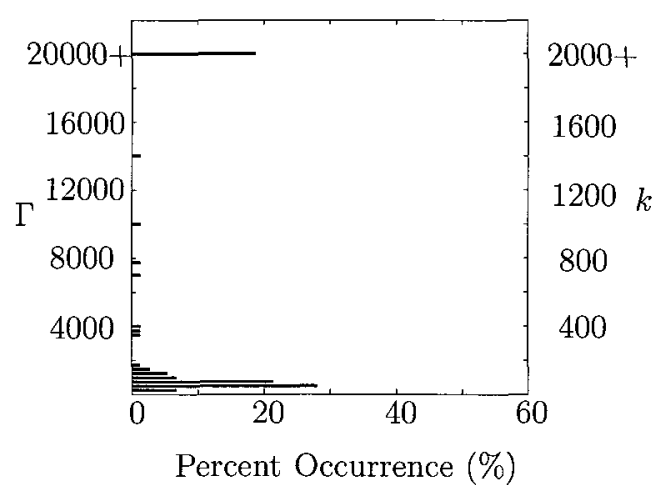

(a) $m=10$

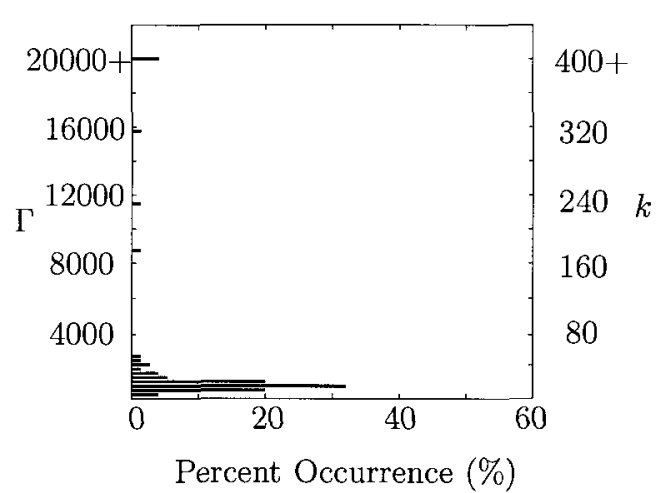

(b) $m=50$

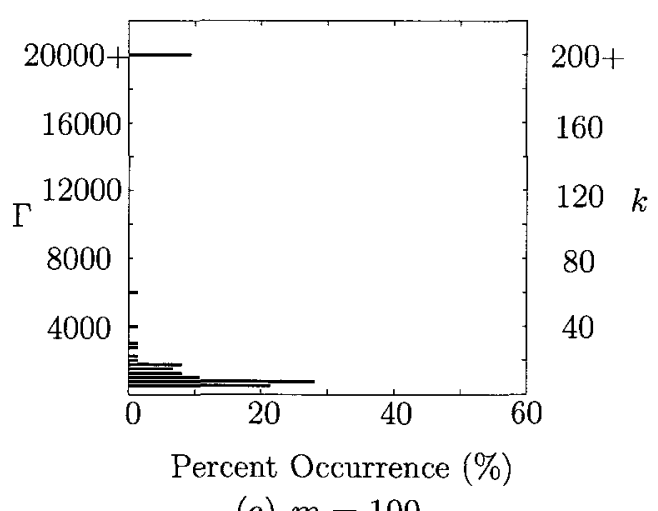

(c) $m=100$

Figure 3.4: Histogram plots for several values of $m$ showing the expected rate of convergence. 


\subsection{Effect of Probability of Mutation}

The effect of probability of mutation is studied by analyzing the convergence trends of three probabilities of mutation: $P_{m}=0.01,0.1,0.5$. Figs 3.5(a), 3.5(b), and 3.5(c) illustrate three runs of the GA corresponding to $P_{m}=0.01,0.10$, and 0.50 , respectively. The remaining genetic operators are fixed throughout the analyzes $(m=50$, $s=1$, and $\left.P_{c}=0.6\right)$. Fig 3.6(a), 3.6(b), and 3.6(c) show histogram plots of the convergence rate for 100 simulations of the GA corresponding to $P_{m}=0.01,0.10,0.50$, respectively.

Fig 3.6(a) shows that for $P_{m}=0.01$ the most frequent occurrence corresponds to the $\Gamma=20000+$ bin, with a percent occurrence of $18.3 \%$. This indicates that there is a high chance of the GA failing to converge to the global most fit solution. The GA is expected to converge to the most fit solution within $\Gamma=0-2000(k=0-40)$ $33.5 \%$ of the time.

Fig 3.5(a) shows a typical convergence history for $P_{m}=0.01$. It is observed that there are many instances of the majority of the population being composed of identical individuals, as shown by $f_{1}^{k} \approx \overline{F^{k}} \approx f_{i-}^{k}$. This indicates that despite the mid population size of $m=50$, a low probability of mutation of $P_{m}=0.01$ is not high enough to maintain genetic diversity throughout the population.

Fig 3.6(b) is identical to Fig 3.4(b) since the genetic operator parameters are identical. The histogram shows that a probability of mutation of $P_{m}=0.1$ is expected to show a fast rate of convergence with a low probability of failed convergence. The GA is expected to converge to the most fit solution within $\Gamma=0-2000(k=0-40)$ $89.3 \%$ of the time. Fig 3.5(b) shows a typical convergence history for $P_{m}=0.1$. It is observed that genetic diversity of the population is maintained throughout the convergence history, as shown by the spacing between $f_{1}^{k}, \overline{F^{k}}$, and $f_{i-}^{k}$.

Fig 3.5(c) shows that for $P_{m}=0.5$ the most frequent occurrence corresponds to 
the $\Gamma=20000+$ bin, with a percent occurrence of $56 \%$. This indicates that a high probability of mutation of $P_{m}=0.5$ results in an extremely high chance of the GA failing to converge to the global most fit solution. In fact the GA is more likely to converge to a sub-optimal solution than the global optimal solution. The GA is expected to converge to the most fit solution within $\Gamma=0-2000(k=0-40) 20 \%$ of the time. Fig 3.5(c) shows an atypical convergence history for $P_{m}=0.5$. For this sample run the GA converged to the most fit solution at $\Gamma=2200(k=44)$. The high probability of mutation and high diversity is shown by the fact that $\overline{F^{k}}$ is approximately midway between $f_{1}^{k}$ and $f_{i-}^{k}$. This indicates the average fitness of the population is low which leads to a slow rate of convergence.

Comparing the results of Fig 3.5 and 3.6 it is observed that a moderate probability of mutation of $P_{m}=0.1$ shows a consistently good rate of convergence with a low probability of failed convergence. A low probability of mutation of $P_{m}=0.01$ results in a slower expected rate of convergence with a higher probability of failed convergence. This is due to the fact that a low $P_{m}$ is not sufficient to maintain genetic diversity and the GA becomes inefficient. A high probability of mutation of $P_{m}=0.5$ results in an extremely high probability of failed convergence since a high $P_{m}$ reduces the GA to an ineffective random search function. 


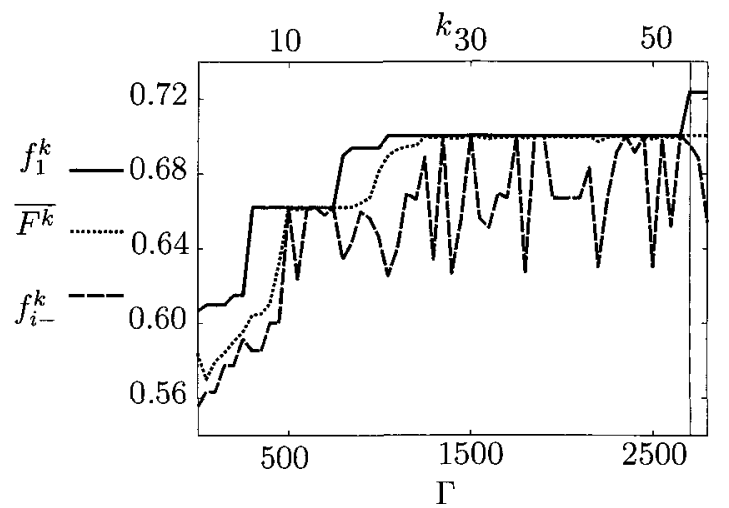

(a) $P_{m}=0.01$

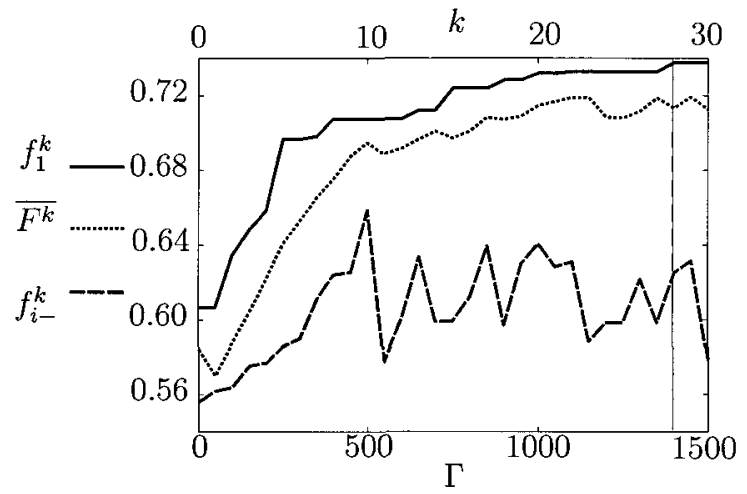

(b) $P_{m}=0.10$

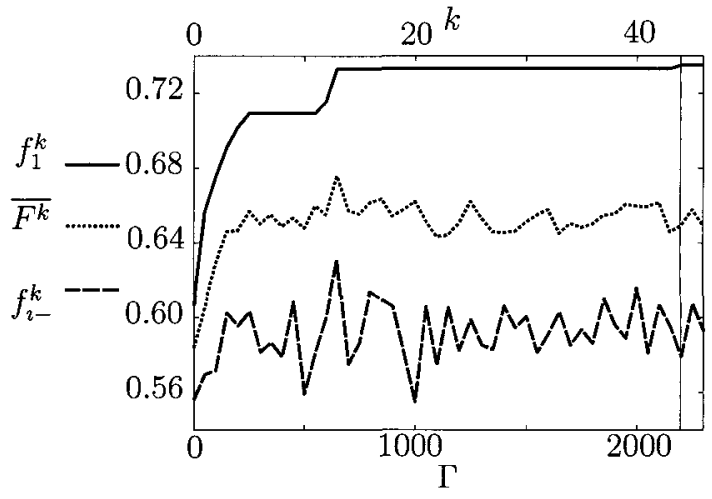

(c) $P_{m}=0.50$

Figure 3.5: Effect of varying probability of mutation. Constant genetic operators: $m=50, s=1$ and $P_{c}=0.6$.

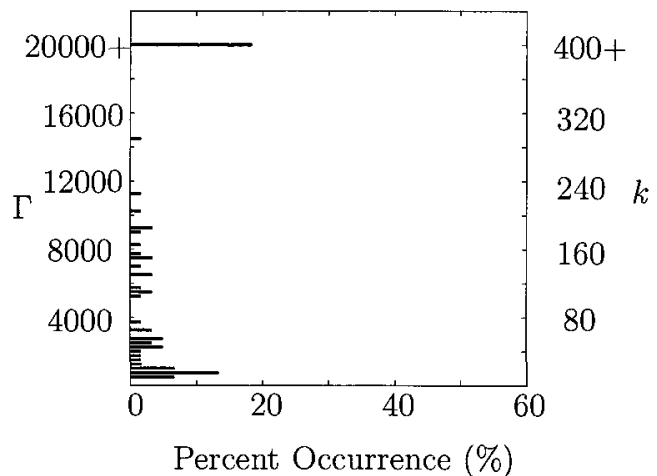

(a) $P_{m}=0.01$

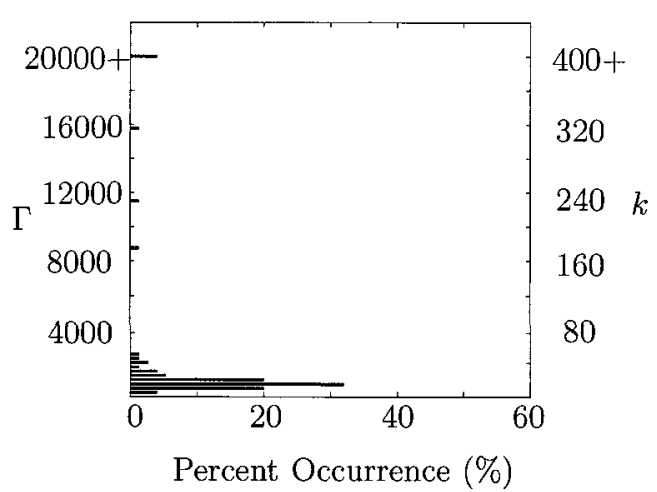

(b) $P_{m}=0.10$

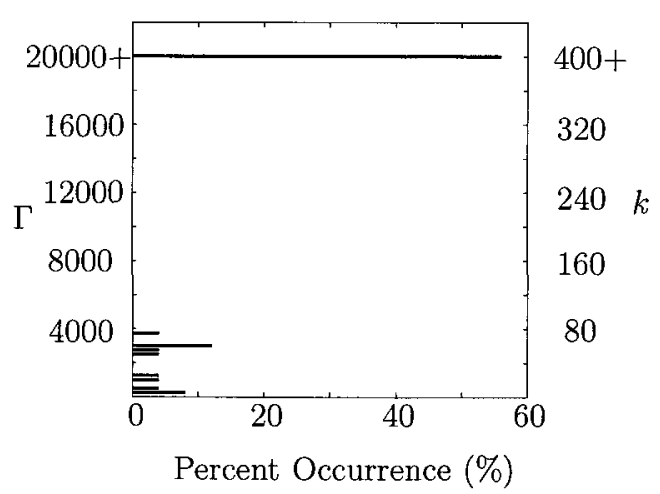

(c) $P_{m}=0.50$

Figure 3.6: Histogram plots for several values of $P_{m}$ showing the expected rate of convergence. 


\subsection{Effect of Selection Pressure}

For the Roulette Wheel method the selection pressure influences the probability that an individual will be selected for reproduction. A high selection pressure favours the more fit individuals being selected, whereas a low selection pressure shows no favoritism. The effect of selection pressure is studied by analyzing the convergence trends of three selection pressure: $s=0.1,1,5$. Fig 3.7(a), 3.7(b), and 3.7(c) illustrate three runs of the GA corresponding to $s=0.1,1$, and 5 , respectively. The remaining genetic operator parameters are fixed throughout the analyzes $\left(m=50, P_{m}=0.1\right.$, and $\left.P_{c}=0.6\right)$. Fig 3.8(a), 3.8(b), and 3.8(c) show histogram plots of the convergence rate for 100 simulations of the GA corresponding to $s=0.1,1$, and 5 , respectively.

Fig 3.8(a) shows that for $s=0.1$ the most frequent convergence rate occurrence corresponds to the $\Gamma=500-750(k=10-15)$ bin, with a percent occurrence of $26.7 \%$. It is expected that the GA will converge to the most fit solution within $\Gamma=0-1000(k=0-20) 66.7 \%$ of the time. Failed convergence is expected to occur $8 \%$ of the time.

Fig 3.8(b) is identical to Fig 3.4(b) and 3.6(b) since the genetic operator parameters are identical. Fig 3.8(b) shows that a selection pressure of $s=1$ is expected to show a fast rate of convergence with a low probability of failed convergence $(4 \%)$. The GA is expected to converge to the most fit solution within $\Gamma=0-1000(k=0-20)$ $76 \%$ of the time.

Fig 3.8(c) shows that for $s=5$ the most frequent convergence rate occurrence corresponds to the $\Gamma=250-500(k=5-10)$ bin, with a percent occurrence $28 \%$. It is expected that the GA will converge to the most fit solution within $\Gamma=0-1000$ ( $k=0-20$ ) $76 \%$ of the time. The probability of failed convergence is $6.7 \%$.

Comparing the results of Fig 3.8 it is observed that the selection pressure does not have as strong an influence on the rate of convergence or probability of failed 
convergence as the population size or probability of mutation. However, a selection pressure of $s=1$ showed a good combination of consistently fast rate of convergence and low percent occurrence of failed convergence. Therefore since both $s=1$ and $s=5$ show convergence within $\Gamma=100076 \%$ of the time, but $s=1$ fails to converge to the most fit solution only $4 \%$ of the time compared to $6.7 \%$ for $s=5$, a selection pressure of $s=1$ is used for the remainder of this work.

Considering Fig 3.7 it is observed that manipulating the selection pressure does not adversely affect the diversity of the population throughout the convergence history. This is shown by the fact that for all three values of selection pressure, the fitness of the most fit individual of the population and the least fit individual of the mating pool maintain a good separation. 


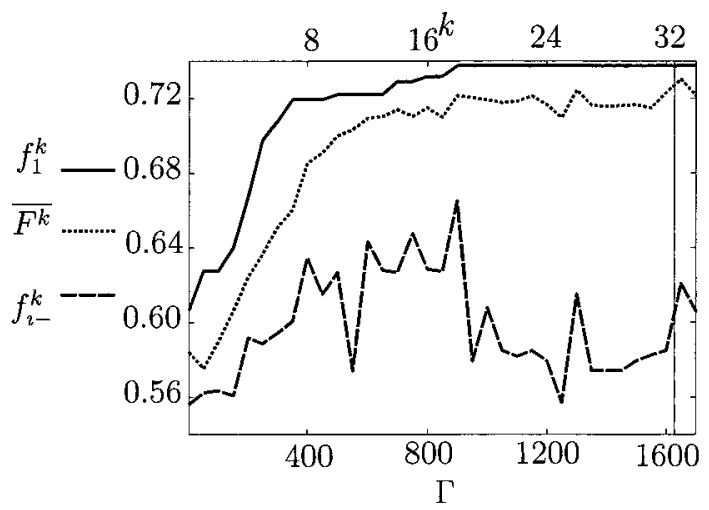

(a) $s=0.01$

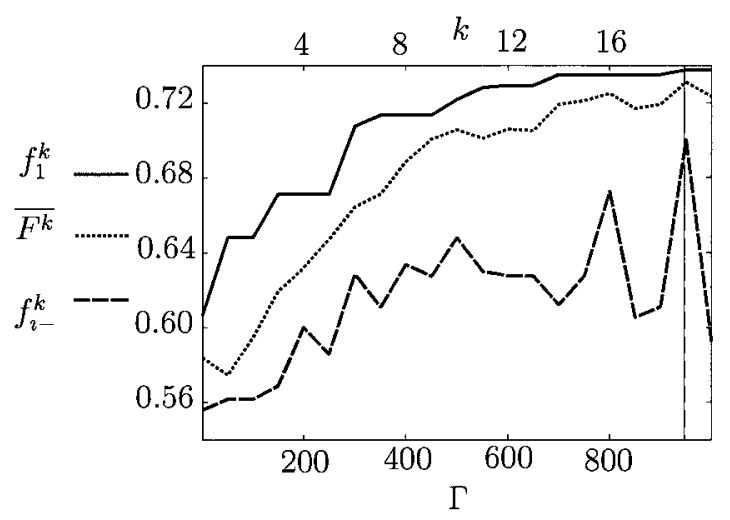

(b) $s=1$

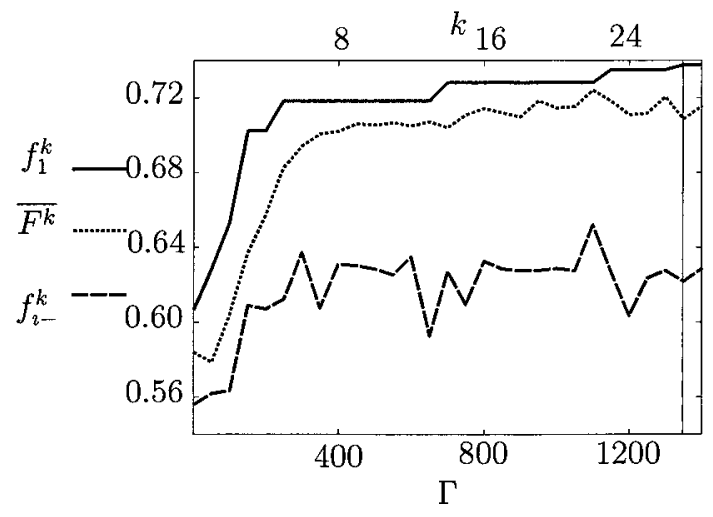

(c) $s=5$

Figure 3.7: Effect of varying selection pressure. Constant genetic operators: $m=50, P_{m}=0.1$ and $P_{c}=0.6$.

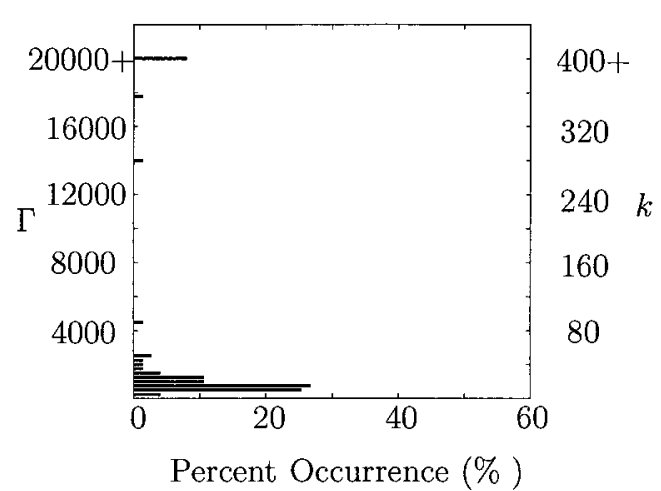

(a) $s=0.1$

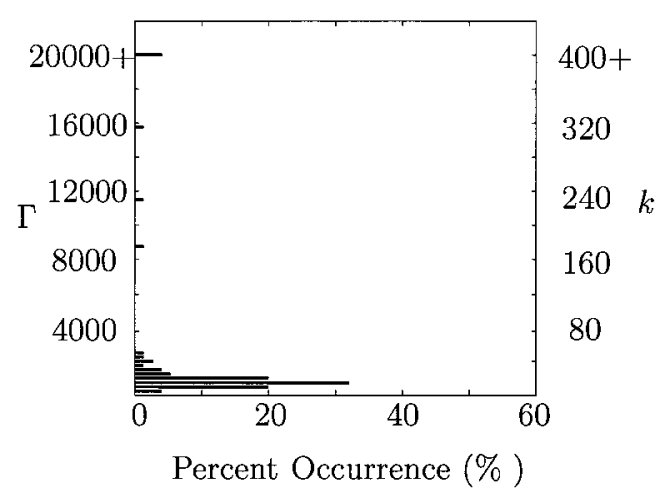

(b) $s=1$

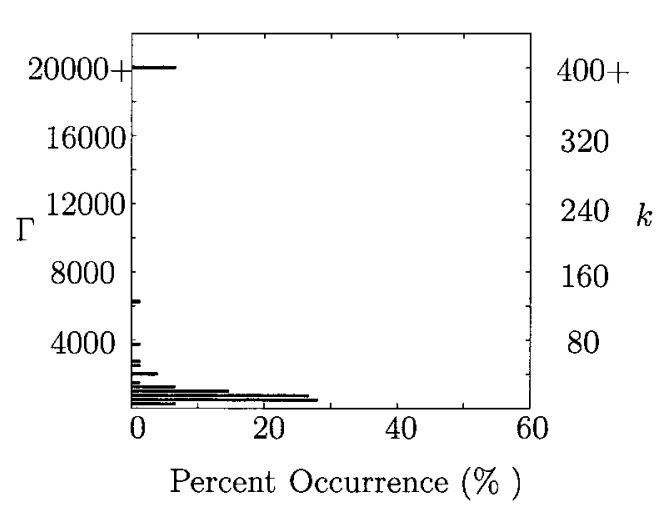

(c) $s=5$

Figure 3.8: Histogram plots for several values of $s$ showing the expected rate of convergence. 


\subsection{Effect of Elitism}

Up to this point all simulations of the GA have used the Elitism method where the most fit individual of the current generation is passed onto the following generation. This is evident by the fact that $f_{1}^{k}$ never decreases or diverges toward less optimal solutions (see Fig 3.3, 3.5, 3.7).

Fig 3.9 shows three runs of the GA without Elitism. $f_{1}^{k}$ is plotted versus $\Gamma$. Comparing Fig 3.9 with Fig 3.1, it is observed that the familiar asymptotic trend is present for the case of no Elitism. However, the average convergence rate without Elitism is slower than when Elitism is implemented. It should also be noted that without Elitism as $\Gamma \rightarrow \infty, f_{1}^{k}$ is not guaranteed to be the global optimum. Instead $f_{1}^{k}$ will likely fluctuate about a fitness value close to the global optimum, as shown by the solid and dotted line in Fig 3.9 .

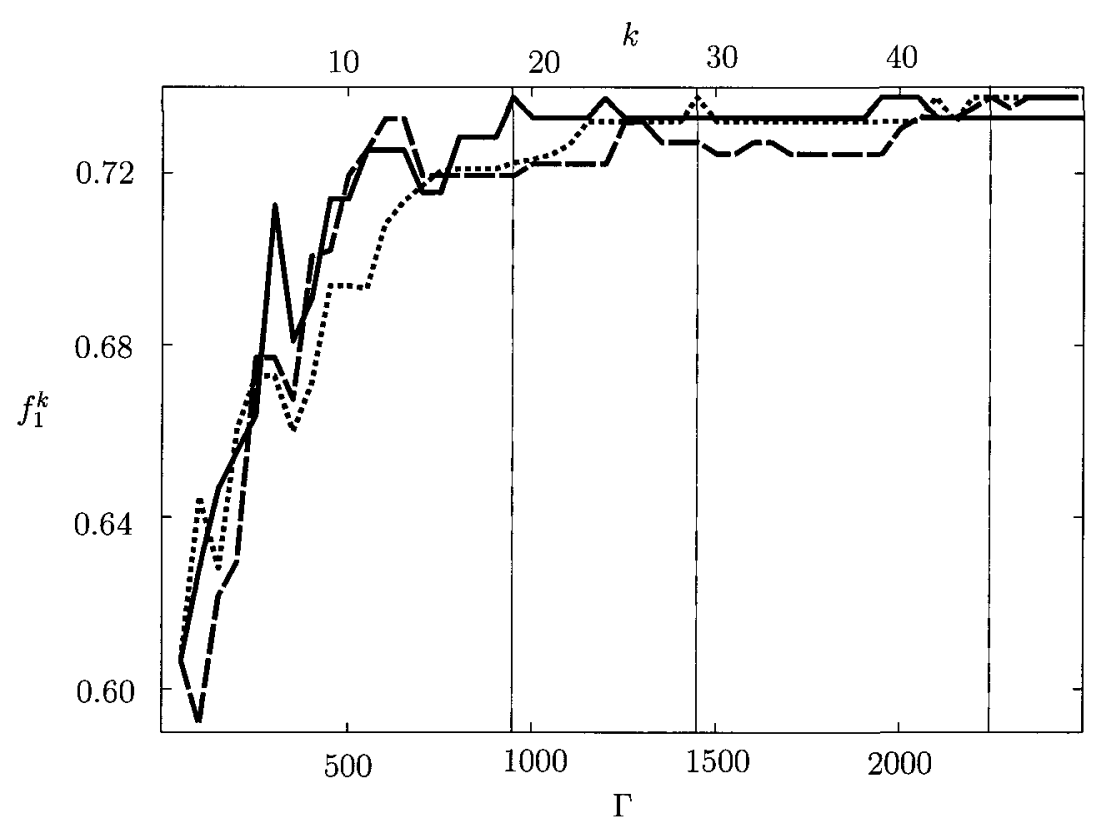

Figure 3.9: Three runs of GA without Elitism. Constant genetic operators: $m=50$, $P_{m}=0.1, s=1$ and $P_{c}=0.6$. 


\subsection{Effect of Adaptive Genetic Operators}

The solid bars of Fig 3.10 show a histogram plot of the convergence rate for several population sizes using constant genetic operator parameters $\left(P_{m}=0.1\right.$ and $\left.s=1\right)$. The hollow bars of Fig 3.10 shows a histogram plot for the same population sizes using adaptive genetic operator parameters $\left(P_{m}=0.1 \leftrightarrow 0.5\right.$ and $\left.s=1 \leftrightarrow 0.8\right)$. In each case the GA is run to convergence 100 times (i.e. the sum of all the bars for a given population size totals 100).

In the adaptive technique $P_{m}$ is altered based on the homogeneity of the population at a given generation. When the population is deemed to be too homogenous, $P_{m}$ is increased to 0.5 in order to increase the diversity of the population. When the population is deemed to have sufficient genetic diversity $P_{m}$ is decreased to 0.1 . The goal is to maintain sufficient genetic diversity while ensuring that the GA is not reduced to a random search function. The selection pressure is switched between 1 and 0.8 based on trap situations (Eq 2.5). When the GA is suspected to be trapped in a local maximum, $s$ is decreased to 0.8 to increase the explorative power of the GA (i.e. less fit individuals of the mating pool have a greater chance to mate, thereby reducing the dominance of the locally most fit individuals).

Comparing the solid and hollow bars of Fig 3.10 it is observed that the technique of constant genetic operator parameters is susceptible to trap situations. The bars in the $\Gamma=20000+$ bin are indicative of situations of failed convergence; the GA did not converge to the most fit solution after $\Gamma=20000$ and was terminated. The technique of adaptive genetic operator parameters, however, did not show any instances of failed convergence, as shown by the absence of hollow bars in the $\Gamma=20000+$ bin of Fig 3.10 .

It is also observed that for each population size, the adaptive technique converges 
faster than the constant technique. The solid lines of Fig 3.10 represent the distribution of the convergence rate of the constant parameter technique, while the dotted lines represent the distribution of the convergence rate of the adaptive parameter technique. The skewness of the adaptive technique toward lower values of $\Gamma$ indicates that the adaptive technique has a higher probability of converging to the most fit solution in a shorter period of time than the constant technique.

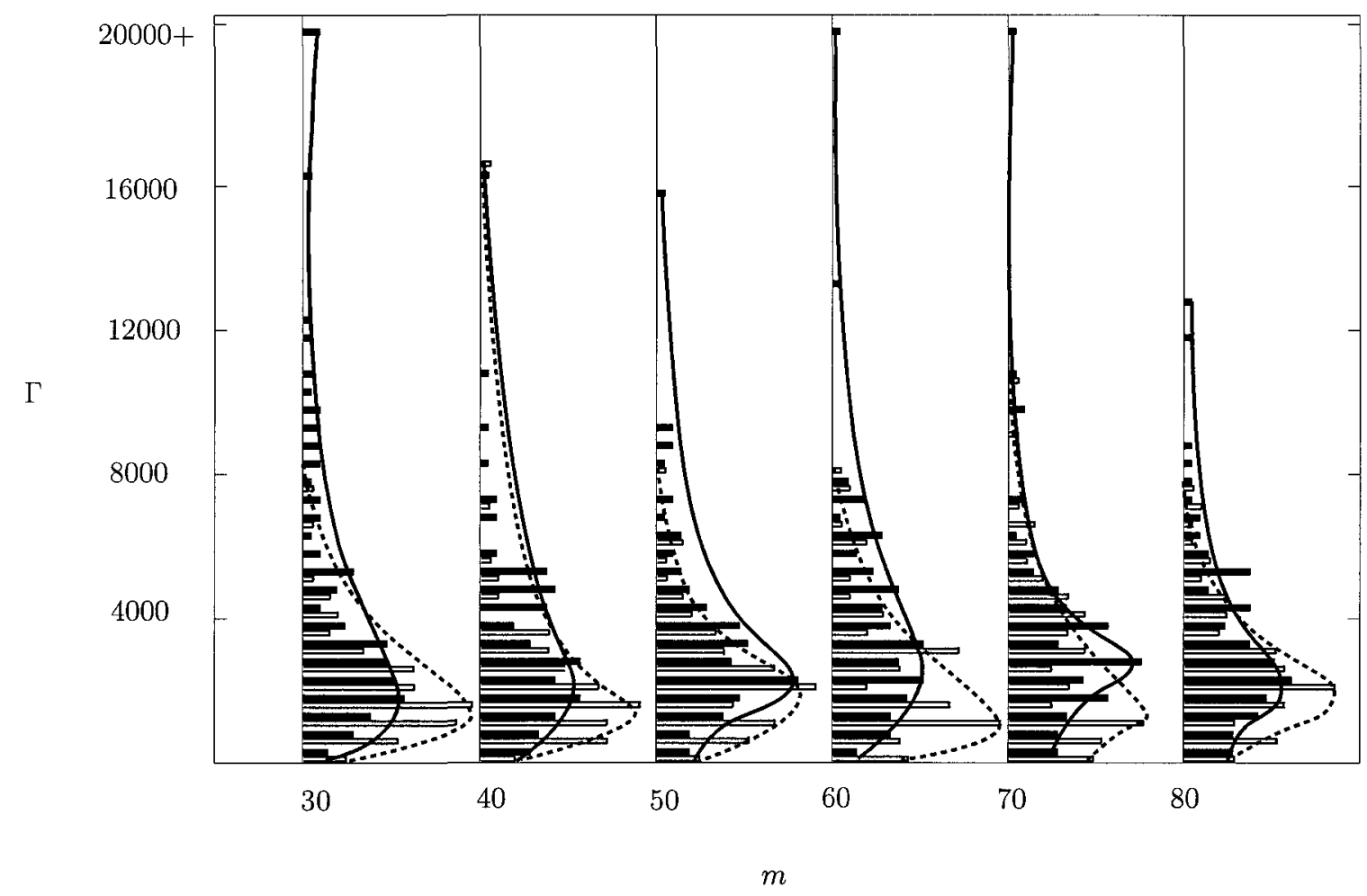

Figure 3.10: Histogram of $\Gamma$ for several population sizes. Comparing constant genetic operator parameters (solid bars and solid lines) versus adaptive genetic operator parameters (hollow bars and dotted lines). 
As a consequence of the previous results, the following genetic operator parameters are used throughout the analyses of Chapters 4 and 5. Table 3.1 lists the selected genetic operator parameters.

Table 3.1: Genetic Operators of GA.

\begin{tabular}{|l|l|}
\hline Mechanism & Model \\
\hline \hline Genetic Representation & Real-parameter \\
\hline Population Size & $m=50$ \\
\hline Selection & $\begin{array}{l}\text { Roulette wheel with Elitism } \\
s^{-}=0.8, s^{+}=1\end{array}$ \\
\hline Reproduction & Uniform crossover \\
& $P_{c}=0.6$ \\
\hline Mutation & Adaptive mutation \\
& $P_{m}^{-}=0.1, P_{m}^{+}=0.5$ \\
\hline \hline
\end{tabular}




\section{Chapter 4}

\section{Rocket Flowpath Optimization Results}

\subsection{Atlas E/F LR-105-5}

The rocket flowpath developed by Cerantola and Etele $[55,60]$ was designed to match the performance of the Atlas E/F LR-105-5 sustainer engine. The specifications used to approximate the kerosene $C_{12} H_{24} /$ air LR-105-5 engine are given in Table 4.1. The fixed geometric variables for this design are a throat radius $\left(r_{t h}=0.0551 \mathrm{~m}\right)$ corresponding to the throat of the LR-105-5 nozzle and an exit radius $\left(r_{e}=0.5 \mathrm{~m}\right)$. This is four times greater than the exit radius of the axisymmetric LR-105-5 nozzle $(r=0.12 m)$ to allow for potential air intake area. Fig 4.1 shows the desired Mach number distribution of the LR-105-5 nozzle. The rocket flowpath design code generates rocket flowpath geometries that produce this Mach number distribution. 
Table 4.1: Approximate Atlas E/F LR-105-5 Specifications.

\begin{tabular}{|l|c|}
\hline Specification & Value \\
\hline \hline Thrust & $190 \mathrm{kN}$ \\
Isp & $220 \mathrm{~s}$ \\
Chamber Pressure & $48 \mathrm{~atm}$ \\
Equivalence Ratio & 1.49 \\
Length $\left(z_{e}\right)$ & $1.12 \mathrm{~m}$ \\
Mass Flow Rate $\left(\dot{m}_{\text {rocket }}\right)$ & $29.8 \mathrm{~kg} / \mathrm{s}$ \\
\hline
\end{tabular}

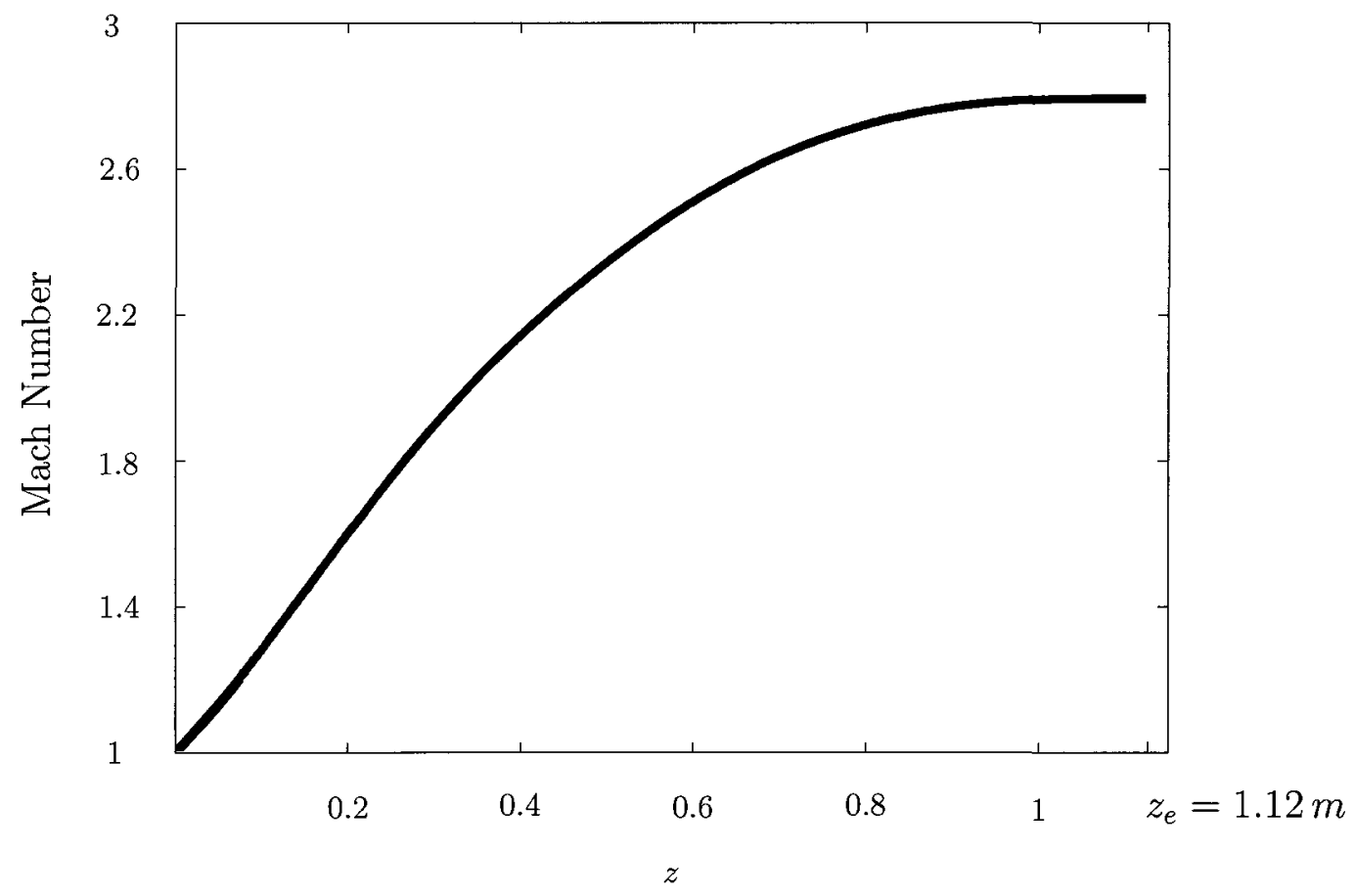

Figure 4.1: Pre-specified Mach number distribution corresponding to Atlas E/F LR-105-5 nozzle. 


\subsubsection{Performamce Criteria Weights}

By varying the performance criteria weights of the rocket flowpath fitness function (Eq 2.16 shown below), the GA can be made to converge to different optimal solutions. Each solution is optimal since it performs best for its corresponding fitness function. In order to study the effect of various weights, four cases are presented, as given by Table 4.2. The user can manipulate the fitness function weights to meet the desired criteria, however the following analysis shows that a balance of the three performance criteria weights is necessary to produce a rocket flowpath that is expected to perform well as a rocket-ejector nozzle under the expected operating conditions.

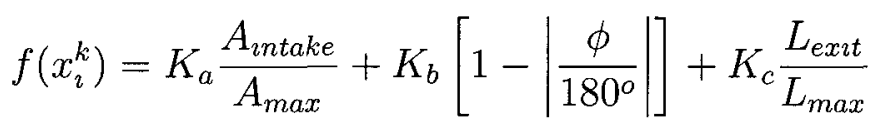

Table 4.2: Rocket flowpath fitness function weights.

\begin{tabular}{|cccc|}
\hline Case & $K_{a}$ & $K_{b}$ & $K_{c}$ \\
\hline \hline $\mathrm{A}$ & 1 & 0 & 0 \\
$\mathrm{~B}$ & 0 & 1 & 0 \\
$\mathrm{C}$ & 0 & 0 & 1 \\
$\mathrm{D}$ & 0.34 & 0.23 & 0.43 \\
\hline \hline
\end{tabular}

For case A, the first term of the fitness function is given $100 \%$ weight. Thus the GA produces a rocket flowpath that is optimized for air intake area only (see Fig 4.2(a)). The optimized rocket flowpath has large air intake area $\left(A_{\text {intake }}=0.56 \mathrm{~m}^{2}\right)$. However, the rocket flowpath exhaust profile is not annular and has low shear layer length $\left(L_{\text {exit }}=1.49 \mathrm{~m}\right)$. Therefore, it is expected that this rocket flowpath will not provide good mixing of the primary rocket stream and the secondary air stream.

For case B, the fitness function considers only the second term. Thus the GA 
produces a rocket flowpath that is optimized for flow turning angle at the gate (see Fig 4.2(b)). The flow turning angle at the gate is $\phi=0^{\circ}$ and thus the rocket exhaust does not experience large expansion in the circumferential direction. This is desirable since the rocket flowpath should avoid excessive boundary layer thickening and separation. However, this solution does not have large air intake area $\left(A_{\text {intake }}=0.22 \mathrm{~m}^{2}\right)$ or large shear layer length $\left(L_{\text {ext }}=2.49 \mathrm{~m}\right)$.

For case $\mathrm{C}$, the third term of the fitness function is given $100 \%$ weight. Thus the GA produces a rocket flowpath that is optimized for rocket exhaust shear layer length. As expected, the most fit solution (see Fig 4.2(c)) represents a rocket flowpath configuration that has a fully-annular exhaust shear layer length $\left(L_{\text {exit }}=3.14 \mathrm{~m}\right)$. A large $L_{\text {exit }}$ is expected to result in thorough mixing of the primary rocket stream and the secondary air stream within the remainder of the RBCC engine. However, this rocket flowpath is likely not an ideal design since the low air intake area $\left(A_{\text {tntake }}=0.14 \mathrm{~m}^{2}\right)$ suggests low entrainment of atmospheric air. Without sufficient air entrainment the RBCC performs more like a simple rocket and thus the potential for good mixing is irrelevant as there are no longer two flow streams.

Case D considers a nearly equal balance of all three performance criteria. Thus the GA produces a rocket flowpath that is optimized for a combination of the three criteria (see Fig 4.2(d)). This solution has a relatively large air intake area $\left(A_{\text {intake }}=0.36 \mathrm{~m}^{2}\right)$ which is only $36 \%$ lower then the maximum $A_{\text {intake }}$ found by Case A, fully-annular exhaust profile $\left(L_{e x i t}=3.14 \mathrm{~m}\right)$, and a reasonable flow turning angle $\left(\phi=32^{\circ}\right)$. Thus, it is expected that this rocket flowpath is well suited for a rocket-ejector nozzle within an RBCC engine. Table 4.3 summarizes the results of the four cases. 


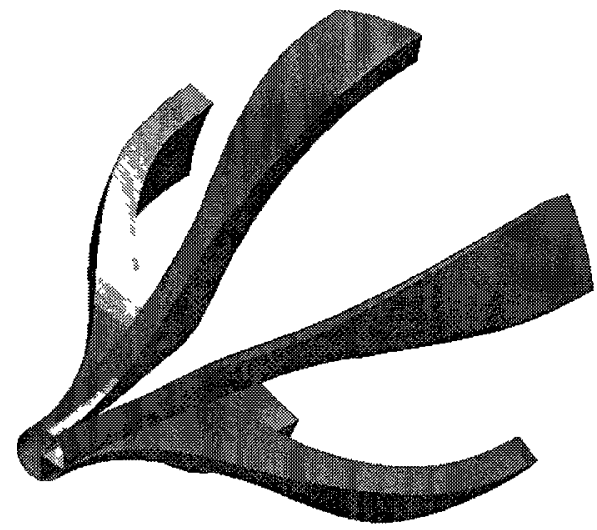

(a) Case A

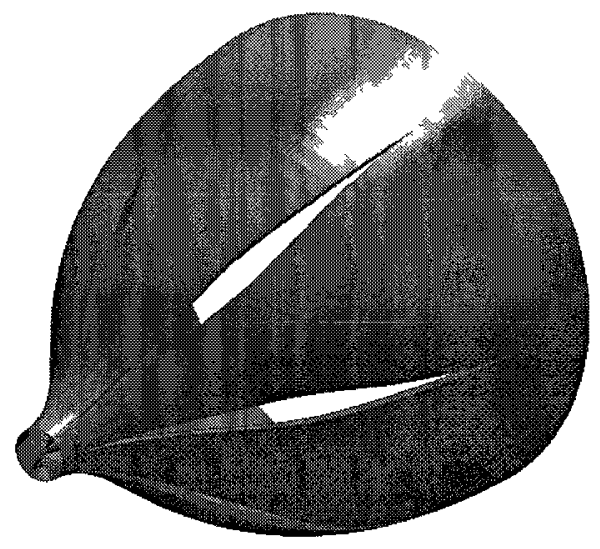

(c) Case C

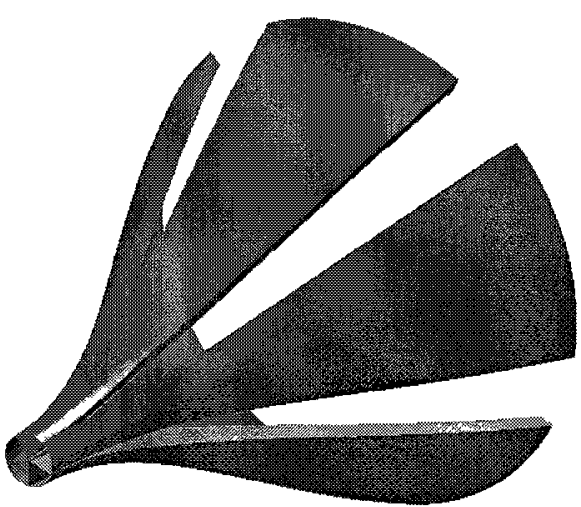

(b) Case B

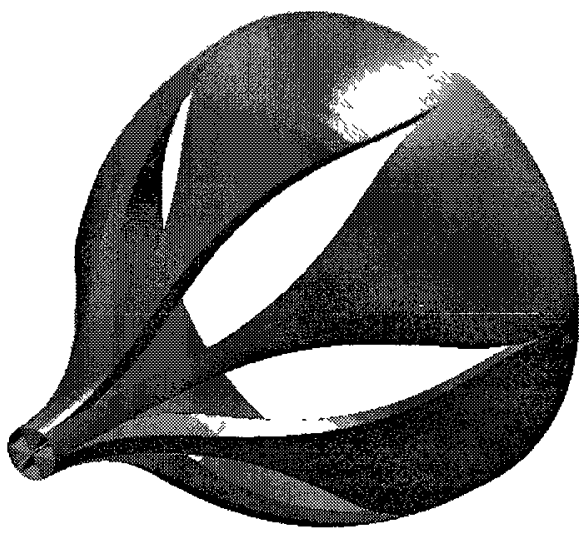

(d) Case D

Figure 4.2: Four cases of different fitness function weights showing the most fit rocket flowpath for each case.

Table 4.3: Performance criteria results.

\begin{tabular}{|cccc|}
\hline Case & $A_{\text {intake }}\left(m^{2}\right)$ & $\phi($ deg. $)$ & $L_{\text {exit }}(m)$ \\
\hline \hline A & 0.56 & 2 & 1.49 \\
B & 0.22 & 0 & 2.49 \\
C & 0.14 & 18 & 3.14 \\
D & 0.36 & 32 & 3.14 \\
\hline
\end{tabular}




\subsection{H-IIA LE-7A}

The following analysis is presented to show that the GA can optimize a variety of rocket flowpath designs. Section 4.1 discussed the successful optimization of the rocket flowpath design for the LR-105-5 engine under a variety of performance criteria weights. This section discusses the optimization of the rocket flowpath for the LE-7A engine using the performance criteria weights corresponding to case D.

The rocket flowpath used throughout Waung's analysis [56] was designed to match the performance of the LE-7A rocket engine. This rocket engine is used by the Japanese Aerospace Exploration Agency as the first stage of the H-IIA launch vehicle. The specifications for the LE-7A liquid $\mathrm{O}_{2}$ /liquid $\mathrm{H}_{2}$ rocket engine are provided in Table 4.4 [61]. The fixed geometric variables for this design are a throat radius $\left(r_{t h}=0.121 \mathrm{~m}\right)$ corresponding to the throat of the LE-7A nozzle, and an exit radius $\left(r_{e}=3.1 \mathrm{~m}\right)$ that is set to be $1 \mathrm{~m}$ greater than the radius of the H-IIA launch vehicle. Fig 4.3 shows the desired Mach number distribution to produce the specifications similar to those of the LE-7A nozzle.

Table 4.4: Approximate LE-7A Specifications.

\begin{tabular}{|l|c|}
\hline Specification & Value \\
\hline \hline Thrust & $870 \mathrm{kN}$ \\
Isp & $338 \mathrm{~s}$ \\
Chamber Pressure & $121 \mathrm{bar}$ \\
O/F Ratio & 5.90 \\
Length $\left(z_{e}\right)$ & $8.7 \mathrm{~m}$ \\
Mass Flow Rate $\left(\dot{m}_{\text {rocket }}\right)$ & $247 \mathrm{~kg} / \mathrm{s}$ \\
\hline \hline
\end{tabular}




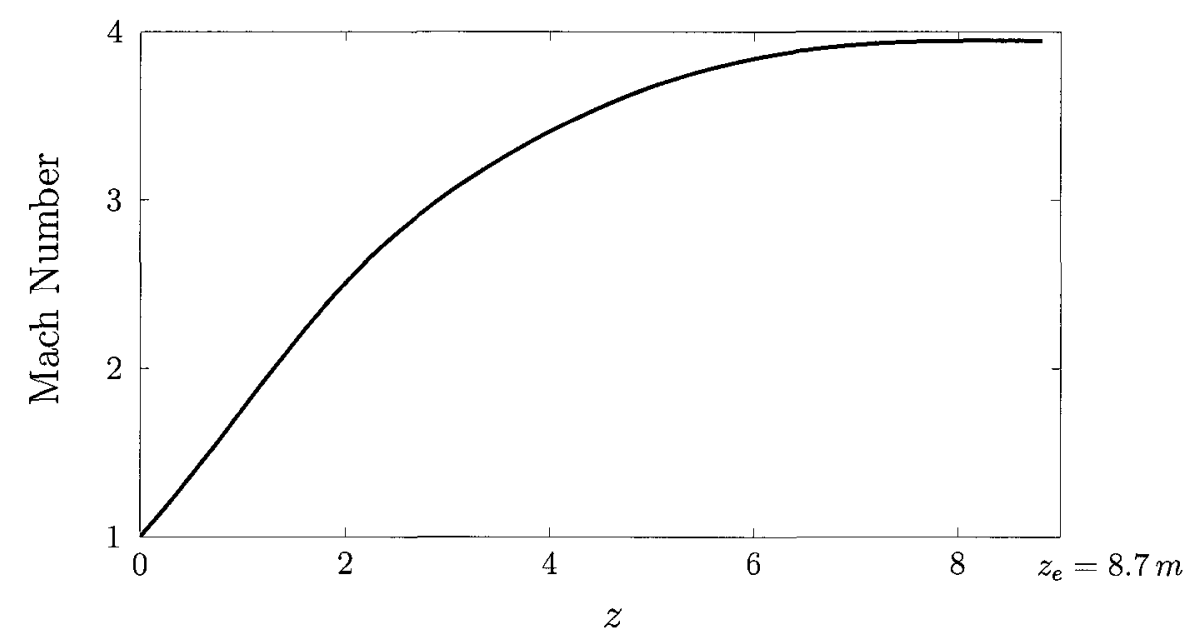

Figure 4.3: Pre-specified Mach number distribution corresponding to H-IIA LE-7A.

\subsubsection{LE-7A: Rocket Flowpath Convergence History}

Fig 4.4 shows the convergence history of population's fitness and Fig 4.5 shows the convergence history of the three performance criteria $\left(A_{\text {rntake }}, L_{\text {exit }}, \phi\right)$ of the most fit individual at each generation. Fig 4.6 shows the rocket flowpath design corresponding to the most fit individual at $k=0,5,40$.

Considering Fig 4.4, 4.5, and 4.6 the influence of the performance criteria on the fitness of an individual is observed. For example, the most fit individual of the initial population (see Fig $4.6(\mathrm{a})$ ) has a low fitness $\left(f\left(x_{1}^{0}\right)=0.58\right)$ because the exhaust shear layer length is low, $L_{\text {ext }}\left(x_{1}^{0}\right)=10.3 \mathrm{~m}$. At $k=5$, the most fit individual has evolved (see Fig 4.6(b)) to an improved fitness $\left(f\left(x_{1}^{5}\right)=0.66\right)$ because the shear layer length increased by $97 \%$ to $L_{e x t t}\left(x_{1}^{5}\right)=20.3 \mathrm{~m}$. This improvement was achieved despite a decrease of air intake area by $31 \%\left(A\left(x_{1}^{5}\right)=11.4 m^{2}\right)$. At $k=40$, the most fit individual (see Fig 4.6(c)) reached the most fit solution $\left(f\left(x_{1}^{40}\right)=0.71\right.$ ) due to the increase of air intake area by $63 \%\left(A_{\text {rntake }}\left(x_{1}^{40}\right)=18.6 \mathrm{~m}^{2}\right)$ while maintaining the shear layer length of $20.3 \mathrm{~m}$. 


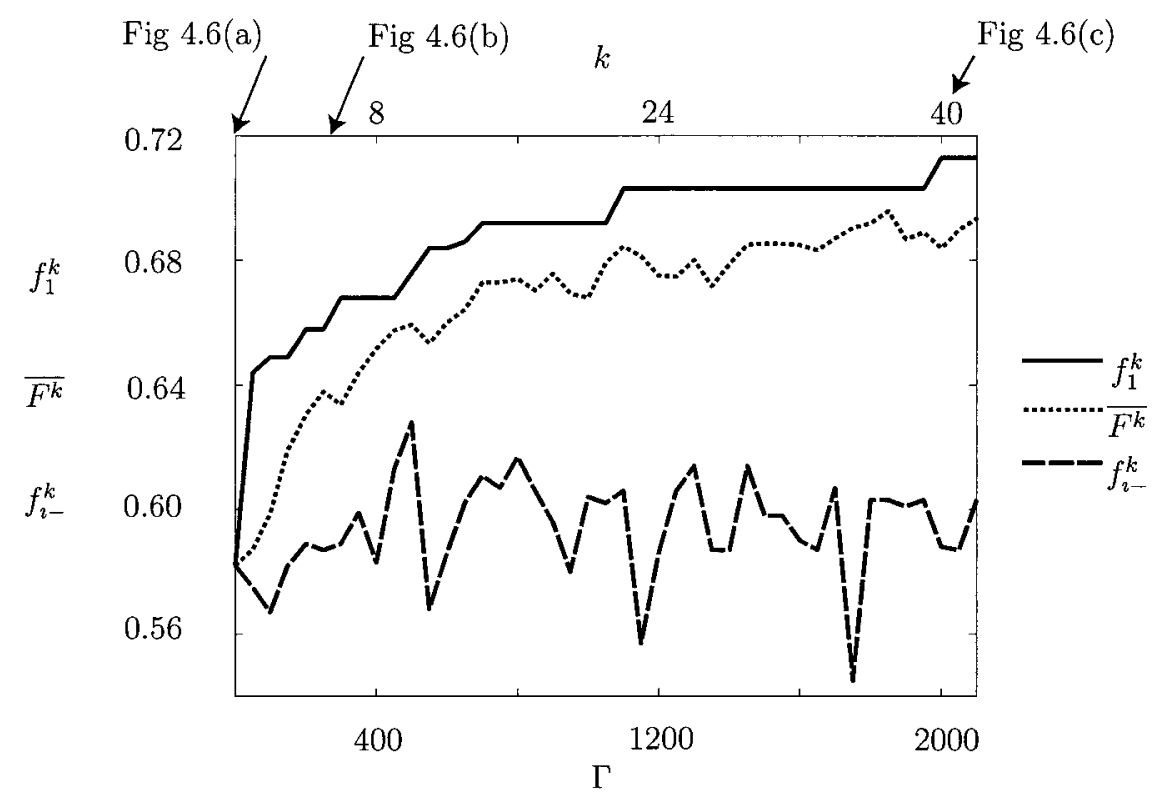

Figure 4.4: LE-7A fitness convergence history.

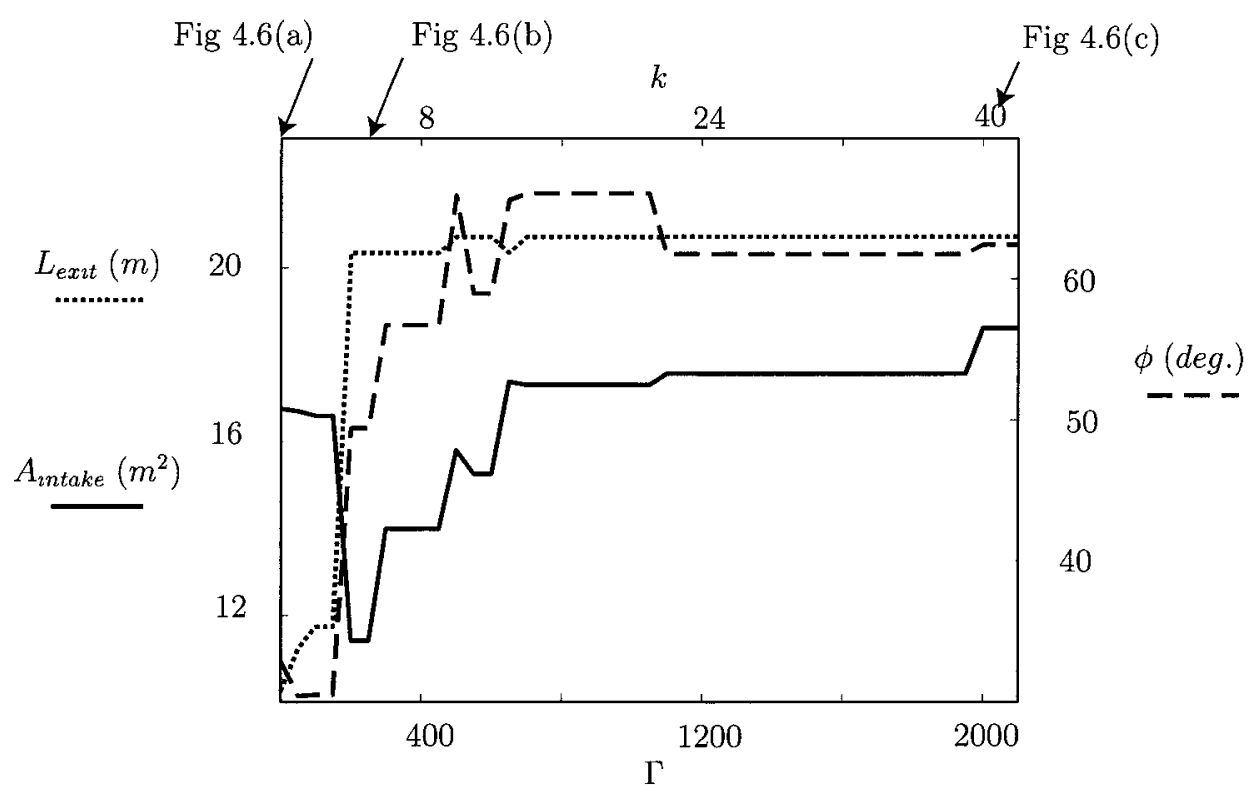

Figure 4.5: LE-7A performance criteria convergence history. 


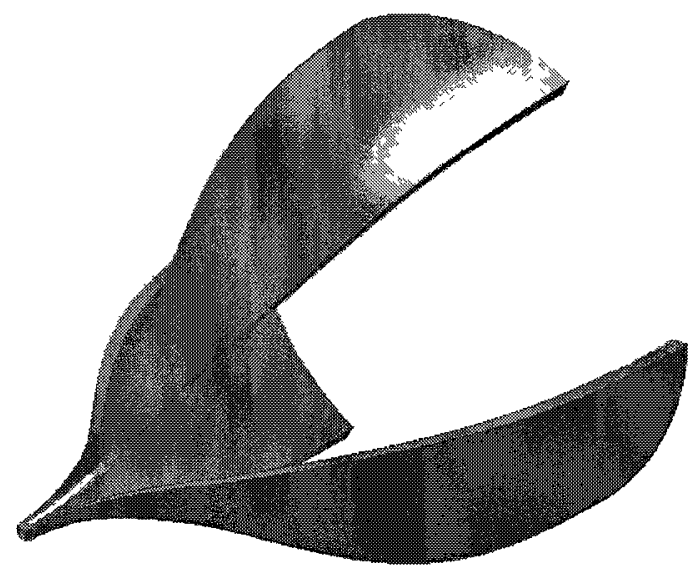

(a) $k=0(\Gamma=0)$

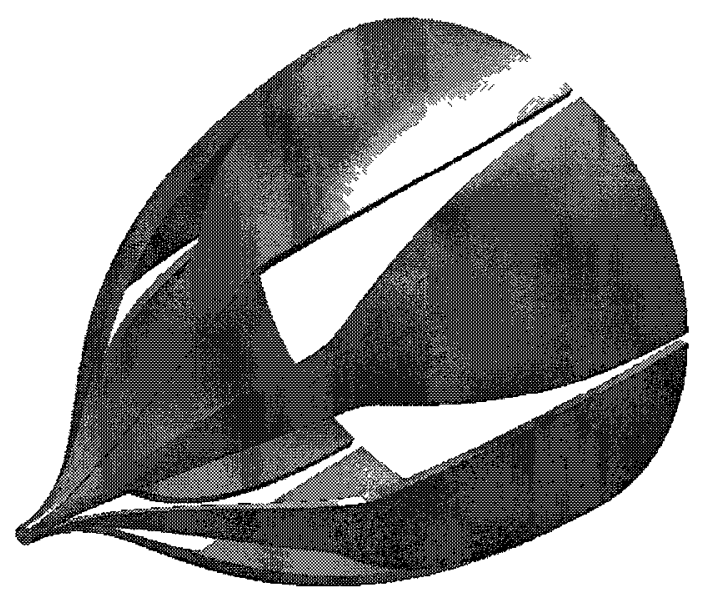

(b) $k=5(\Gamma=250)$

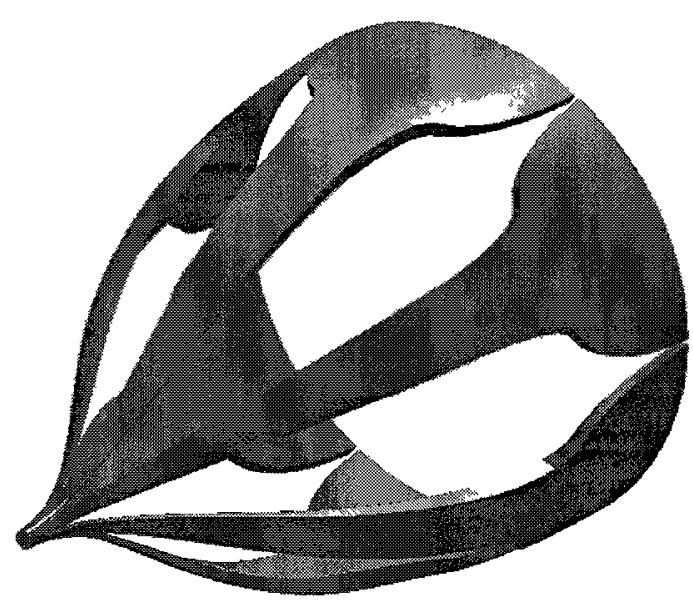

(c) $k=40(\Gamma=2000)$

Figure 4.6: Most fit individual at $k=0,5,40(\Gamma=0,250,2000)$. 


\subsection{Solution Space Hyperplanes}

The rocket flowpath design is controlled by five design variables, therefore the solution space has five dimensions. The solution space can be thought of as a 5-D hypercube [62]. A hyperplane is then a 4-D cross-section through the 5-D hypercube. Fig 4.8 shows four $\tilde{z}_{g}-\tilde{r}_{g}$ (rocket flowpath gate depth-gate radius) projection-planes and

Fig 4.9 shows four $\tilde{\psi}_{e}-\tilde{\psi}_{g}$ (rocket flowpath exit arc angle-gate arc angle) projectionplanes.

Each projection-plane is a snapshot of the solution space as the GA converges toward the most fit solution. The circles represent solutions that have been evaluated. An empty circle $\bigcirc$ represents an invalid solution, which is assigned a fitness of zero so that it cannot be selected for reproduction. A filled circle - represents a viable solution with a fitness greater than zero. The double circle $\bigcirc$ represents the most fit individual of the population at the given generation $k$.

There is one $\tilde{z}_{g}-\tilde{r}_{g}$ plane for each combination of the remaining three design variables $\left(\left[\varepsilon, \tilde{\psi}_{e}, \tilde{\psi}_{g}\right]\right)$. For this example there would be $4464 \tilde{z}_{g}-\tilde{r}_{g}$ planes at each generation $k$ (the number of $\tilde{z}_{g}-\tilde{r}_{g}$ planes is determined by Eq 2.15 with $j=1,2$, $3)$. By projecting all of the $\tilde{z}_{g}-\tilde{r}_{g}$ planes onto one projection-plane we are able to visualize the progression of the GA along the $\tilde{z}_{g}-\tilde{r}_{g}$ dimensions. For a given $\left[\tilde{z}_{g}, \tilde{r}_{g}\right]$ combination there could potentially be 4464 circles stacked on top of each other. Therefore only the most fit $\left[\tilde{z}_{g}, \tilde{r}_{g}\right]$ combination is plotted. Similarly, there are 900 $\tilde{\psi}_{e}-\tilde{\psi}_{g}$ planes projected onto one projection-plane with only the most fit $\left[\tilde{\psi}_{e}, \tilde{\psi}_{g}\right]$ combination plotted (refer to Eq 2.15 with $j=1,4,5$ ).

Fig 4.7 shows an example of how several $\tilde{z}_{g}-\tilde{r}_{g}$ planes are projected onto one projection plane. In this example, there are a total of nine unique individuals that have been evaluated ( 4 on $\tilde{z}_{g}-\tilde{r}_{g}-1,2$ on $\tilde{z}_{g}-\tilde{r}_{g}-2$ and 3 on $\tilde{z}_{g}-\tilde{r}_{g}-3$ ). Projecting the three planes onto $\tilde{z}_{g}-\tilde{r}_{g}$ results in the overlap of four individuals so that only 
five individuals can be visualized on the projection-plane. Fig 4.7 also illustrates an interesting effect of the interrelationship of the five design variables. It is observed that a $\left[\tilde{z}_{g}, \tilde{r}_{g}\right]$ combination can be invalid on one plane but valid on another due to changes in the remaining three design variables. This illustrates that a GA is a good choice for this type of design problem. 


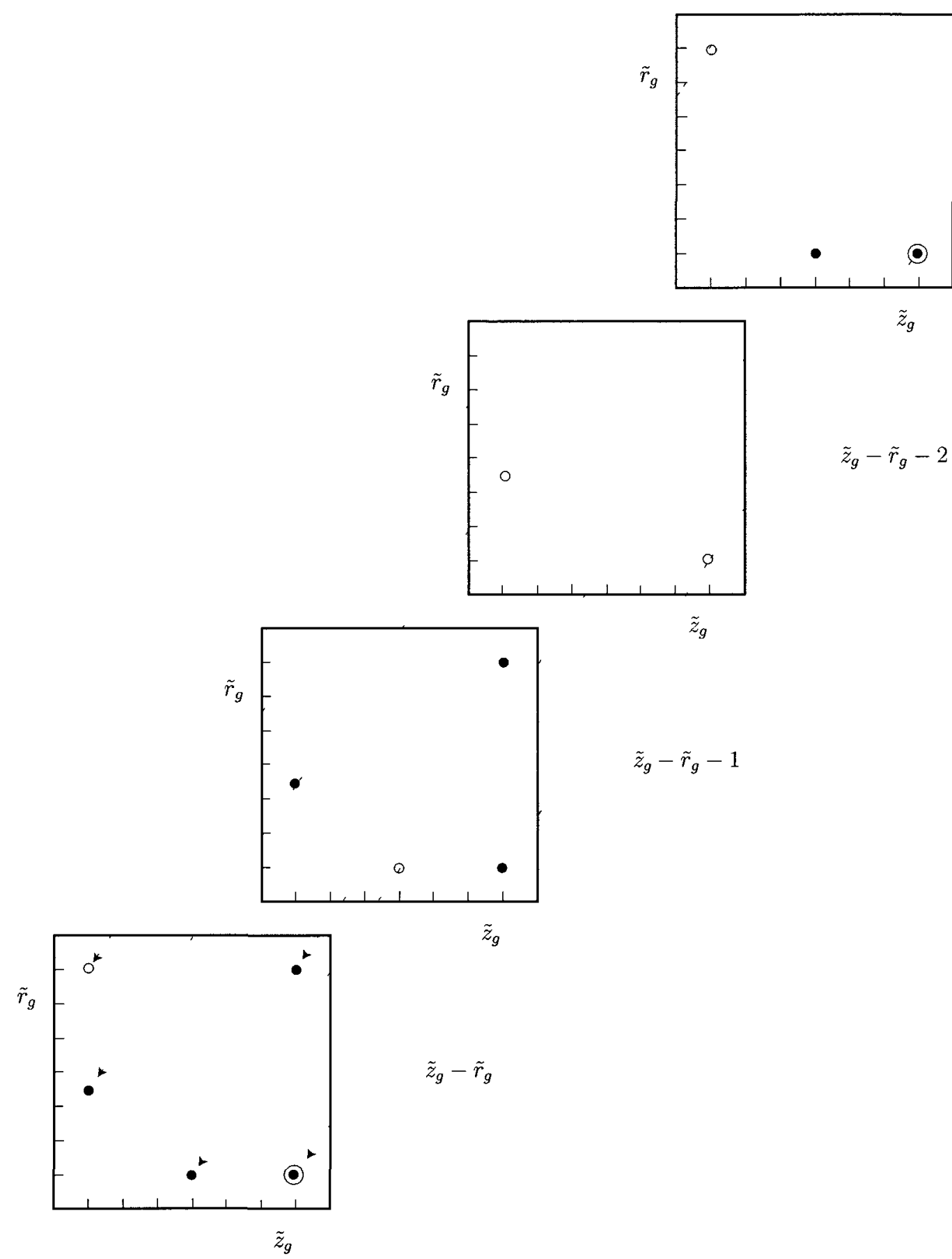

Figure 4.7: An example of the creation of the $\tilde{z}_{g}-\tilde{r}_{g}$ projection-plane. 
Considering Fig 4.8 it can be seen that the number of newly evaluated solutions increases with $k$. However the rate of newly evaluated solutions decreases with $k$. This is due to the fact that as $k \rightarrow \infty$ there are repeated individuals from one generation to another. For instance, the Elitism method ensures that at least one individual is repeated in the following generation.

Fig 4.8 illustrates the progression of the most fit solution with $k$. This is indicated by the arrows pointing from the location of the previous most fit solution to the location of the new most fit solution. No change occurs between $k=25-100$ (Fig 4.8(c)-4.8(d)), meaning the GA reached the most fit $\left[\tilde{z}_{g}, \tilde{r}_{g}\right]$ combination between $10<k \leq 25$.

Considering Fig 4.9 the same effect of the number of newly evaluated solutions increasing with $k$ can also be seen. The progression of the most fit solution is also illustrated. A slight change occurs between $k=25-100$ (Fig 4.9(c)-4.9(d)), meaning the GA reached the most fit $\left[\tilde{\psi}_{e}, \tilde{\psi}_{g}\right]$ combination between $25<k \leq 100$. In fact, convergence is achieved at $k=40$.

Fig 4.8 and 4.9 illustrate the tendency of the GA to focus exploration along hyperplanes of the solution space. Holland's Schema Theory says that schemata (groups of genes with the same alleles) define hyperplanes, and a GA will focus on strong schemata with high fitness. This tendency is more easily observed in Fig 4.9. Considering Fig 4.9(b), the most fit solution is located at $\left[\tilde{\psi}_{e}, \tilde{\psi}_{g}\right]=[0.92,0.32]$. Therefore the schemata defined by $\left[*, 0.92,{ }^{*},{ }^{*},{ }^{*}\right]$ and $\left[{ }^{*},{ }^{*}, 0.32,{ }^{*}, *\right]$ are found to be strong schemata (* is a wild card). Considering Fig $4.9(\mathrm{c})$, it can be seen that many good solutions appear along the hyperplanes defined by the strong schemata. Fig 4.9(d) shows that as the strongest schemata shifts to $\left[{ }^{*}, 0.96,{ }^{*},{ }^{*}, *\right]$ and $\left[{ }^{*}, *, 0.30,{ }^{*},{ }^{*}\right]$, new hyperplanes are developed as $k$ increases.

This tendency to explore for solutions along strong hyperplanes is what makes the GA a powerful optimization technique. Fig 4.9(d) shows that the GA focuses the 
majority of evaluations on hyperplanes close to the most fit solution and does not waste computational resources by evaluating many individuals far from the most fit solution.

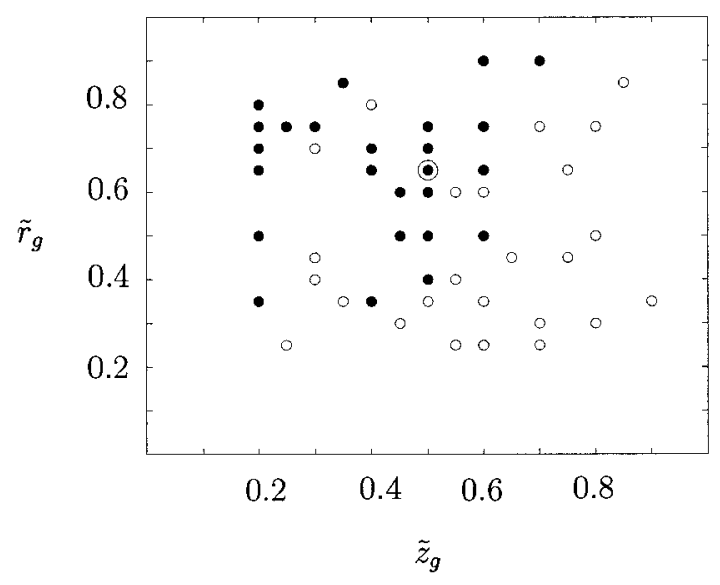

(a) $k=1(\Gamma=50)$

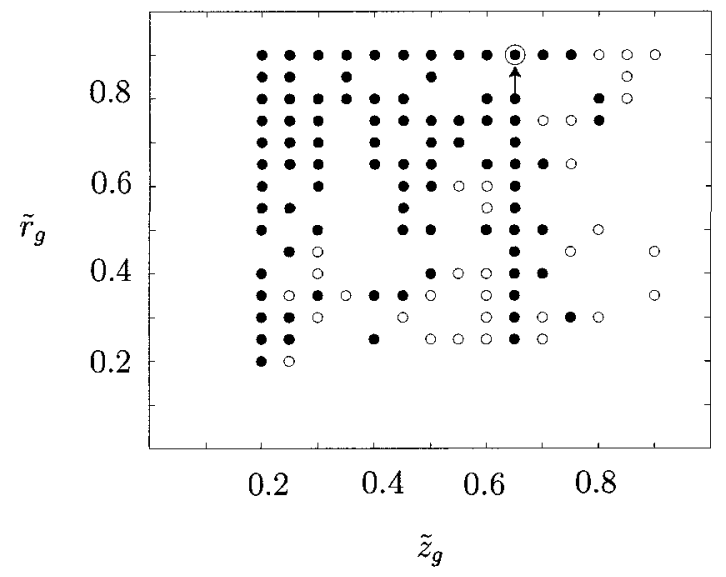

(c) $k=25(\Gamma=1250)$

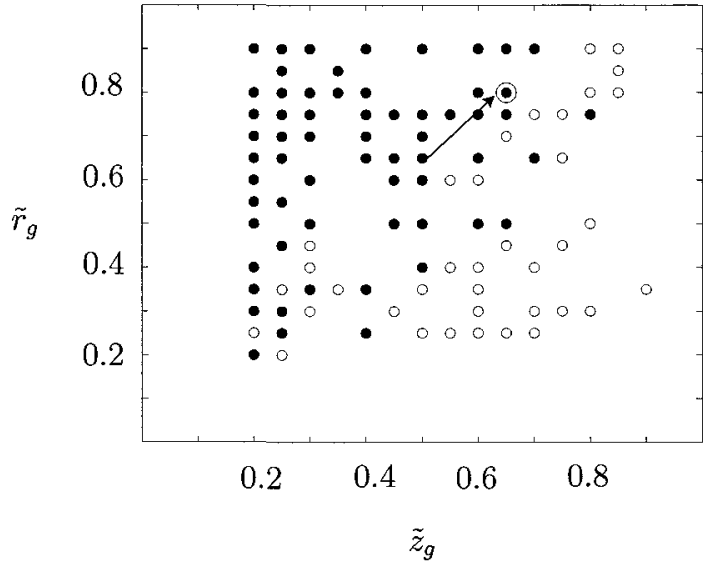

(b) $k=10(\Gamma=500)$

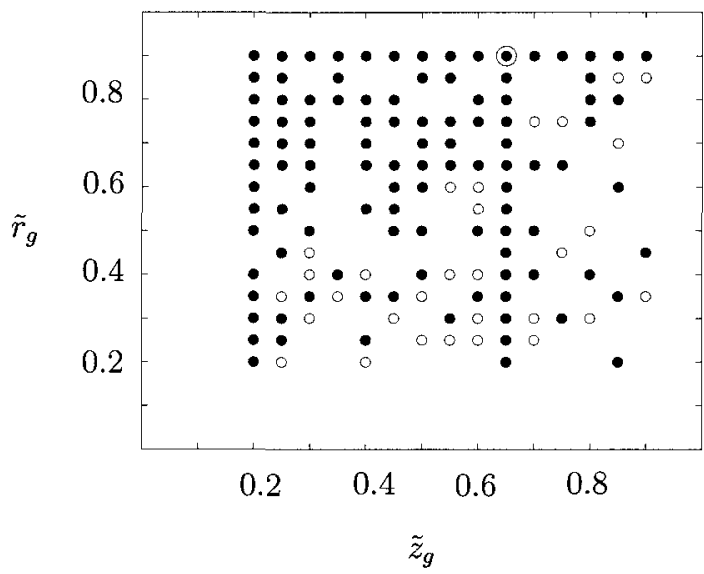

(d) $k=100(\Gamma=5000)$

Figure 4.8: $\tilde{z}_{g}-\tilde{r}_{g}$ projection-plane illustrating evaluation of new solutions, progression of the most fit solution, and formation of hyperplanes. The most fit individual of the population is represented by a double circle. Individuals with fitness greater than zero are represented by filled circles. Invalid individuals are represented by empty circles. 

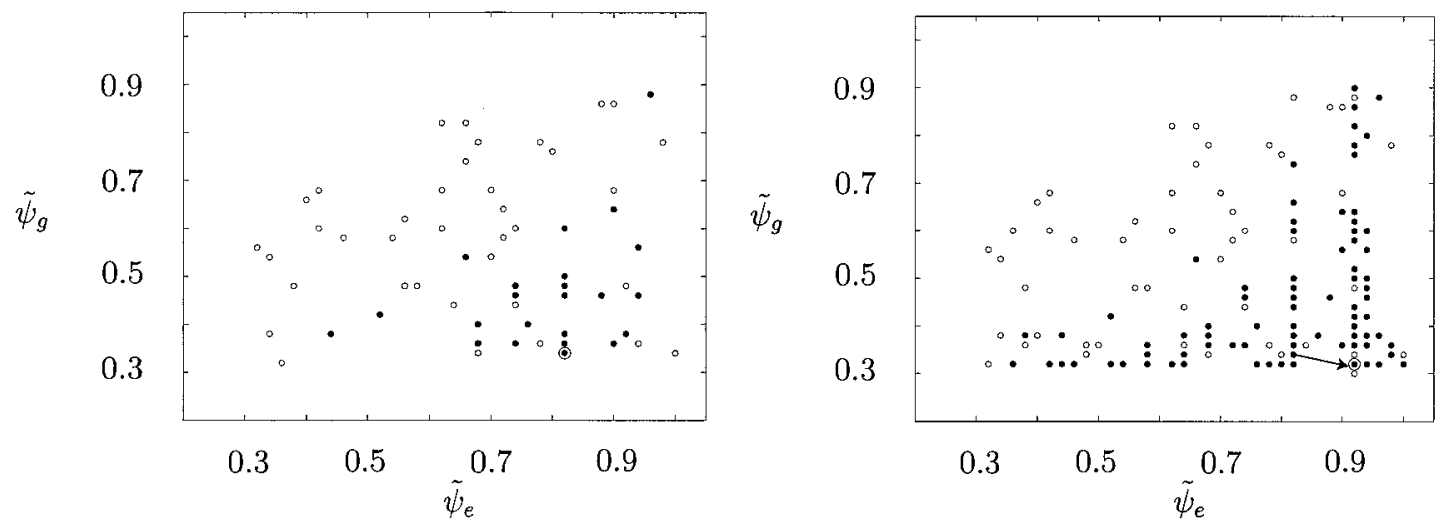

(a) $k=1(\Gamma=50)$

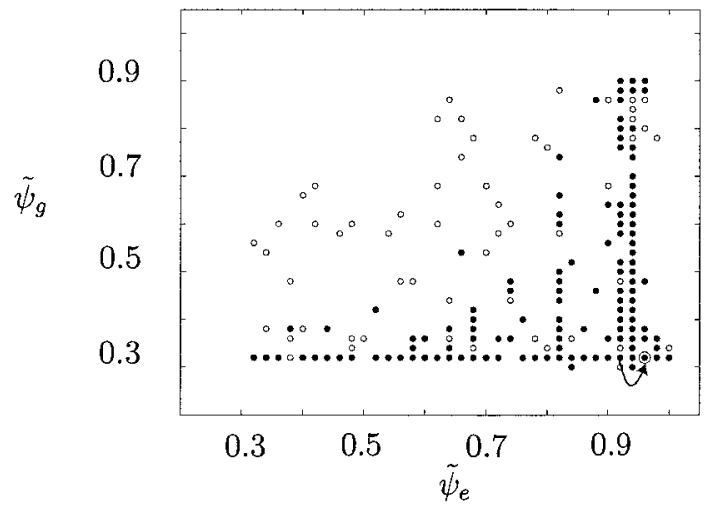

(b) $k=10(\Gamma=500)$

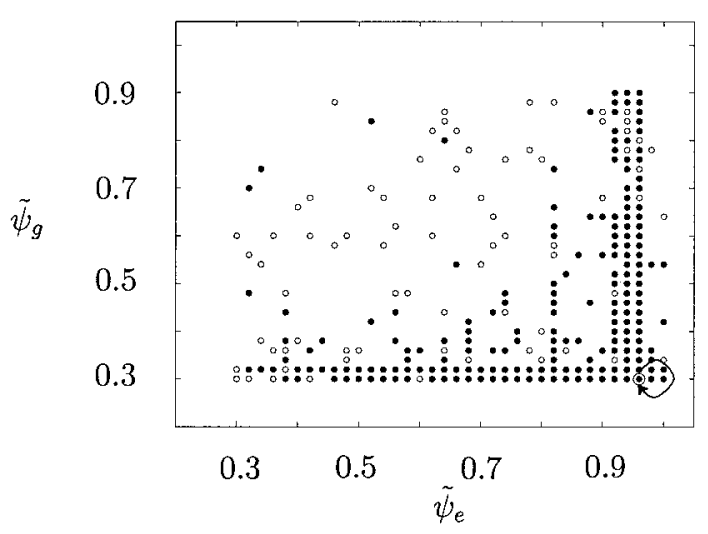

(c) $k=25(\Gamma=1250)$

(d) $k=100(\Gamma=5000)$

Figure 4.9: $\tilde{\psi}_{e}-\tilde{\psi}_{g}$ projection-plane illustrating evaluation of new solutions, progression of the most fit solution, and formation of hyperplanes. The most fit individual of the population is represented by a double circle. Individuals with fitness greater than zero are represented by filled circles. Invalid individuals are represented by empty circles. 


\section{Chapter 5}

\section{Air Flowpath Optimization Results}

The purpose of the air flowpath optimization is to produce a rocket-ejector design that is expected to perform well during the first mode of operation of the RBCC propulsion system. In order to design the rocket-ejector one must specify the operating conditions and desired performance. For this work, the operating conditions represent flight conditions just after takeoff $\left(M_{\infty}=0.01, h_{\text {alt }}=40 \mathrm{~m}\right.$ and $p_{3}=97.7 \mathrm{kPa}$ ). The desired performance is measured by the entrainment ratio $\alpha$ which is influenced by $\sigma$, the ratio between the rocket exhaust flow area $\left(A_{R}\right)$ and the total air flow area at plane $3\left(A_{3}\right)$. For this work, $\sigma=0.1$ leads to $A_{3}=9 \cdot A_{R}$, as found using Eq 5.1.

$$
A_{3}=\left(\frac{1}{\sigma}-1\right) A_{R}
$$

where $A_{R}$ is a set value based on the defined rocket flowpath throat radius $\left(r_{t h}\right)$ and the exhaust Mach number (see Fig 4.3).

The 1-D rocket-ejector analysis developed by Etele et al. [58] is used to determine 
the maximum $\alpha$ that can be expected based on the operating conditions and $\sigma$. Fig 5.1 shows a diagram of the 1-D rocket-ejector used for the analysis where under isentropic conditions and expansion of the exhaust to $p_{\text {atm }}$, completely mixed flow within the RBCC engine would achieve an entrainment ratio $(\alpha)$ of 7.52. As this represents an ideal configuration, this value will be used in the fitness function for non-dimensionalization purposes.

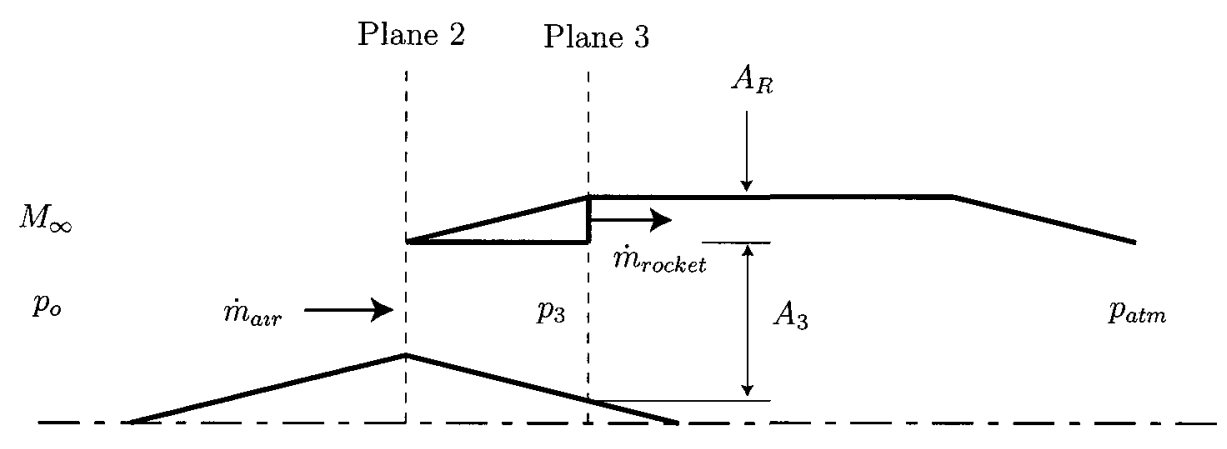

Figure 5.1: 1-D rocket-ejector used for rocket-ejector analysis.

The axisymmetric potential flow panel method used by Waung [56] calculates a more realistic estimate of the entrainment ratio $(\alpha)$ of the rocket-ejector design. This estimate of $\alpha$ will always be lower than $\alpha_{\max }$ since the code accounts for $\dot{m}_{\text {air }}$ losses due to separation, boundary layers, and viscous effects. All of these losses are influenced by the geometry of the air flowpath. Therefore, the GA is implemented to determine the most fit air flowpath design which will minimize these losses and maximize $\alpha$, with the goal of approaching $\alpha_{\max }$.

Optimization of the air flowpath design uses the same GA settings as the rocket flowpath design. The only differences are the genetic representation of solutions, the evaluation function, and the fitness function as described in Section 2.3. Section 5.1 discusses the optimization results of the air flowpath design based on the five air flowpath design variables and the previously optimized LE-7A rocket flowpath. Section 5.2 discusses the optimization results of the entire Exchange Inlet design considering all 10 design variables throughout the optimization process. 


\subsection{Air Flowpath Optimization}

The most fit rocket flowpath design found in Section 4.2.1 is used as the basis around which the air flowpath design is optimized. The rocket flowpath design variables are fixed, therefore the rocket flowpath has a nearly annular exhaust profile and has a six clover configuration (see Fig 4.6(c)). Since the rocket flowpath design variables are fixed, the second and third terms of the fitness function are also fixed. Therefore the GA is used to determine the best combination of the five air flowpath design variables to produce a design with maximum entrainment ratio $\alpha$. Eq 2.26 from Section 2.3.2 is the fitness function used throughout the optimization process with the following weighting factors: $K_{a}=0.34, K_{b}=0.23$, and $K_{c}=0.43$. The second and third term can be simplified since they are constant throughout the optimization process.

$$
\begin{aligned}
& f_{i}^{k}=K_{a} \frac{\alpha}{\alpha_{\max }}+K_{b}\left[1-\left|\frac{\phi}{180^{\circ}}\right|\right]+K_{c} \frac{L_{e x i t}}{L_{\max }} \\
& =\quad 0.34 \frac{\alpha}{\alpha_{\max }}+0.58
\end{aligned}
$$

Fig 5.2 shows the convergence history for the optimization of the air flowpath design. Convergence is reached at $\Gamma=400(k=8)$, which indicates that the rate of convergence is slightly faster when compared with the optimization of the rocket flowpath design. This result is expected since the size of the search space defined by the five air flowpath design variables is less than the size of the search space defined by the five rocket flowpath design variables. However, the computational time required to reach convergence is greater since each evaluation $(\Gamma)$ of the air flowpath requires approximately 1 minute of computational time, as compared to approximately 2 seconds for the rocket flowpath design. Therefore, for the air flowpath optimization, $\Gamma=400$ equates to approximately 7 hours of computational time. Whereas for the rocket flowpath optimization, $\Gamma=400$ is only 13 minutes of computational time. 
Fig 5.3 shows the optimized air flowpath design corresponding to $\Gamma=400$. The design has an annular rocket exhaust profile $\left(L_{e x i t}=20.7 \mathrm{~m}\right)$, a moderate flow turning angle $\left(\phi=64^{\circ}\right)$, and an entrainment ratio of $\alpha=7.16$. The fitness value of this individual is found by substituting these values into Eq 5.2 and gives $f_{1}^{8}=0.90$.

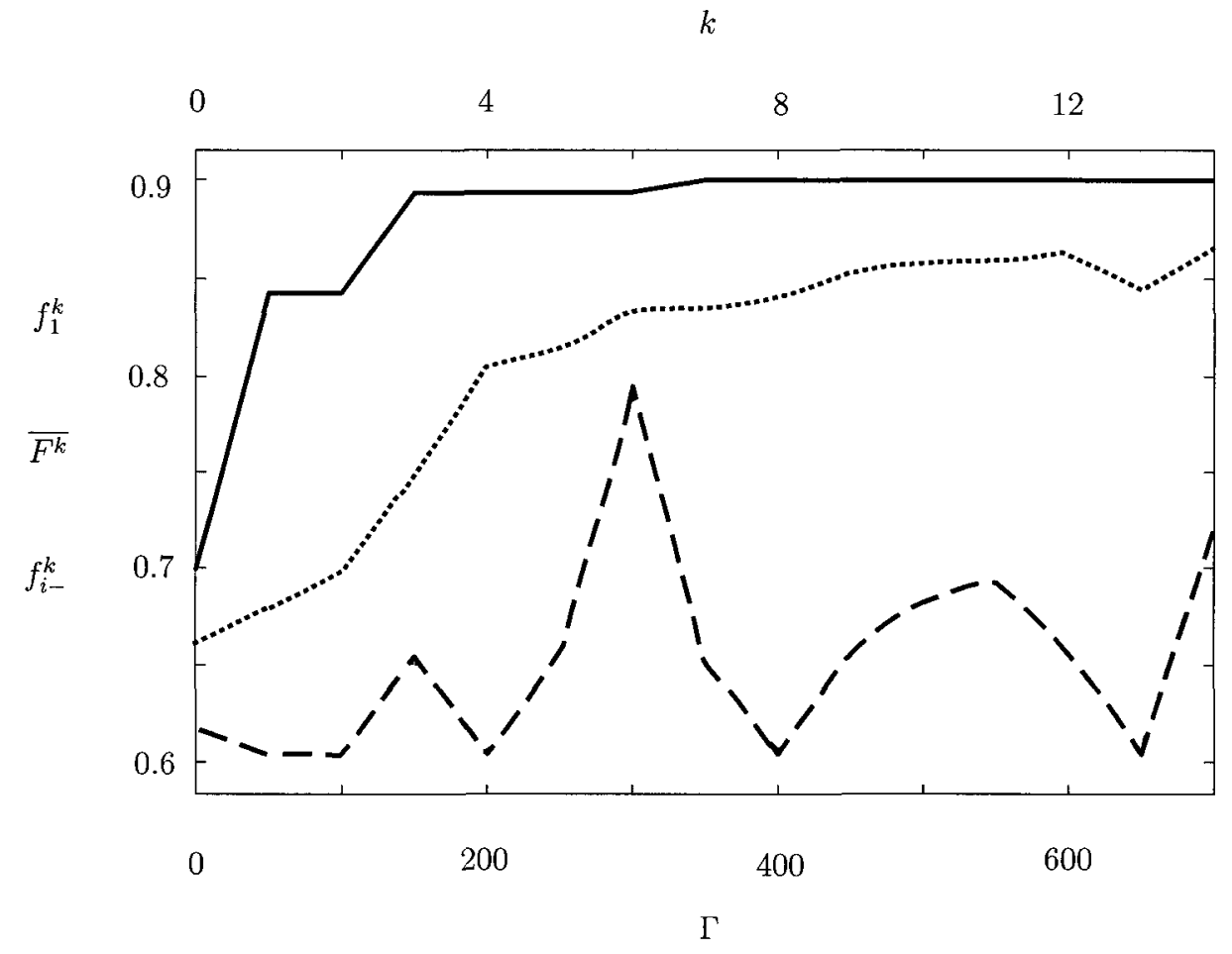

Figure 5.2: Convergence history for the optimization of the air flowpath design. 


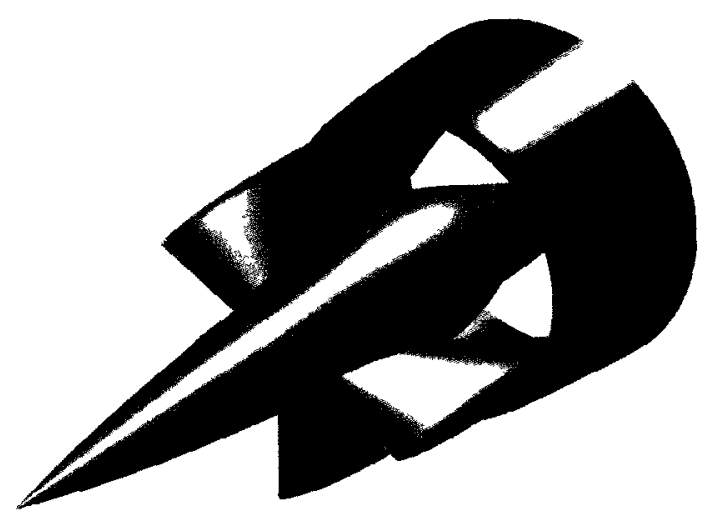

(a) 3D View

(b) Front View

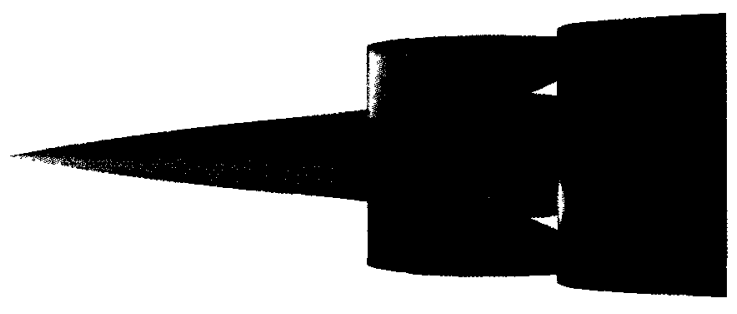

(c) Side View

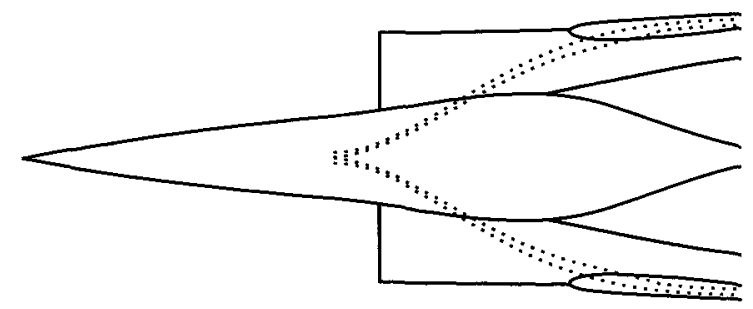

(d) Wire View

Figure 5.3: Optimized Exchange Inlet design considering five air flowpath design variables. 


\subsection{Exchange Inlet Optimization}

Simultaneous optimization of the five rocket flowpath design variables and the five air flowpath design variables is accomplished by using 10 genes to define individuals (see Eq 5.3). Therefore, the GA is able to manipulate the entire Exchange Inlet design (the rocket flowpath geometry and the air flowpath geometry) as it searches for the most fit design. The fitness function from Section 2.3.2 (Eq 2.26) is used throughout the optimization process with the following weighting factors: $K_{a}=0.34, K_{b}=0.23$, and $K_{c}=0.43$. In this case all terms of the fitness function are relevant since all 10 design variable are manipulated by the GA.

$$
x_{i}^{k}=\left[\varepsilon \tilde{\psi}_{e} \tilde{\psi}_{g} \tilde{z}_{g} \tilde{r}_{g} \tilde{z}_{2} \tilde{c}_{\text {fair } \max } \tilde{t}_{3} \tilde{r}_{C B_{1}} C R\right]
$$

Given that the 10 design variables that define the Exchange Inlet design of Fig 5.3 are contained within the current search space and that the same fitness function is used, it is expected that the simultaneous optimization of all the Exchange Inlet design variables will yield a more fit solution (or at least equally fit) when compared to the solution of Section 5.1.

Fig 5.4 shows the convergence history of the population's fitness. Convergence is reached at $\Gamma=8000(k=160)$. This result indicates that convergence rate is slower when the size of the search space increases. Considering the 10 design variables increases the size of the search space to $S \approx 430 \times 10^{9}$. The convergence history shows that the GA found a near-optimal solution at $\Gamma=1400(k=28)$ and remained at this solution until $\Gamma=8000$. From $\Gamma=8000-20000$ the most fit solution did not change, therefore convergence is achieved at $\Gamma=8000$. Fig 5.5 shows the optimized Exchange Inlet design, the design has a nearly-annular rocket exhaust profile $\left(L_{e x i t}=15.2 \mathrm{~m}\right)$, a low flow turning angle $\left(\phi=3^{\circ}\right)$, and an entrainment ratio of $\alpha=7.07$. The fitness value of this individual is found by substituting these values into Eq 2.26 and gives 
$f_{1}^{160}=0.88$

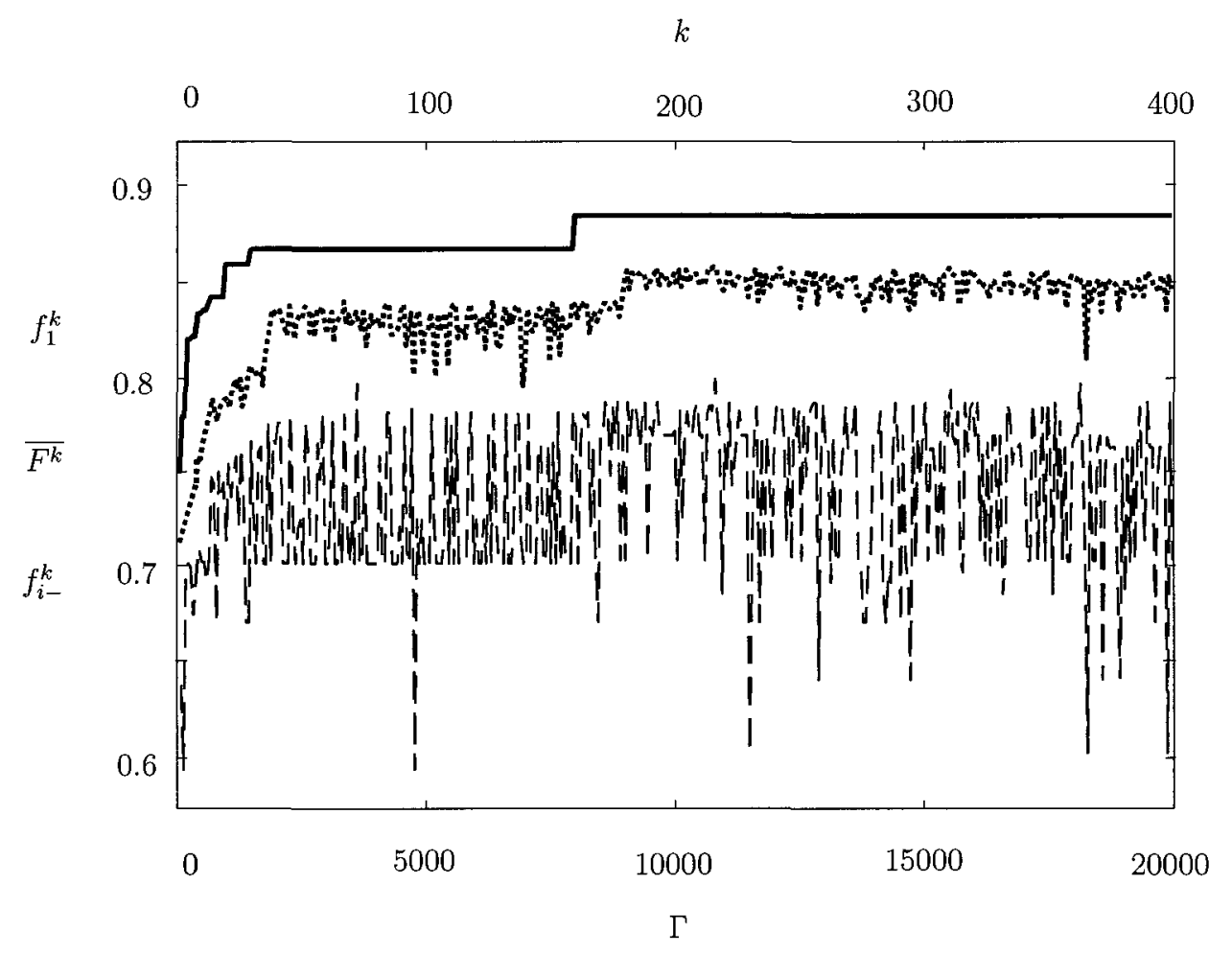

Figure 5.4: Convergence history for the optimization of the Exchange Inlet design.

Comparing the result of the air flowpath design optimization (Fig 5.3) and the result of the Exchange Inlet design optimization (Fig 5.5), it is observed that the two designs are similar. Both designs represent a six clover configuration with a nearannular rocket exhaust profile. The optimized air flowpath design from Section 5.1 has a slightly higher fitness since the rocket exhaust shear length is closer to fullyannular and the entrainment ratio is higher. This result indicates the optimization routine from Section 5.2 converged to a near-optimal solution. It is expected that given more computational time (such as $\Gamma=100000$ ) the GA will converge to the same solution as Section 5.1 or an even better solution.

The fact that the GA reached a better solution in Section 5.1 than Section 5.2 indicates that if the amount of computational time is limited, a two stage optimization process is a good choice for determining a near-optimal Exchange Inlet design. 
However, if the designer has extensive computational resources, the single stage optimization of all the design variables will produce the same, if not better Exchange Inlet design. 


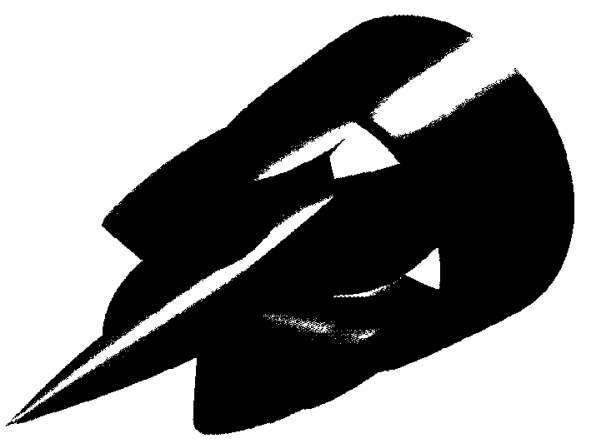

(a) 3D View

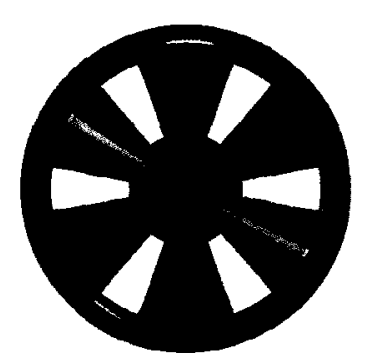

(b) Front View

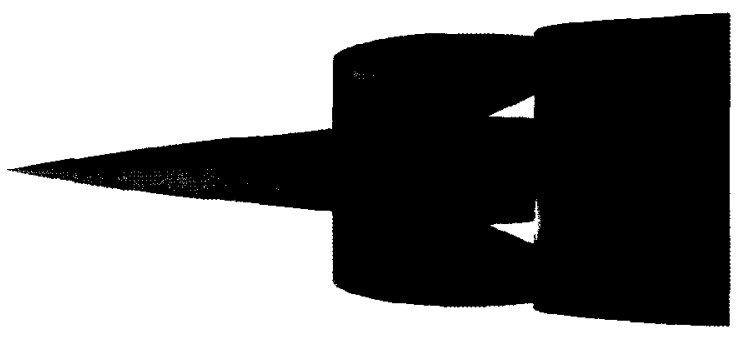

(c) Side View

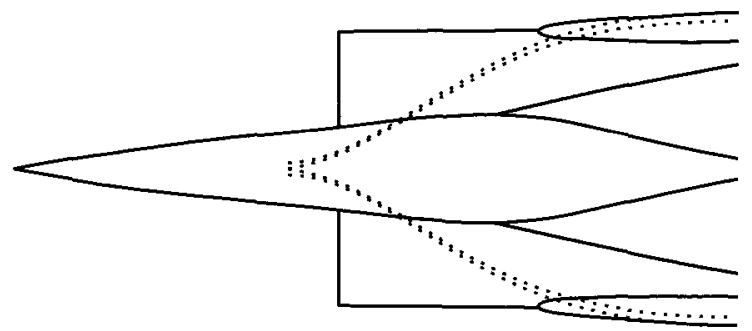

(d) Wire View

Figure 5.5: Optimized Exchange Inlet design considering all 10 design variables. 


\section{Chapter 6}

\section{Conclusions and Recommendations}

This thesis considers using a Genetic Algorithm as an optimization tool for the design of a Rocket-Based Combined-Cycle rocket-ejector known as the Exchange Inlet. As a starting point, the GA was used to optimize the design of the rocket flowpath of the Exchange Inlet. The GA was then used to optimize the design of the air flowpath and finally the entire Exchange Inlet design was optimized. It has been shown that by formulating a different set of design variables, fitness function and evaluation function, the GA is capable of optimizing a wide variety of design problems.

The optimization of the rocket flowpath was found to be computationally inexpensive since the size of the search space was relatively small and the evaluation of solutions was relatively fast. Therefore, a convergence study of the GA was conducted using the optimization of the rocket flowpath as a test case. The effect of varying the genetic operator parameters was studied and the conclusion is that the GA will find a near-optimal solution in a relatively short period of time when the GA has a good balance of explorative and exploitative genetic operators. 
It was found that a moderate population size results in good rate of convergence while maintaining genetic diversity of the population. Low population sizes showed a loss of genetic diversity, meaning that a high probability of mutation would be necessary to offset the genetic drift. High population sizes showed low rates of convergence since the GA evaluated many individuals.

Results showed that a low probability of mutation leads to loss of genetic diversity and makes the GA susceptible to convergence toward local optima. A high probability of mutation reduces the GA to a random search function and also makes the GA susceptible to trap situations. Therefore, a moderate probability of mutation is ideal to maintain genetic diversity while not hindering the exploitative power of the GA.

A comparison of the effect of selection pressure showed that weak selection pressure maintains good genetic diversity but results in low rates of convergences since the GA does not exploit the current search space. A strong selection pressure has a detrimental affect on the rate of convergence of the GA since a strong selection pressure hinders the explorative power of the GA. A moderate selection pressure permits the GA to exploit the current search space while also exploring new areas of the search space.

The GA developed in this thesis implemented a technique known as Adaptive Genetic Algorithms. Comparison of the convergence results of the adaptive technique versus the constant technique showed that by allowing the probability of mutation to adapt to the genetic diversity of the population and the selection pressure to adapt to the state of convergence (whether or not the GA is trapped), the GA experienced faster rates of convergence while also avoiding trap situations. Therefore, the adaptive technique not only makes the GA faster, but also increases the likelihood of converging to a near-optimal solution rather than a local optimum.

Using the adaptive technique and the genetic operator parameters found from the convergence study, the GA was used to optimize the design of the rocket flowpath. 
The rocket flowpath was optimized using a variety of the fitness function weights. As expected, it was found that varying performance criteria weights significantly altered the most fit solution. Therefore, the user is required to define the combination of performance criteria weights that will best suit his/her desired rocket flowpath design. It was shown that the GA is robust and is capable of optimizing multiple rocket designs, including the Atlas E/F LR-105-5 engine and the H-IIA LE-7A engine.

The GA was then applied to a more complex and more computationally expensive optimization problem, that of optimizing the Exchange Inlet. Initially, five design variables were used to define the air flowpath, the five rocket flowpath design variables were fixed. Next, all 10 design variables were used to define the combined Exchange Inlet design (five rocket flowpath design variables and five air flowpath design variables). This increased the size of the search space and the amount of time required to attain the most fit solution. However, the GA was able to find a near-optimal solution. This shows how the GA can solve a simple optimization problem and by adding more and more complexity the same GA is capable of solving a highly complex optimization problem.

The amount of computational resources required to optimize the entire Exchange Inlet design is significant. On a single desktop computer, the amount of time required is on the order of magnitude of days. This is due to the computationally intensive potential flow panel method implemented during the Exchange Inlet design. In order to reduce the run time of the GA, it is recommended that an alternative calculation method be implemented to approximate the atmospheric air mass flow rate losses across the Exchange Inlet. If an accurate estimation of the air mass flow rate is desired, then it is suggested that a distributed computing technique be incorporated into the GA. 


\section{List of References}

[1] M. Griffin. Why explore space? Technical report, www.nasa.gov, 2007.

[2] Britannica. Roman empire. website [www.britannica.com], 2010.

[3] J. C. Mankins. Highly reusable space transportation: Advanced concepts and the opening of the space frontier. Acta Astronautica, 2002.

[4] C. J. Trefny and J. M. Roche. Performance validation approach for the gtx air-breathing launch vehicle. Technical Report E-13263, NASA. John H. Glenn Research Center at Lewis Field, April 2002.

[5] R. L. Daines and R. M. Russell. Numerical analysis of the effects of combustion in rocket ejectors. AIAA, (98-3772), July 1998.

[6] J. F. Walker, H. Kamhawi, T. M. Krivanek, S. R. Thomas, and T. D. Smith. Status of the RBCC direct-connect mixer combustor experiment. Technical report, NASA/TM 2002-211555, 2002.

[7] S. Yungster and C. J. Trefny. Analysis of a new rocket-based combined-cycle engine concept at low speed. AIAA, (99-2393), September 1999.

[8] R. M. Russell, D. S. Brocco, and R. L. Daines. Modeling and validation of an ejector primary rocket for shielded afterburning fuel injection. AIAA, (99-2241), 1999.

[9] D. S. Brocco and R. L. Daines. Numerical analysis of three-dimensional and pressure effects in rocket ejectors. AIAA, (2000-3596), 2000.

[10] J. M. Cramer, M. Greene, S. Pal, and R. J. Santoro. RBCC ejector mode operating characteristics for single and twin thruster configurations. AIAA, (20013464-635), 2010.

[11] C. C. Jos, W. E. Anderson, V. Sankaran, and A. Gujarathi. Ducted rocket tests with a fuel rich primary thruster. AIAA, (2005-4282), 2005. 
[12] M. Lehman, S. Pal, and R. J. Santoro. Experimental investigation of the RBCC rocket-ejector mode. AIAA, (2000-3725), 2000.

[13] H. Kamhawi, T. M. Krivanek, S. R. Thomas, and J. F. Walker. Direct-connect ejector ramjet combustor experiment. AIAA, (2003-16), 2003.

[14] F. Dijkstra, A. G. M. Marée, M. Caporicci, and H. Immich. Experimental invesitgation of the thrust enhancement potential of ejector rockets. AIAA, 1997.

[15] E. A. Odegaard and K. E. Stroup. 1966 advanced ramjet concepts program. Ejector Ramjet Engine Tests - Phase 1. Technical Report AFAPLTR-67-118, The Marquardt Corporation, January 1968.

[16] R. L. Daines and C. L. Merkle. Computation analysis of mixing and jet pumping in rocket ejector engines. AIAA, (95-2477), 1995.

[17] W. J. Escher. Synerjet for earth/orbit propulsion: revisiting the 1966 NASA Marquardt Composite (airbreathing/rocket) propulsion system study. SAE, (851163), May 1985.

[18] J. Etele, J. P. Sislian, and B. Parent. Effect of rocket exhaust configurations on ejector performance in rbcc engines. Journal of Propulsion and Power, 21(4), July - August 2005.

[19] R. W. Foster, W. J. D. Escher, and J. W. Robinson. Studies of an extensively axisymmetric rocket based combined cycle ( $\mathrm{rbcc}$ ) engine powered ssto vehicle. AIAA 89-2294, 10-12 July 1989. Presented at the 25th Joint Propulsion Conference, Monterey, California.

[20] J. Holland. Adaptıon in Natural and Artıficıal Systems. The University of Michigan Press, 1975.

[21] D. E. Goldberg. Genetıc Aglorıthm in Search, Optımızatıon, and Machıne Learnıng. Addison-Wesley Pub. Co., Inc., 1989.

[22] M. C. R. Rojas. From quasi-solutions to solutions: An evoluationary algorithm to solve csp. Proceedings of 2nd International Conference on Principles and Practıce of Constraint Programmıng, 1996.

[23] P. Chu. Genetıc Algorıthms for Combinatoral Optımızatıon Problems. PhD thesis, The Management School. Imperial College. University of London, 1997. 
[24] G. D. Smith, A. Kapsalis, V. J. Rayward-Smith, and A. Kolen. Radio link frequency assignment problem report 2.1 - implementation and testing of genetic algorithm approaches. Technical report, School of Infomration Science. University of East Anglia, 1995.

[25] B. L. Miller and D. E. Goldberg. Genetic algorithms, tournament selection, and the effects of noise. Technical report, Department of General Engineering. University of Illinois at Urbana Champaign, July 1995.

[26] C. R. Reeves. Handbook of Metaheurıstıcs. Springer Science, 2010.

[27] F. Herrera, M. Lozano, and J.L. Verdegay. Tackling real-coded genetic algorithms: Operators and tools for behavioural analysis. Artıficial Intelligence Revıew, 12:265-319, 1998.

[28] K. A. DeJong and J. Sarma. On decentralizing selection algorithms. Genetıc Algorithms: Proceedings of the 6th International Conference, 1995.

[29] T. Blickle and L. Thiele. A comparison of selection schemes used in evolutionary algorithms. Evolutionary Computatıon, 4(4):361-394, 1997.

[30] B. Chakraborty and P. Chaudhuri. On the use of genetic algorithms with elitism in robust and nonparametric multivariate analysis. Austrian Journal of Statıstıcs, 2003.

[31] M. B. Anderson. Design of a Missile Interceptor Using Genetıc Algorithm. PhD thesis, Auburn University, December 1998.

[32] D. E. Goldberg, K. Deb, and D. Thierens. Toward a better understanding of mixing in genetic algorithms. Journal of the Socrety of Instrument and Control Engineers, 1993.

[33] A. E. Eiben and C. A. Schippers. On evolutionary exploration and exploitation. Fundamenta Informaticae, 35:1-16, 1998.

[34] A. Wright. Genetic algorithms for real parameter optimization. Foundations of Genetıc Algorithms 1, pages 205-218, 1991.

[35] V. A. Froltsov and K. Reuter. Robustness of 'cut and splice' genetic algorithms in the structural optimization of atomic clusters. Chemıcal Physıcs Letters, 2009.

[36] Z. Michalewicz. Genetıc Algorıthms + Data Structures = Evolutıon Programs. Springer-Verlag, New York, 1992. 
[37] N. J. Radcliffe. Equivalence class analysis of genetic algorithms. Complex Systems, 5(2):183-205, 1991.

[38] H. Mühlenbein and D. Schlierkamp-Voosen. Predictive models for the breeder genetic algorithm i. continuous parameter optimizaiton. Evolutıonary Computatron, 1:25-49, 1993.

[39] D. E. Goldberg. Sizing populations for serial and parallel genetic algorithms. Proceedings of the Third International Conference on Genetıc Algorithms, pages 70-79, 1989.

[40] K. A. DeJong. Analysis of the behaviour of a class of genetic adaptive systems. Technical Report 185, University of Michigan, August 1975.

[41] J. Lampinen. Cam shape optimization by genetic algorithm. Computed-Aıded Design, 35:727-737, 2003.

[42] L. Davis. Handbook of Genetıc Algornthms. Van Nostrand Reinhold, New York, 1991.

[43] H. M. Voigt and T. Anheyer. Model mutations in evolutionary algorithms. Proceedings of the First IEEE Conference on Evolutionary Computation, pages 88$92,1994$.

[44] D. Whitley and J. Kauth. Genitor: A different genetic algorithm. Proceedings of the Rocky Mountain Conference on Artıficıal Intelligence, pages 118-130, 1988.

[45] F. Vavak and T. C. Fogarty. Lecture Notes in Computer Scıence: A Comparatıve Study of Steady State and Generational Genetic Algorithms for Use in Nonstatıonary Environments, volume 1143, pages 297-304. Springer Link, 1996.

[46] M. Srinivas and L. M. Patnaik. Adaptive probabilities of crossover and mutation in genetic algorithms. IEEE Transactıons on Systems, Man and Cybernetucs, April 1994.

[47] J. Zhang, H. S. Chung, and W. Lo. Clustering-based adaptive crossover and mutation probabilities for genetic algorithms. IEEE Transactions on Evolutionary Computation, June 2007.

[48] C. H. Kim. Coupler Poınt Path Synthesıs Usıng a Hybrid Genetıc Algorithm. PhD thesis, Department of Mechanical Engineering, University of Utah, 1995. 
[49] K. West. Mechanıcal Desıgn Usıng the Genetıc Algorıthm. PhD thesis, Department of Mechanical Engineering, University of Alberta, Spring 2001.

[50] A. Oyama, S. Obayashi, and K. Nakahashi. Transonic wing optimization using genetic algorithm. AIAA, (97-1854), 1997.

[51] F. A. Zotes and M. S. Penas. Mutli-criteria genetic optimisation of the manoeuvres of a two-stage launcher. Informatıon Scıences, pages 896-910, 2009.

[52] R. J. Hartfield, R. M. Jenkins, and J. E. Burkhalter. Ramjet powered missile design using a genetic algorithm. AIAA Aerospace Scıences Meetıng and Exhıbıt, (2004-0451), January 2004.

[53] D. J. Bayley. Desıgn Optımızatıon of Space Launch Vehıcles Usıng a Genetıc Algorthm. PhD thesis, Auburn University, August 2007.

[54] J. A. Clough. Modeling and Optımızatıon of Turbıne-Based Combıned-Cycle Engine Performance. PhD thesis, University of Maryland, 2004.

[55] M. N. Jahingir and Z. Huque. Design optimization of rocket-based combinedcycle inlet/ejector system. Journal of Propulsion and Power, 21(4), July-August 2005.

[56] D. J. Cerantola. Rocket Nozzle Desıgn with Ejector Effect Potentıal. PhD thesis, Department of Mechanical and Aerospace Engineering, Carleton University, 2007.

[57] T. S. Waung. An Ejector Air Intake Design Method for a Novel Rocket-Based Combıned-Cycle Rocket Nozzle. PhD thesis, Department of Mechanical and Aerospace Engineering, Carleton University, 2010.

[58] M. J. L. Turner. Rocket and Space Propulsıon: Prıncıples, Practıce, and New Development. Springer, New York, NY, 2005.

[59] J. Etele, B. Parent, and J. Sislian. Analysis of increased compression through area constriction on ejector-rocket performance. Journal of Spacecraft and Rockets, $4(2): 355-364,2007$.

[60] D. J. Cerantola and J. Etele. A nozzle concept to entrain atmospheric air for ejector operation. AIAA, (2006-8089), 2006.

[61] Encyclopedia astronautica: Le-7a. [internet], 2010. www.astronautix.com/engines/le7a. 
[62] D. Whitley. A genetic algorithm tutorial. Statistics and Computing, 4:65-85, 1994. 